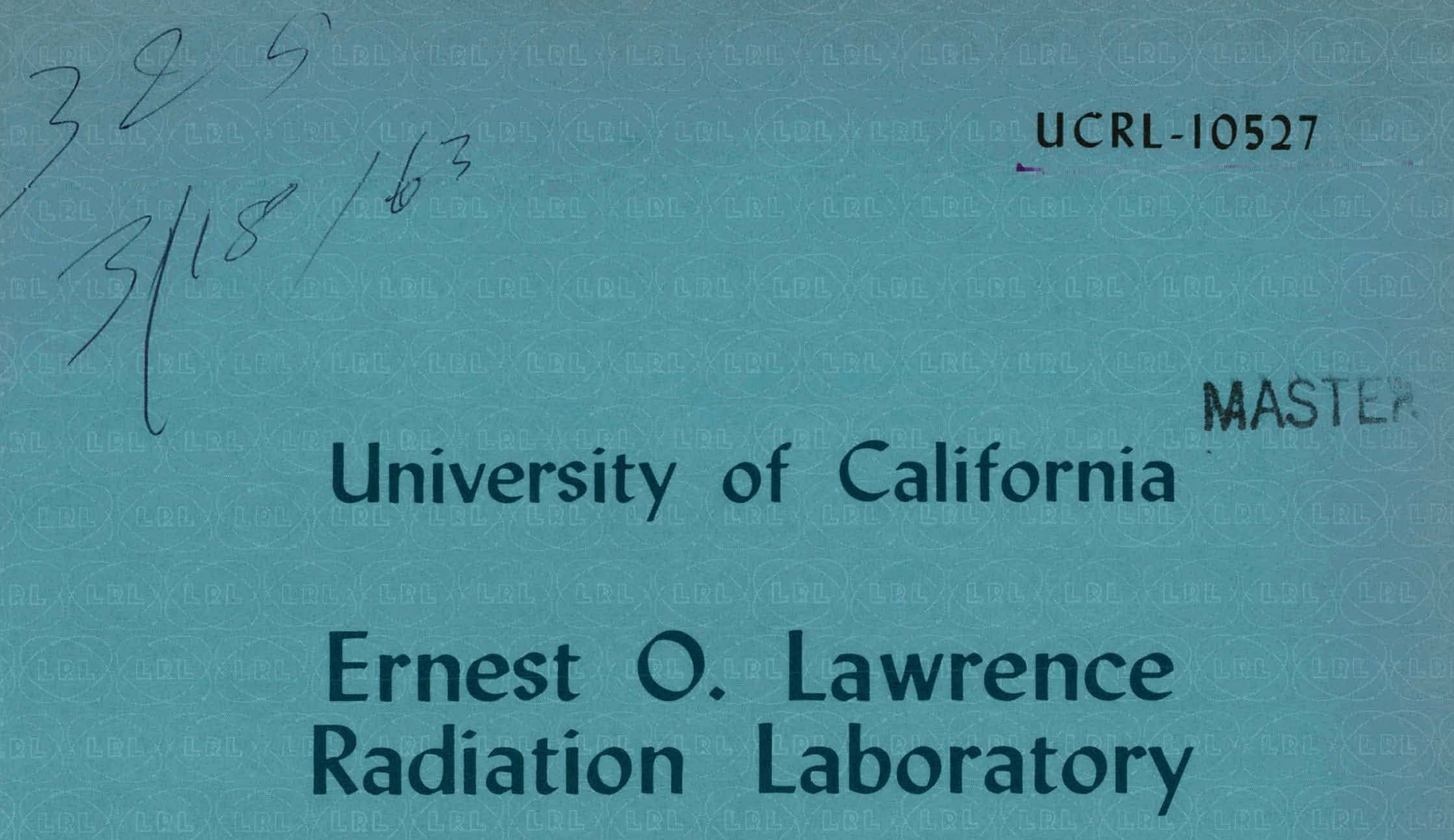

\title{
DOWNFLOW BOILING OF $n$-BUTANOL IN A UNIFORMLY HEATED TUBE
}

Berkeley, California 


\section{DISCLAIMER}

This report was prepared as an account of work sponsored by an agency of the United States Government. Neither the United States Government nor any agency Thereof, nor any of their employees, makes any warranty, express or implied, or assumes any legal liability or responsibility for the accuracy, completeness, or usefulness of any information, apparatus, product, or process disclosed, or represents that its use would not infringe privately owned rights. Reference herein to any specific commercial product, process, or service by trade name, trademark, manufacturer, or otherwise does not necessarily constitute or imply its endorsement, recommendation, or favoring by the United States Government or any agency thereof. The views and opinions of authors expressed herein do not necessarily state or reflect those of the United States Government or any agency thereof. 


\section{DISCLAIMER}

Portions of this document may be illegible in electronic image products. Images are produced from the best available original document. 
UCRL- 10527

UC- 4 Chemistry

TID-4500 (18th Ed.)

\section{UNIVERSITY OF CALIFORNIA \\ Lawrence Radiation Laboratory \\ Berkeley, California \\ Contract No. W-7405-eng-48}

DOWNFLOW BOILING OF $n-B U T A N O L$

IN A UNIFORMT.Y HF.ATFE TURE.

Graham F. Somerville

(M. S. Thesis)

October 29, 1962 
Printed in USA. Price $\$ 2.25$. Available from the office of Technical Services

U. S. Department of Commerce Washington 25 , D.C. 
DOWNFLOW BOILING OF $\mathrm{n}-\mathrm{BUTANOL}$

IN A UNIFORMLY HEATED TUBE

\section{Contents}

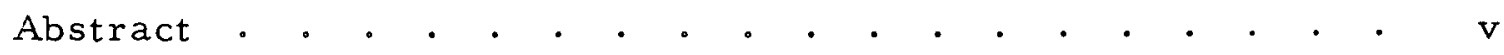

I. Introduction

A. General. . . . . . . . . . . . . . . . 1

B. Forced-Convection Vaporization . • . . . . . 2

C. Previous Work in Forced-Convection Boiling . . . 3

1. Dengler; Dengles and Addoms. . . . . . . 4

2. Mumm . . . . . . . . . . . . 6

3. Schrock and Grossman . . . . . . . . . 7

4. Bennett, Collier, et al. . . . . . . . 8

5. Wright; Sani . . . . . . . . . . . . 8

6. Davis and David . . . . . . . . . . 10

7. Sterman, Morozov, and Kavalev . . . . . . 11

8. Natural-Circulation Boiling of Organic Fluids. . 11

9. Forced-Convection Boiling of Refrigerants. • . 12

D. Pressure Drop in Two-Phase Flow . . . . . , 13

1. Frictional Losses in Two-Phase Flow . . . . 13

2. Holdup Data in Two-Phase Flow . . . . . . 14

3. Total-Pressure Gradients in Two-Phase Flow . 15

II. Experimental Equipment

A. General Flow System . . . . . . . . . . . 17

B. Flow-System Equipment . . . . . . . . . . 22

C. Test Sections . . . . . . . . . . . . 23

D. Electric Power Supply . . . . . . . . . . . 23

E. Instrumentation . . . . . . . . . . . . 27

III. Experimental Procedure . . . . . . . . . . . . 30 
IV. Calculation Procedures
A. Reduction of Experimental Data . . . . . . . . 31
B. Calculation of Inside-Wall Temperature . . . . . 31
C. Bulk Temperature Measurements . . . . . . . 34
D. Estimation of Vapor Quality . . . • . . . . . 34
E. Estimation of Total-Pressure Gradients . . . . . 35
F. Thermodynamic and Physical Properties of n-Butanol . . . . . . . . . 36

1. Vapor Pressure . . . . . . . . . . 36

2. Liquid and Vapor Enthalpy . . . . . . . 36

3. Liquid and Vapor Specific Heat. . . . . . 36

4. Ifiquid and Vapor Density . . . . . . . 38

5. Liquid and Vapor Viscosity . . . . . . 38

6. Liquid and Vapor Thermal Conductivity . . . 38

V. Discussion

A. Boiling Heat Transfer . . . . . . . . . . 39

1. Gcneral。 . . . . . . . . . . 39

2. Comparison with Previous Correlations. . . . 41

3. Correlation of Experimental Data . . . . 45

4. Burnout Heat Flux. . . . . . . , . . 56

B. Pressure Drop in Two-Phase Flow . . . . . . . 59

1. Correlation of Total-Pressure Gradicnts . . : 59

2. Prediction of Frictional-Pressure Losses . . . 61

C. Estimate of Experimental Error . . . . . . . 63

VI. Conclusions . . . . . . . . . . . . . . . 65

Acknowledgments 。 . . . . . . . . . . . 67

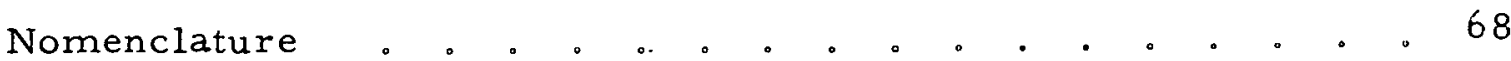

Appendices

A. Solution for the Inside-Wall Temperature. . . . . 71

B. Forced-Convection Boiling Data • . • . 。 74

Bibliography 。. . . . . . . . . . . . . . 98 


\section{DOWNFLOW BOILING OF n-BUTANOL IN A UNIFORMLY HEATED TUBE. \\ Graham F. Somerville \\ Lawrence Radiation Laboratory \\ University of California \\ Berkeley, California}

October 29, 1962

\section{ABSTRACT}

Local heat-transfer coefficients and two-phase total-pressure drops were measured for the forced-convection boiling of $n$ butanol in electrically heated tubes having an inside diameter of $0.4670 \mathrm{in}$. and heated lengths of 5.69 and $4.10 \mathrm{ft}$ respectively. Heat fluxes ranged from $2.8 \cdot 10^{4}$ to $6.6 \cdot 10^{4} \mathrm{Btu} / \mathrm{h}-\mathrm{ft}{ }^{2}$ and mass fluxes from 136 to $440 \mathrm{lbm} / \mathrm{sec} \mathrm{ft}^{2}$. Exit qualities up to $31 \%$ were obtained at pressures between 16.9 and 50.0 psia. Measured heat-transfer coefficients ranged between 2,000 and $10,000 \mathrm{Btu} / \mathrm{h}-\mathrm{ft}^{2}-^{\circ} \mathrm{F}$.

The boiling heat-transfer data were compared with previous correlations that had been based on the water-steam system. A new boiling heat-transfer correlation was derived having the form

$$
\mathrm{St}=0.9005 \mathrm{Re}_{\ell}^{-0.286} \mathrm{X}_{\mathrm{tt}}^{-0.292} \mathrm{Bo}^{0.191} \operatorname{Pr}_{\ell}^{-0.233}
$$

it was successful in correlating data for both water and $n$-butanol to within $\pm 30 \%$ 。

Local two-phase total-pressure gradients which ranged up to $8 \mathrm{psi} / \mathrm{ft}$, have been successfully correlated by the method of Schrock and Grossman. Local two-phase frictional-pressure gradients have been obtained and compared with previous results for the water-steam system.

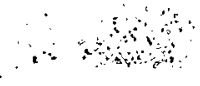




\section{INTRODUCTION}

\section{A. General}

The phenomena of heat transfer to boiling liquids has been the subject of several experimental and theoretical studies during the past decade. The ability of boiling systems to remove large quantities of heat has stimulated interest in this field of heat transfer. In singlephase heat transfer, the heat flux is proportional to the first power of the temperature difference. However, in heat-transfer systems with a change of phase the heat flux may be proportional to the fourth power of the temperature difference.

The majority of the experimental investigations, and almost all of the theoretical studies, have been concerned with the boiling of saturated or subcooled liquids on surfaces submerged in pools. However, a considerable amount of experimental work has been carried out on the forced-convection heat transfer to two-phase systems with net generation of vapor. In this latter area the majority of the experimental work has dealt with heat transfer to steam-water mixtures over a wide range of heat flux, mass flux, vapor quality, and pressures. Circular, annular, and rectangular cross sections have been examined in upflow, downflow, and horizontal-flow systems.

Systems other than steam-water have not been examined in detail. Studies on the natural-convection boiling of organic liquids and on the forced-convection boiling of refrigerants are available. The main objectives of this work have been the measurement of heattransfer coefficients and pressure drops during the forced-convection boiling of $\mathrm{n}$-butanol. It was hoped that employing a system having physical properties different from water would permit determination of the effect of the fluids physical properties on the forced-convection boiling-heat-transfer coefficient. 


\section{B. Forced-Convection Vaporization}

During the forced-convection vaporization of a fluid stream flowing in a closed channel three regimes of heat transfer have been postulated:

1. A nucleate boiling region characterized by bubble growth and nucleation at the heat-transfer surface. Here the heat-transfer mechanism is a combination of nucleate boiling, eharacterieed by the heat flux, and forced convection, characterized by the mass flux.

2. A convection-controlled regime wherein the heat-transfer coefficient is relatively independent of heat flux but dependent on the mass flux and the vapor quality.

3. A regime characterized by liquid deficieicies at ccrtain locations along the wall. This occurs when the vapor mass fraction becomes so large that the liquid film on the wall is removed. This regime is commonly known as the transition and film-boiling region. This investigation is concerned with heat transfer in only the first two regimes.

Whichever regime is considered it is characterized by a thermal entrance region. When a fully developed turbulent flow of an isothermal liquid or liquid-vapor mixture enters a heated section, a certain length is required to establioh a thermal gradient within the fluid. This length, called the thermal entrance length, is characterized by heat-transfer coefficients which vary from very large down to the fully developed value. It is unlikely that coefficients in this entrance region are typical of the region where the fully developed thermal gradient exists. 1,2

For flow of a two-phase mixture this entrance phenomenon occurs in conjunction with the vaporization process, and although this overall effect is not known there must be an entrance phenomenon that is not characteristic of the heat-transfer mechanism occurring in the region of fully developed thermal gradients. Wright has noted 
that although this phenomenon has not been mentioned in previous work on forced-convection boiling, its existence.should be recognized and experimental data examined in the light of its possible presence. 3

\section{Previous Work in Forced-Convection Boiling}

The two-phase flow of fluids with net vapor generation is an extremely complex problem. The flow mechanism encountered in isothermal two-phase flow is not completely understood; when a phase change due to heat transfer is superimposed upon this flow the analytic complexity of the problem becomes unmanageable. As a consequence most of the previous work in this area has been experimental.

Sterman has presented an analysis of the appropriate dimensionless groups for forced-convection boiling. ${ }^{4}$ By applying the theory of similarity directly to the one-dimensional forms of the differential equations for the momentum and energy balances together with the boundary conditions at the wall and between the wall and the bulk boiling liquid, Sterman was able to obtain the functional form

$$
\begin{aligned}
& N_{b}=f {\left[\operatorname{Re}, F r, \operatorname{Pr}, \frac{q}{h_{f g} V_{f}^{\rho} g}, \frac{h_{f g}}{C_{p} T_{b}}, \frac{v_{f}{ }^{2}}{h_{f g} g},\right.} \\
&\left.\frac{V_{f}^{2}}{g} \sqrt{\frac{\rho_{f}}{\sigma}}, \frac{\rho_{g}}{\rho_{f}}, \frac{V_{g}}{V_{f}}\right] .
\end{aligned}
$$

For the range of variables covered by most experiments this list reduces to.

$$
\mathrm{Nu}_{b}=f\left[\operatorname{Re}, \operatorname{Pr}, \frac{q}{h_{f g} V_{f} \rho_{g}}, \frac{\rho g}{\rho_{f}}, \frac{V g}{\nabla_{f}}\right] .
$$

To this list the quality $x$ should be added. Martinelli and Nelson have shown ${ }^{5}$ that the volumetric vapor and liquid fractions--which are simply related to $V_{g} / V_{f}, \rho_{g} / \rho_{f}$, and the quality--are dependent on the 
pressure and the Martinelli parameter, $x_{t . t}$. [. The parameter $x_{t t}$ was originally introduced by Lockhart and Martinelli for the correlation of two-phase two-component, isothermal pressure-drop data. ${ }^{6}$ Its possible use as a correlating parameter for two-phase heat transfer data was suggested at that time. It is defined by

$$
X_{t t .}=\left(\frac{\rho_{g}}{\rho_{f}}\right)^{0.5 .}\left(\frac{\mu_{f}}{\mu_{g}}\right)^{0.1}\left(\frac{1-x}{x}\right)^{0.9} .
$$

The subscript tt refers to the turbulent-turbulent nature of the flow pattern for the vapor and liquid phases.] Thus Eq. (I-2) might be reduced to

$$
N u_{b}=f\left[R e, \operatorname{Pr}, \frac{q}{h_{f g} V_{f}^{p} g}, x_{t t}\right] .
$$

This approach has been used by Schrock and Grossman. 7

Several of the experimental reports on the subject of forcedconvection boiling are summarized below. There have been attempts to extend pool boiling and one-phase forced-convection heat-transfer correlations to this area; however, these have generally been unsuccessful. In view of the radical physical departure of forced-convection boiling from either of the two aforementionedareas, this is not surprising. 8

\section{Dengler; Dengler and Addoms}

Dengler studied the heat transfer to watei-steam mixtures in an upflow system employing a 1 -in. i.d. copper tube $20 \mathrm{fl}$ luing. 9,10 Five closely spaced steam jackets were used as a heat source; the amount of condensate collected was a measure of the heat flux. Pressures ranged from 7.2 to 40 psia; qualities varied between 0 and $100 \%$. Mass fluxes ranged between $3 \cdot 10^{4}$ and $2 \cdot 10^{5} \mathrm{Btu} / \mathrm{h}-\mathrm{ft}^{2}$. The heattransfer coefficients obtained were not true local coefficients, but rather an average value taken over the 3-ft-long heated jacket. 
The authors suggested that below the dry wall condition the local heat-transfer coefficients are dependent on the combined influence of a nucleate boiling and a forced-convection mechanism. As the mass flow rate is increased the nucleate boiling mechanism is suppressed and the forced-convection mechanism becomes dominant. For the region of suppressed nucleate boiling, the latter region, a correlation of the form

$$
\frac{h_{b}}{h_{0}}=3.5 x_{t t}^{-0.5}
$$

was.found to correlate $85 \%$ of the purely convective data to within $\pm 20 \%$. The region of suppressed nucleate boiling was defined as that region for which the value of $\mathrm{X}_{t \mathrm{t}}$ is less than 4. The heat-transfer coefficient for liquid flow, $h_{0}$, is calculated from the Dittus-Boelter equation

$$
\mathrm{h}_{0}=0.023 \frac{\mathrm{k}_{\ell}}{\mathrm{D}_{\mathrm{i}}} \cdot \operatorname{Re}_{\mathrm{T}}^{0.8} \operatorname{Pr}_{\ell}^{0.4} . .
$$

The physical properties are those of the liquid and are evaluated at the local saturation temperature.

In the entrance region of the test section, where the linear velocities were low, values of the heat-transfer coefficient greatly exceeded those predicted by Eq. (I-5). The authors postulated that this was the region in which the nucleate boiling mechanism was dominant. A temperature difference to initiate nucleate boiling, $\Delta T_{i}$, was defined as

$$
\Delta \mathrm{T}_{\mathrm{i}}=10\left[\frac{\mathrm{GV}_{\mathrm{f}}}{\mathrm{a}_{\mathrm{f}}}\right]^{0.3}
$$

This was applied as a criterion for nucleate boiling and incorporated into an empirically developed correction factor, $F$, given by

$$
F=0.673\left[\left(\Delta T-\Delta T_{i}\right)\left(\frac{d P}{d T}\right)_{\text {sat }} \frac{D_{i}}{\sigma}\right]^{0.1} \text {. }
$$


The factor was employed only when it exceeded unity. Although its physical significance is not apparent, it was successful in reducing the scatter of the data in the nucleate boiling region.

Wright has suggested ${ }^{3}$ that thermal entrance effects may form a more plausible explanation for the large heat-transfer coefficients observed in the entrance region than the mechanism suggested by Dengler。

2. Mumm

Mumm measured local heat-transfer coefficients to water in an electrically heated horizontal $0.465-$ in. - i. d. stainless steel tube $7 \mathrm{ft}$ ling. 11 . Cocfficients were obtained over the quality range 0 to $60 \%$ at operating pressures between 45 and 200 psia. Heat fluxco ranged from $5 \cdot 10^{4}$ to $2.5 \cdot 10^{5} \mathrm{Btu} / \mathrm{h}-\mathrm{ft}^{2}$ and mass fluxes between 70 and $200 \mathrm{lbm} / \mathrm{sec} \mathrm{ft}^{2}$. For qualities less than $40 \%$ the local coefficients could be correlated by

$$
\mathrm{Nu}_{\mathrm{b}}=\operatorname{Re}_{\ell}^{0.808}\left[\frac{\mathrm{q}}{3600 \mathrm{Gh}}\right]^{0.464}\left[4.3+5 \cdot 10^{-4}\left(\frac{\rho_{\mathrm{f}}^{-\rho_{\mathrm{g}}}}{\rho_{\mathrm{g}}}\right)^{1.64} \mathrm{x}\right]
$$

with a standard deviation of $\pm 10 \%$.

The quantity $\left(\frac{\mathrm{q}}{3600 \mathrm{Gh}}\right)$, called the boiling number, Bo, was first introduced by Davidson. ${ }^{12}$ It may be interpreted as a measure of the suppression of nucleate boiling; as the heat flux is imereascd, nucleation is increased; as the mass flux is increased, nucledtion is supa pressed. Thus nucleate boiling would be more likely at high values of the boiling number. All investigators have reported an increase in the heat-transfer coefficient with heat flux at constant mass flux and quality, indicating that nucleate boiling contributes to the overall heat-transfer mechanism. 


\section{Schrock and Grossman}

Schrock and Grossman measured local heat-transfer coefficients to steam-water mixtures in an upflow system. 7,13 Tube inside diameters were $0.1162,0.2370$, and $0.4317 \mathrm{in.}$, with lengths varying from 15 to $40 \mathrm{in.}$ Mass fluxes varied from 49 to $91 \mathrm{llbm} / \mathrm{sec}-\mathrm{ft}^{2}$ and heat fluxes from $6 \cdot 10^{4}$ to $1.45 \cdot 10^{6} \mathrm{Btu} / \mathrm{h}-\mathrm{ft}^{2}$. Pressures ranged from 42 to 505 psia for exit qualities up to $59 \%$.

During the initial stages of the project the data were correlated in two regimes. For low qualities, when a nucleate boiling mechanism was thought to predominate, the correlation was

$$
\frac{h_{b}}{h_{b}}=1.15 \cdot 10^{-5} \mathrm{q} \text {. }
$$

At higher qualities a vapor core-liquid annulus type of flow was postulated and the data were correlated with the aid of the Martinelli parameter

$$
\frac{h_{b}}{h_{\ell}}=2.5 x_{t t}^{-0.75}
$$

Here $h_{\ell}$ is the local nonboiling liquid heat-transfer coefficient that would be obtained from the Dittus-Boelter equation if the liquid in the two-phase mixture were considered flowing alone and filling the tube.

In the final stages of their work, the authors modified their correlation to include both regimes in..a single expression. Postulating that the heat-transfer mechanism is a combination of a nucleate boiling mechanism and a forced-convection mechanism, the authors used the boiling number and the Martinelli parameter to express these. contributions:

$$
\frac{\mathrm{Nu}_{\mathrm{b}}}{\mathrm{Re}_{\ell}^{0.808} \mathrm{Pr}_{\ell}^{1 / 3}}=170\left[\mathrm{Bo}+1.5 \cdot 10^{-4} \mathrm{x}_{\mathrm{tt}}^{-2 / 3}\right]
$$

This expression correlated data in both regimes to $\pm 35 \%$. 
4. Bennett, Collier, et al.

These authors obtained coefficients for local heat transfer to a steam-water mixture in upflow, electrically heated annuli。 ${ }^{14}$ The latter consisted of precision-bore glass tubes, 29 in. 1ong, in which there was a coaxial stainless steel tube. Two sizes were employed, having 0.375 - and 0.623 -in. o.d. steel tubes inside 0.552 - and 0.866 in. i.d. glass tubes, respectively. Exit qualities up to $60 \%$ were measured at essentially atmospheric pressures. Heat fluxes ranged between $3 \cdot 10^{4}$ and $2 \cdot 2 \cdot 10^{5} \mathrm{Btu} / \mathrm{h}-\mathrm{ft}^{2}$ and mass fluxes from 14 to 61 $\mathrm{lbm} / \mathrm{sec}-\mathrm{ft}^{2}$.

The authors suggested that at qualities between 7 and $15 \%$ the heat-transfer mechanism changed from a nucleate boiling to a convective one. In the former region the heat-transfer coefficient appeared to be dependent upon the heat flux, whereas the effects of mass flux and quality could not be determined.

In the latter region the data for both test sections were correlated satisfactorily by the expression

$$
\frac{h_{b}}{h_{\ell}} \cdot[q]^{-0.11}=0.64 x_{t t}^{-0.74} .
$$

$D_{0}-D_{i}$ was used as an equivalent diameter. The experimental values were correlated to within $\pm 1 b \%$ for the smaller test section and $\pm 20 \%$ for the larger section.

Beyond a quality of $65 \%$ the heat-transfer coefficient was found to decrease and approach the value given by the dry steam coefficient.

5. Wright; and Sani

Both authors measured local heat-transfer coefficients in the downflow forced-convection boiling of water in electrically heated tubes. 3,15 Tube inside diameters were 0.719 and 0.472 in., with lengths of 5.67 and $4.69 \mathrm{ft}$, respectively. Mass fluxes ranged from 110 to $700 \mathrm{lbm} / \mathrm{sec}_{-\mathrm{ft}}{ }^{2}$ and heat fluxes from 13,800 to $88,000 \mathrm{Btu} / \mathrm{h}-\mathrm{ft}^{2}$. Qualities ranged up to $19 \%$ for pressures between 15 and 70 psia. 
The authors found that their data could be correlated by an equation similar in form to that proposed by Dengler ${ }^{9}$ or Schrock and Grossman; ${ }^{7}$ however, the experimental coefficients differed. Using a form suggested by Dengler, Wright and Sani obtained

$$
\frac{h_{b}}{h_{0}}=2.43 x_{t t}^{-0.562} \text {, }
$$

with a standard deviation of $\pm 15.3 \%$. Using the form suggested by Schrock and Grossman, they obtained

$$
\frac{\mathrm{Nu}_{\mathrm{b}}}{\operatorname{Re}_{\ell}^{0.8} \operatorname{Pr}_{\ell}^{1 / 3}}=320\left[\mathrm{Bo}+1.5 \cdot 10^{-4} \mathrm{x}_{\mathrm{tt}}^{-2 / 3}\right] \text {, }
$$

with a standard deviation of $\pm 21.3 \%$.

Later Wright correlated the data with equations having the general.skeletal form

$$
h_{b} \approx G^{0.6} q^{0.3} x^{0.04}
$$

His experimental data were correlated with the least. error by an equation of the form

or

$$
\mathrm{St}=0.003377 \cdot \mathrm{Re}_{\ell}^{0.106} \mathrm{Bo}_{\mathrm{m}}^{0.296} \mathrm{x}_{\mathrm{tt}}^{-0.457} \operatorname{Pr}_{\ell}^{0.4}
$$

$$
h_{b}=4.192 \operatorname{Re}_{\ell}^{0.455} q^{0.289}{ }^{0.379} \operatorname{Pr}_{\ell}^{0.4}
$$

The standard deviation of the former correlation was $\pm 9.5 \%$ and that of the latter $\pm 12.9 \%$ 。

Wright suggested that a modified boiling number, $\mathrm{Bo}_{\mathrm{m}}$, defined by

$$
\mathrm{Bo}_{\mathrm{m}}=\mathrm{Bo} \cdot \frac{\rho_{\mathrm{f}}}{\rho_{\mathrm{g}}} \text {, }
$$

might be a more successful correlating parameter than the boiling number. The modified form introduced a strong pressure dependence and was found to be a more successful parameter for correlating his data than the original boiling number. 
6. Davis and David.

These authors investigated the heat transfer to water-steam. mixtures flowing in an electrically heated horizontal duct of rectangular cross section. 16 The test section was 0.769 in. high by 0.260 in. wide and had a heated length of $6.0 \mathrm{in}$. Measurements were made for qualities between 30 and $90 \%$ at pressures between 25 and 150 psia. Heat fluxes ranged trom $b \cdot 1 u^{4}$ to $2.5 \cdot 10^{5} \mathrm{Bru} / \mathrm{h}-\mathrm{fl}^{2}$, dill ulass fluxes from 13.9 to $167 \mathrm{lbm} / \mathrm{sec}-\mathrm{ft}^{2}$.

The investigators were primarily concerned with"heat transfer in the region where the forced-convection mechanism was dominant. The data were corrclated by two different methods. Assuming a separated-annular-flow mode1, the following correlation was proposed:

$$
\frac{h_{b} D_{e}}{k_{\ell}}=0.060\left(\frac{\rho_{f}}{\rho_{g}}\right)^{0.28}\left(\frac{D_{c} G}{\mu_{f}}\right)^{0.87} \operatorname{Pr}_{\ell}^{0.4} .
$$

The authors' data were correlated to within $\pm 20 \%$ and, in addition, data of Dengler ${ }^{9}$ and Kvamme ${ }^{17}$ were correlated to within $\pm 20 \%$.

The second approach employed a homogeneous model and assumed that the heat-transfer coefficient was dependent on the Reynolds number of the core and the physical properties of the liquid adjacent to the wall. They suggested a correlation of the form

$$
\frac{h_{b} D_{e}}{k_{\ell}}=0.033\left(\frac{D_{e} G}{\mu_{t p^{2}}}\right)^{0.8 \overline{1}} \operatorname{Pr}_{\ell}^{0.4}
$$

which was successful in correlating their data to within $\pm 20 \%$. 
7. Sterman, Morozov, and Kavalev

The authors describe forced-convection boiling work carried out in the U.S.S.R., and present data for the boiling of water up to $90 \mathrm{~atm}$. and for the boiling of $95 \%$ ethanol at $2 \mathrm{~atm}$. 18 The test sections employed were approximately $4.7 \mathrm{in.}$ long and $0.63 \mathrm{in}$. in diameter. Heat fluxes up to $179,000 \mathrm{Btu} / \mathrm{h}-\mathrm{ft}^{2}$ were produced by electric heating; superficial velocities ranged from 6 to $10 \mathrm{ft} / \mathrm{sec}$. No indication was given as to the magnitude of the mass vapor fraction. Volumetric vapor fractions varied from 0 to $27 \%$, although no mention was ma.de of how these were measured. At the low pressures employed the mass vapor fraction could easily have been less than $1 \%$.

Local heat-transfer coefficients for both fluids were correlated by the relation

$$
\frac{h_{b}}{h_{\ell}}=6150 \cdot\left[\left(\frac{q}{h_{f g} V_{0} \rho_{g}}\right)\left(\frac{\rho_{g}}{\rho_{f}}\right)^{1.45}\left(\frac{h_{f g}}{C_{P^{T}} T_{b}}\right)^{1 / 3}\right]^{0.7},
$$

where $V_{0}$ is the superficial velocity. The authors report that there was no increase in heat-transfer coefficient with increasing vapor. fraction. In the light of results obtained by other investigators it would appeax that their data were taken at very low values of vapor mass fraction.

\section{Natural-Circulation Boiling of Organic Fluids}

Guerrieri and Talty presented data for the natural-circulation boiling of several organic liquids in a vertical tube at low heat fluxes (up to $17,400 \mathrm{Btu} / \mathrm{h}-\mathrm{ft}^{2}$ ). 19 Local heat-transfer coefficients were correlated in a manner similar to that of Dengler:

$$
\frac{h_{b}}{h_{\ell}}=3.4 \mathrm{x}_{\mathrm{tt}}^{-0.45}
$$


A correction factor for nucleate boiling was introduced, based on the minimum radius of a the rmodynamically stable bubble for a given degree of superheat, $r^{*}$, and the thickness of the laminar layer of liquid along the wall, $\delta$. This correction factor had the form

$$
\text { N.. B.C.: } F \text {. }=0.187\left[\frac{r^{*}}{\delta}\right]^{-.5 / 9} \text {. }
$$

: When $r^{*} / \delta$ exceeded 0.049 it was physically interpreted to mean that the flow velocity near the wall was large enough to prevent nucleation.

9. Forced-Convection Evaporation of Refrigerants

In a recent paper Altman has summarized previous work in this field and presented some new dala. 20 The data were taken at relatively low mass fluxes (less than $150 \mathrm{lbm} / \mathrm{sec}-\mathrm{ft}{ }^{2}$ ) and heat fluxes (less than $20,000 \mathrm{Btu} / \mathrm{h}-\mathrm{ft}^{2}$ ). Mass vapor fractions greater than $90 \%$ were common; however, the difference between the inlet and outlet qualities was usually less than $15 \%$ 。

An equation of the form.

$$
N u_{b}=0.0225\left[\operatorname{Re}_{T}\right]^{0.75}\left[\frac{\mathrm{J \Delta xh_{fg }}}{L}\right]^{0.375} .
$$

has been used to correlate the existing data for average heat-trinsfer coefficients; $\Delta x$ refers to the change of vapor fraction $x$ over the test. section length $L$. 


\section{Pressure Drop in Two-Phase Flow.}

The total-pressure gradient in two-phase flow with net generation of vapor is the sum of three contributions: losses due to friction, losses due to momentum changes, and losses (or gains) due to the hydrostatic head of fluid in the flow channel. Each of these losses may be considered independent of the others although the latter two are closely related to the holdup.

It is possible to estimate the frictional losses in a boiling system from studies dealing with adiabatic two-phase flow. Ilowever, the momentum and hydrostatic-head losses are both dependent on the relative velocities of the two phases and the fraction of the flow channel occupied by each phase. These quantities were not measured in this experiment, nevertheless it was hoped that published correlations of the liquid holdup could be utilized to determine the magnitude of the momentum and hydrostatic head losses.

As the measurement of two-phase pressure gradients was not the primary purpose of this investigalion, only total-pressure measurements were taken. Thus it has not been considered worth while to undertake a complete review of all the previous work in this area. However, in the following sections some of the more important publications have been discussed.

\section{Frictional Losses in Two-Phase Flow}

There have been numerous publications on the magnitude of the frictional losses occurring during isothermal two-phase flow. Several of these have been reviewed by Lottes and Marchaterre. ${ }^{21}$ The major portion of this work has been experimental, although some theoretical papers have appeared. Unfortunately predictions made from these latter papers have been found to be valid only over a small range of vapor mass fractions. Thus the more successful approaches have been empirical. 
One of the earliest but still most quoted papers is that of Lockhart and Martinelli. ${ }^{6}$ For the horizontal flow of a variety of dissimilar fluids they correlated the isothermal two-phase friction losses to within $\pm 30 \%$. Their results were presented graphically by using two parameters, $\phi_{\ell}$ and $\mathrm{X}_{t t^{\circ}}$. The former is defined by

$$
\phi_{\ell}=\left(\frac{(\mathrm{dP} / \mathrm{d} \ell)_{\mathrm{tpf}}}{(\mathrm{dP} / \mathrm{d} \ell)_{\ell}}\right)^{1 / 2}
$$

and is the square root of the ratio of the two-phase frictional-pressure gradient to the pressure gradient that would be obtained if the liquid phase were flowing alone. Liter lata by "Jcnkins" indicated that the mass velocity might be an important parameter that is overlooked in the Lockhart-Martinelli correlation. 22 In a recent paper Hughmark and Pressburg have presented an empirical correlation for two-phase frictional-pressure losses which was successful in correlating their own and other experimental data to within $\pm 15 \% .23$

2. Holdup Data in Two-Phase Flow

The approach to the prediction of the derisity and volume fractions of two-phase mixtures has been of nccessity almost completely empirical. Lockhart and Martinelli obtained liquid holdup data at atmospheric pressure for several liquid-vapor systems and correlated these data.as a function of $\mathrm{x}_{\mathrm{tt}}{ }^{6}{ }^{6}$ They also presented an extension of their correlation to the regions of higher pressure. Dengler reported measurements for the steam-water system at atmospheric pressure. 9 These data were also correlated with the aid of the Martinelli parameter. Ibsen obtained volume fraction data for the steam-water system in both horizontal and vertical flows over a wide range of pressures. ${ }^{24} \mathrm{He}$ reported that the velocity ratios were a function of mixture quality and pressure. In a recent publication Marchaterre and Petrick have summarized the pertinent information derived from several experimental studies. 25 Hughmark and Pressburg have presented an empirical correlation for the liquid holdup in two-phase systems based on their own experimental data. 23 
3. Total-Pressure Gradients in Two-Phase Flow

By introducing a correction to account for changes in momentum, Martinelli and Nelson were able to extend the correlation by Lockhart and Martinelli to a system with considerable mass transfer between the two phases. ${ }^{5}$ This extension consisted of modifying the friction-factor multiplier and vapor fraction values to be more consistent at higher pressures, and integrating the frictional and momentum losses over the entire length of the boiling tube. The resulting total-pressure drops were plotted against the average test-section pressure and the cxit qualily.

In order to set limits of these total-pressure drops, they examined two models. The first, a homogeneous or fog-flow model, assumed that the liquid and vapor velocities were equal. The second, a separated-annular-flow or slip model, assumed that a slip ratio existed between the two phases. This slip ratio has been experimentally observed to be a function of the pressure, the mass fraction in each phase, and the total mass velocity. 24,25

In the fog-flow model it was assumed that the vapor-liquid mixture could be treated as a homogeneous fluid having a character o istic density and viscosity. Thus the friction, momentum, and head losses could be calculated individually and summed to yield the totalpressure gradient. At mass fractions below 15\% this method tends to predict total-pressure gradients that greatly exceed the measured valús: At higher qualities the predicted and experimental values are in closer agreement. The fog-flow model is considered to set an upper limit on the total-pressure gradient. For the prediction of total-pressure gradients by the separated-annular-flow model a knowledge of the slip ratio or the volumetric vapor fraction is required; however, pressure gradients predicted according to this model agree more closely with the experimental results. 
Hatch and Jàcobs examined total-pres sure gradients for hydrogen and trichloromonofluoromethane. ${ }^{26}$ They concluded that the Martinelli-Nelson approach using the fog-flow model was successful in predicting total-pressure gradients for two-phase flow systems with appreciable mass transfer.

Schrock and Grossman ${ }^{27}$ have correlated total-pressure gradients in a manner similar to that of Lockhart and Martinelli. They replaced the two-phase frictionat-pressure gradient with the total-pressure gradient in the definition of $\phi_{\ell}$ and were able to correlate $95 \%$ of their data to within $\pm 15 \%$. The authors concluded that the individual losses nced not be considered separately but that the Martinelli paramctcr could be used as the sole correlating parameter for total-pres = sure gradicnts in two-phase flow.

Using a similar approach, Wright correlated the total-pressure gradients for the downflow boiling of water ${ }^{3}$ and obtained

$$
\left[\frac{(\mathrm{dP} / \mathrm{d} \ell)_{t p t}}{(\mathrm{dP} / \mathrm{d} \ell)_{\ell}}\right]=40.12 \mathrm{x}_{\mathrm{tt}}^{-1.16} \text {. }
$$

His data lay above the upflow data of Schrock and Grossman. This was attributed to a difference in system geometry, as undoubtedly the liquid holdup and slip ratios were differcnt for the two systems. If, under the influence of gravity, momentum losses were greater in the downflow system, the total-pressure gradient would also be larger, since the hydrostatic-head contributions are generally of such small magnitude as to be negligible. 


\section{EXPERIMENT AL EQUIPMENT}

A. General Flow System

The flow system consisted of a semiclosed loop. Reagentgrade $n$-butanol was pumped from storage tanks through a rotameter system into three steam-fed heaters connected in series. The temperature and pressure at the outlet of the third heater were controlled to insure that the liquid at this point was always subcooled. This location, referred to as station 1 , was the primary reference point for subsequent calculations: Before the stream enlered the test section the stream pressure was lowered to allow a certain amount of the liquid to flash into vapor. (Often the temperature at station 1 was not high enough to allow flashing, and hence vaporization was initiated within the test section.) It was found that a globe valve was satisfactory for this purpose. The resulting two-phase mixture was conducted down into the test section. The test sections were constructed from thin-walled stainless steel tubes and were heated electrically by employing the tcst section as a resistance heater.

Pressure taps were fitted at frequent locations along the test section and thermocouples were soldered to the outside wall for the measurcment of terrperature. The entire test section and connecting pipework were thermally insulated with asbestos tape and glass wool.

The high-velocity two-phase mixture leaving the test section was conducted into a vapor-liquid cyclone separator. The vapor fraction was condensed, cooled, and returned to storage; the liquid fraction was cooled in three heat exchangers in series and also returned to the main storage tanks. Provision was made for simultaneously measuring the weight rate of flow of the condensed vapor and liquid fractions. This served as a check on the initial rotameter reading.

Figure 1 shows a schematic flow diagram of the equipment; Figs. 2 through 4 are photographs of the equipment. 


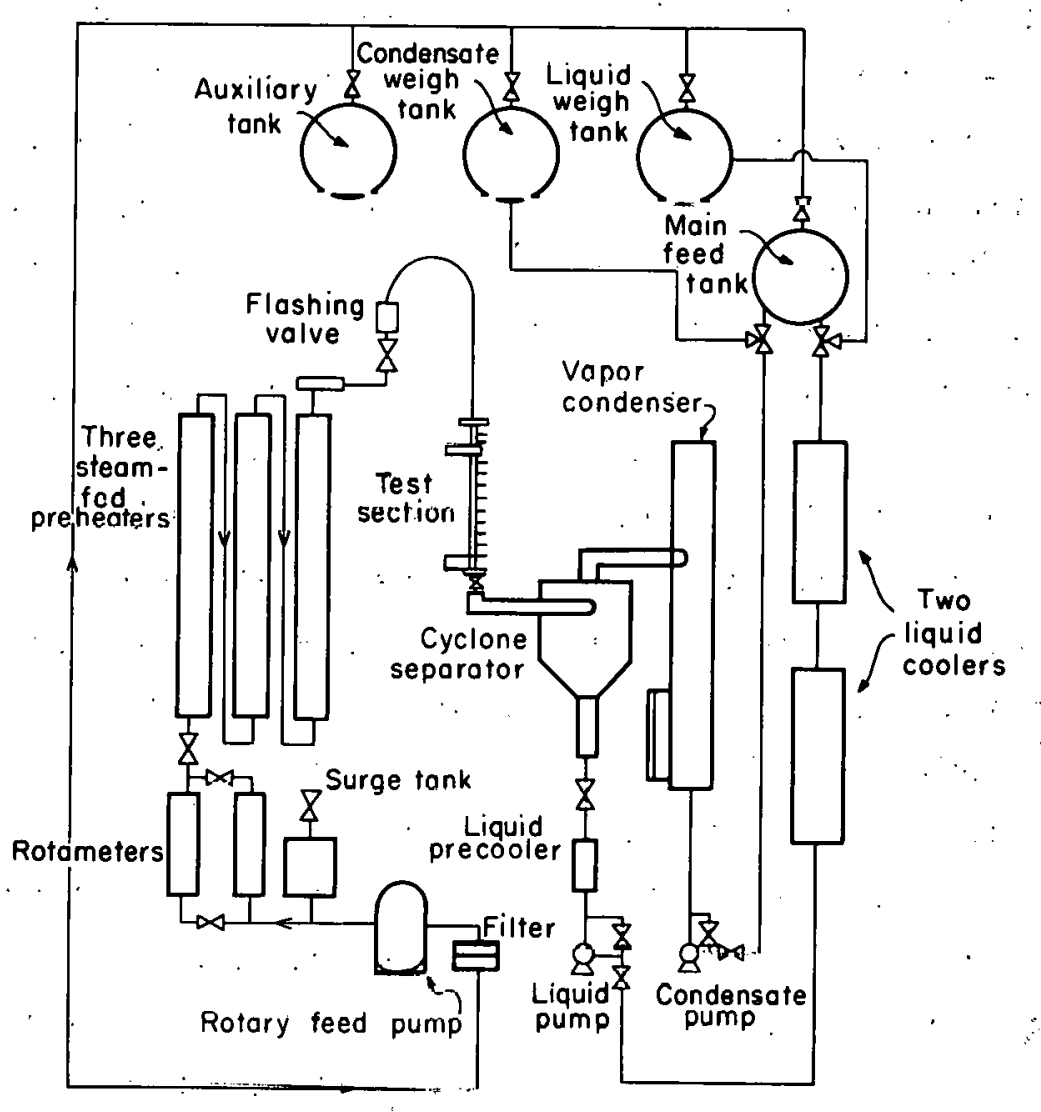

MUL. 28730

Fig. 1. Schematic diagram of the flow system. 


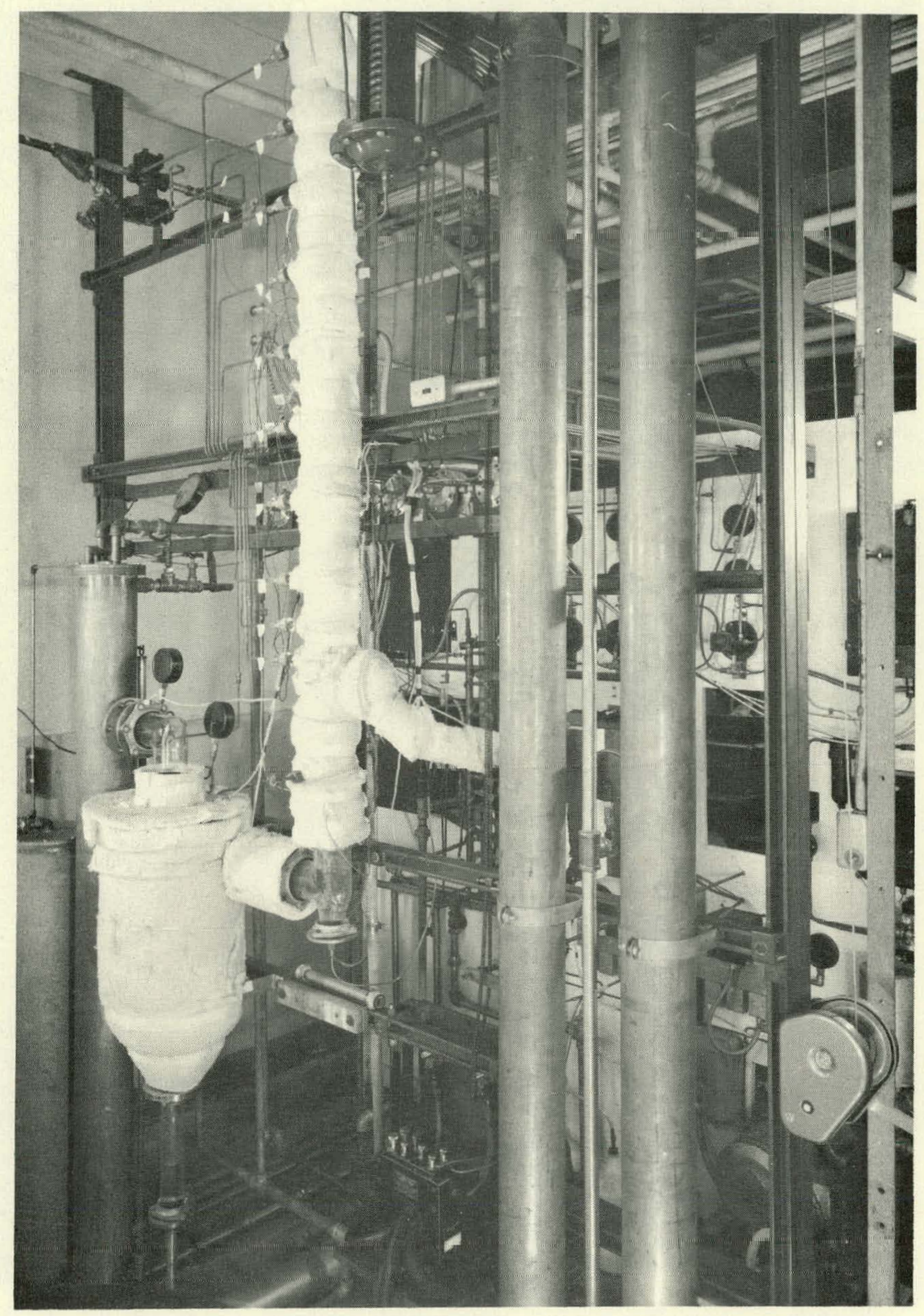

$Z N-2929$

Fig. 2. Flow-system equipment. 


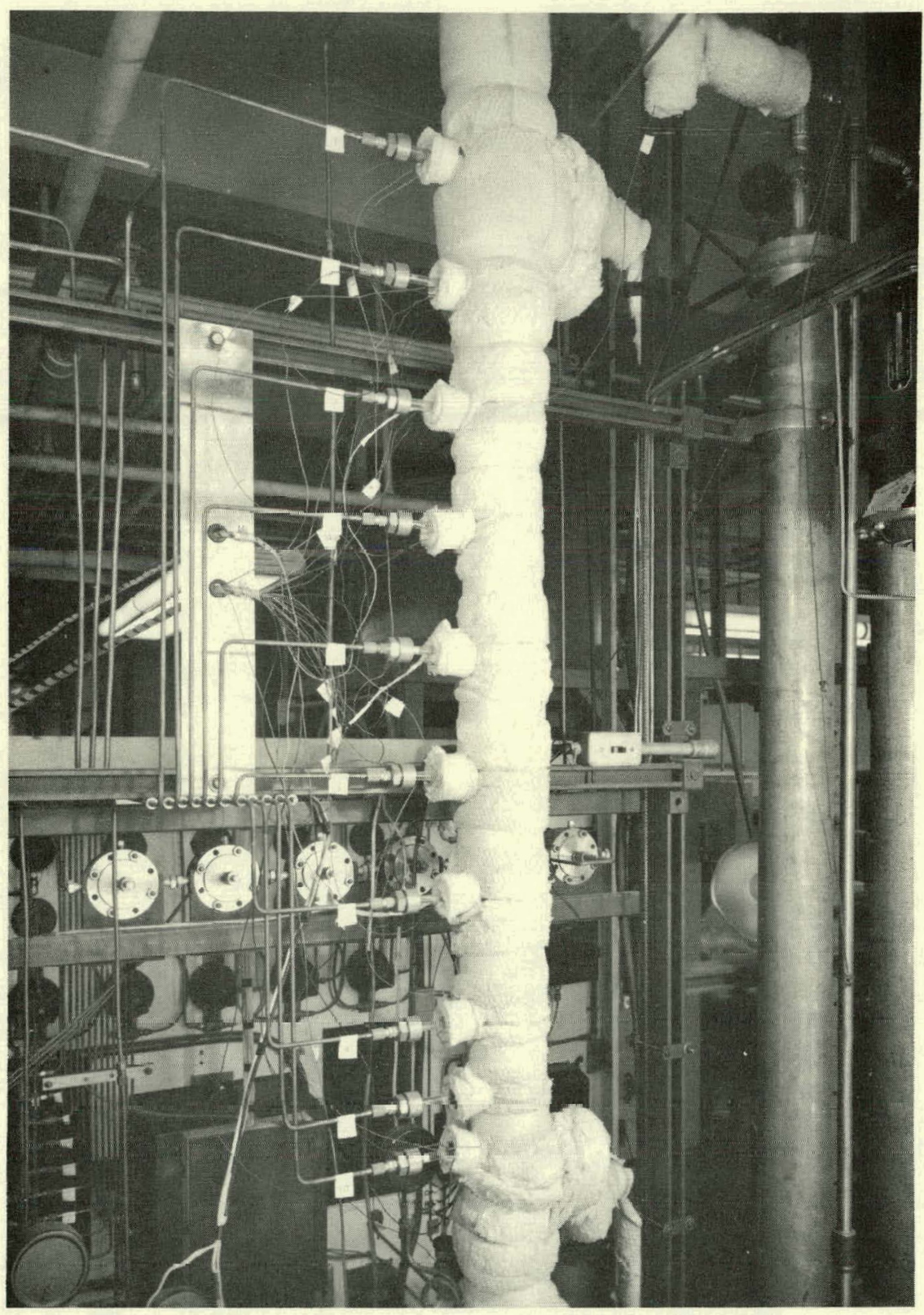

Fig. 3. Insulated test section, showing pressure tap connections. 


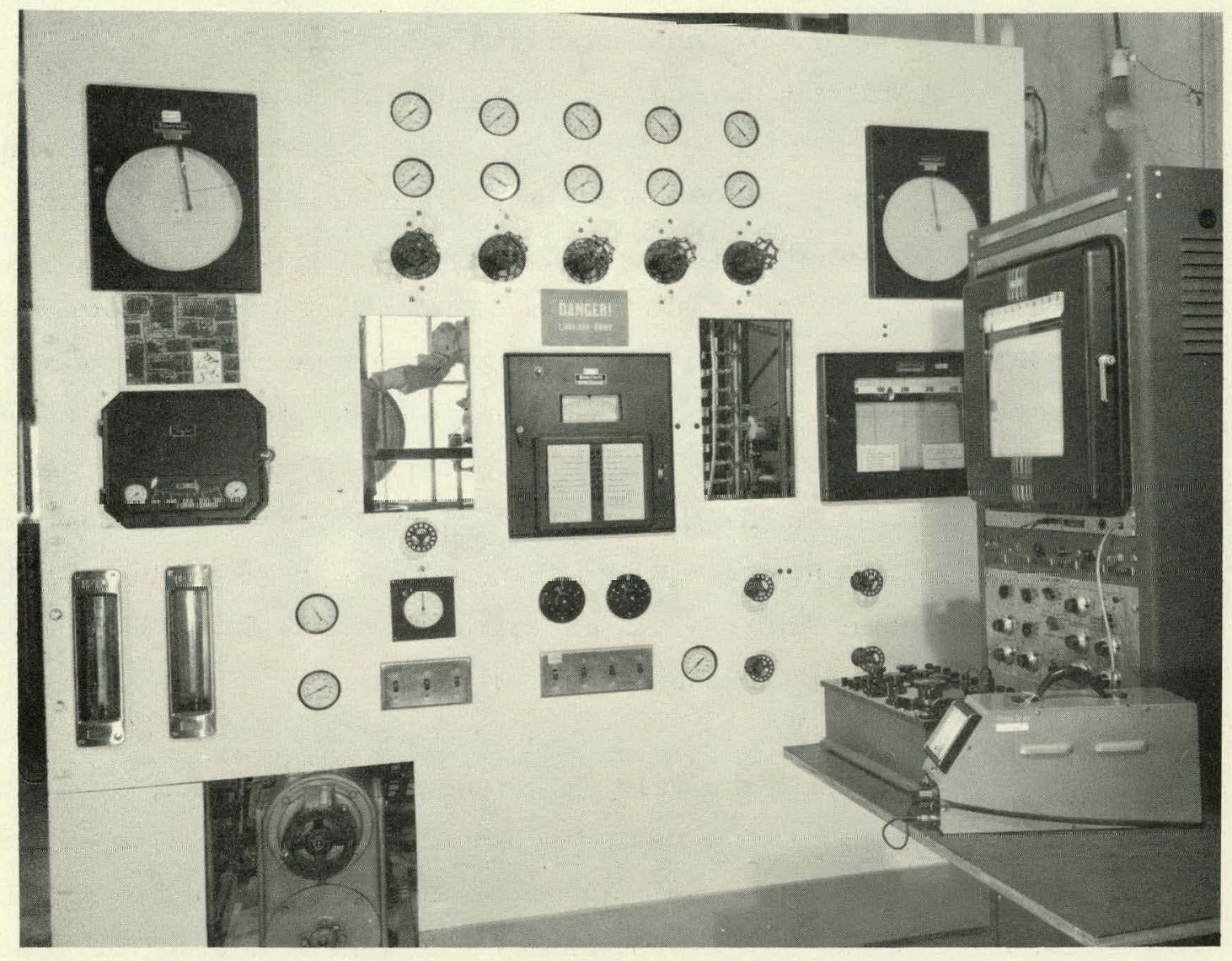

$\mathrm{ZN}-2935$

Fig. 4. Flow-system control panel and data-collecting instruments. 


\section{B. Flow-System Equipment}

A detailed description of the actual equipment used during the experimental work with water has been presented by Wright. ${ }^{3}$ The few minor modifications that were necessary to facilitate use of the equipment with $\mathrm{n}$-butanol are outlined below.

A third steam heater was installed to provide enough heating surface to bring the feed stream close to the saturation temperdure. The shell was made from a 5 -in.-diameter brass tube, and the tube bundle consisted of seven 3/8-in 16-gauge copper tubes, $10 \mathrm{ft}$ long. A third liquid cooler was installed to insure that the temperature of the $\mathrm{n}$-butanol returning to the storage tanks was close to room temperature. It was constructed from a 50-ft length of coiled 3/4-in. copper tubing.

Because of the solvent properties of $n$-butanol it was necessary to replace all the flexible plastic connections with flexible copper. In addition, all the gaskets and $\mathrm{O}$-ring seals were replaced with ones made from silicone rubber. An exception was that Saran O rings were used for the internal seals on the main feed pump.

As a safety precaution a vent system was installed over all the storage tanks and the vapor condenser. In addition, a burnout-protection system was installed which shut off the heating current when the test-section temperature exceeded an arbitrary preset value. This consisted of a "Simplytrol Model 200" on-off controller, manufactured by Assemly Products Inc., and a relay switch installed in the heating circuit. As the mechanism was completely electrical, the only measurable lag was in the thermocouple bead, which was attached to the test section and used as a sensing element. 


\section{Test Sections}

The test sections used in this experiment were constructed from thin-walled type 321 stainless tubing nominally 0.50 in. i. d. and with a 0.0145-in.-thick wall. The maximum deviation in the measurement of the outside diameter was less than $1 \%$; however, the maximum deviation in the wall thickness was $14 \%$.

Wright has given a detailed description of the methods used during the construction and installation of the test sections as well as a discussion of the method of atlaching the thermocouples to the outside wall. ${ }^{3}$ Identical procedures were followed during this investigation. Figure 5 shows the test sections schematically, and Fig. 6 is a photograph of an actual test section.

Test section No. 5 was a modification of test section No. 4. An additional electrical connection was attached to test section No. 4 to reduce the heated length and thus increase the heat flux.

\section{Electric Power Supply}

The equipment for controlling and measuring the heating current to the test section has been described by Wright. ${ }^{3}$ For test sections Nos. 4 and 5 it was found that the maximum heat flux was limited by the maximum voltage output of the transformer. With test section No. 4 the maximum readings were $38.9 \mathrm{~V}$ and $277 \mathrm{~A}$, or $10.6 \mathrm{~kW}$. Test section No. 5 burned out before the maximum power or voltage could be reached. The resistances of test sections Nos. 4 and 5 were 0.140 and $0.100 \mathrm{ohm}$ respectively. 
Fig. 5. Test section dimensions and pressure tap locations.

\begin{tabular}{|c|c|c|c|}
\hline & & Test section No. 4 & Test section No. 5 \\
\hline \multicolumn{2}{|c|}{ Outside diameter (in.) } & 0.4962 & 0.4962 \\
\hline \multicolumn{2}{|c|}{ Inside diameter (in.) } & 0.4670 & 0.4670 \\
\hline \multicolumn{2}{|c|}{ Wall thickness (in.) } & 0.0146 & 0.0146 \\
\hline \multicolumn{2}{|c|}{ Heat transfer area $\left(\mathrm{ft}^{2}{ }^{2}\right)$} & 0.6960 & 0.5013 \\
\hline Distance & No. 1 & 0.01 & -1.58 \\
\hline from & No. 2 & 0.68 & -0.91 \\
\hline entrance & No. 3 & 1.36 & -0.28 \\
\hline of heated & No. 4 & 2.04 & 0.45 \\
\hline section to & No. 5 & 2.70 & 1.11 \\
\hline pressure & No. 6 & 3.38 & 1.79 \\
\hline tap & No. 7 & 4.04 & 2.45 \\
\hline$(\mathrm{ft})$ & No. 8 & 4.70 & 3.11 \\
\hline & No. 9 & 5.38 & 3.79 \\
\hline & No. 10 & 5.69 & 4.10 \\
\hline
\end{tabular}




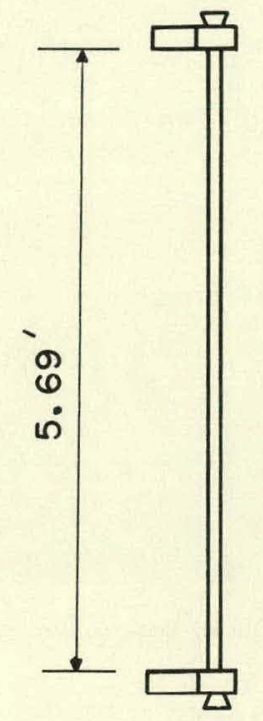

Test section No. 4

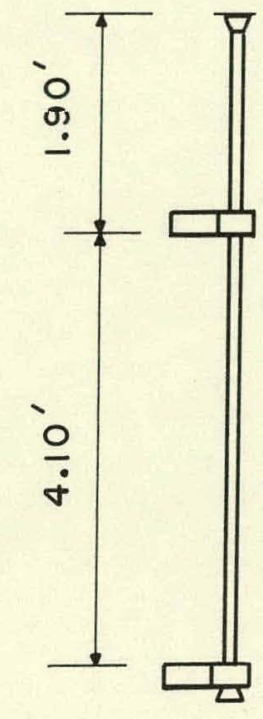

Test section No. 5

MU - 28757 


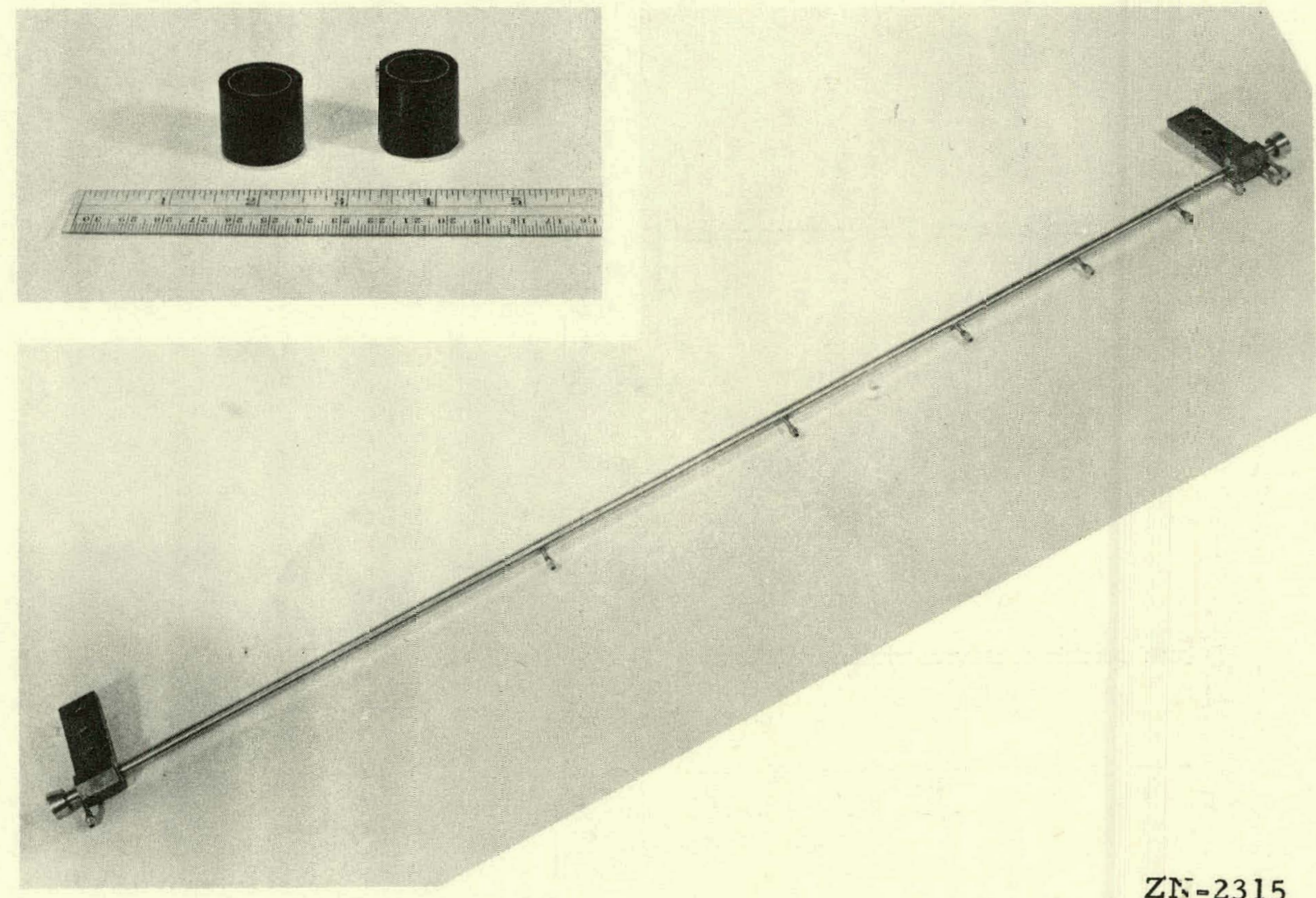

Fig. 6. Test section with specimens mounted for microscopic wall-thickness measurement. 


\section{E. Instrumentation}

The instrumentation for recording pressures within the test section and temperatures throughout the flow equipment and on the

outside test-section wall have been outlined in detail by Wright. 3 Test-section pressures were measured by. a pressure transducer and test-section outside-wall temperatures by a set of 23 copper-constantan thermocouples. Some minor changes were made in the data-collecting circuitry to facilitate measurement of the outside-wall temperatures.

Following these modifications two independent information channels were available for measuring either of two input signals. Channel 1 was a 0 - to $1-m V$ Leeds and Northrup Speedomax-G recorder, used for measuring pressures; Channel 2 was a precision Rubicon laboratory type-B potentiometer with a. suitable null detector used for measuring thermocouple voltages. The first input signal, a voltage output from the pressure transducer, was bucked with a d.c. voltage (bias voltage) and displayed on the Leeds and Northrup recorder. This bias voltage was later measured with the Rubicon potentiometer. The second input signal was a thermocouple voltage signal. Leeds and Northrup rotary thermocouple switches were used to select one of the 23 individual thermocouples. The data-collecting circuitry is illustrated in Fig. 7 .

The thermocouples were calibrated in the following manner. Thermocouples 1 and 2, which were immersed in the flow stream and could be removed, were calibrated against National Bureau of Standards thermometers at the ice point and in a hot water bath held just below the boiling point. The rest of the thermocouples were calibrated in place against thermocouples 1 and 2 at room temperature and at a temperature just below the boiling point of $n$-butanol. The $n$-butanol was circulated through the system at a high flow rate and the thermocouples examined over a period of 3 to 4 hours. The correction applied to thermocouples 1 and 2 was $0.2^{\circ} \mathrm{F}$ at the upper calibration point. For the thermocouples soldered to the test section a positive correction 


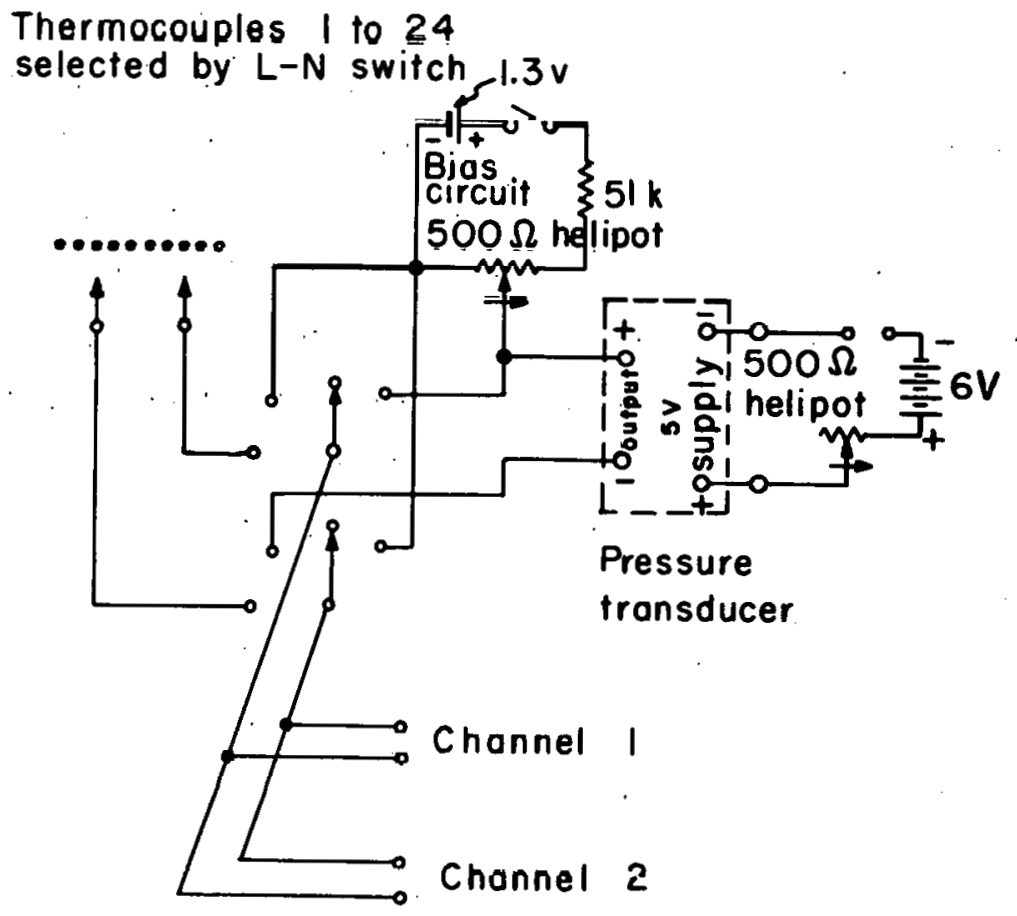

MU-28TS8 


$$
\text { : : } \quad-29-
$$

of between 1 and $2^{\circ}$ was applied at the upper calibration point. The test-section insulation was adequate, and calculations showed that the heat loss was anegligible percentage of the total heat flow. It is thought that stresses must have been introduced in: the thermocouples during fabrication that caused the readings to be: slightly. low.

The transducer was calibrated in its permanent location by a . deadweight gauge tester over a pressure range of 14.7 to 94.7 psia. .. : : The results of six calibration runs were fitted to a straight line by a - least-squares technique. The standard deviation was found to be considerably lower than the guaranteed linearity of the transducer. 


\section{EXPERIMENTAL PROCEDURE}

The procedure followed during a typical experimental run was that outlined by Wright. ${ }^{3}$ For the investigation with n-butanol no modi fication to this procedure was found necessary. The flow system was not cleaned during the course of the investigation; however, frequent inspection of the system revealed no traces of corrosion or fouling.

After every six runs or so the system was recharged with 200.pounds of fresh $\mathrm{n}$-butanol. 'The refractive index of a.sample taken during each run was compared with a reading obtained with fresh n-butanol. The maximum deviation of this reading was less than $0.1 \%$ over a period of six runs. This was taken as evidence that little or no deleriviation of the $n=$ butanol had occurred during this period. 


\section{CALCULATION PROCEDURES}

\section{A. Reduction of Experimental Data}

Prior to the main data-reduction calculations, which were performed on an IBM-7090 digital computer, the raw experimental data were processed to obtain temperature, flow, and pressure measurements that were characteristic of the entire run. The thermocouple millivolt readings were averaged, converted to temperatures, and plotted against $\ell$, the length from the beginning of the heated portion of the test section. The recorded pressure signals were converted into absolute pressures, and also plotted against $\ell$. Smooth curves were then drawn through these experimental points. Figures 8 and 9 show experimental temperatures and pressures for a characteristic run. Values of the total pressure gradient, $-(\mathrm{dP} / \mathrm{d} l)_{\mathrm{tpt}}$, were obtained by graphically differentiating the pressure-versus-length curve and also plotted against $\ell$.

\section{B. Calculation of Inside-Wall Temperature}

As the inner-wall temperature could not be measured directly without disturbing the flow pattern; it was calculated from a measurement of the outer-wall temperature. By means of several simplifying as sumptions, the equation for one-dimensional heat conduction with heat generation was solved to yield the inside-wall temperature,

$$
T_{i}=T_{0}-\frac{\omega}{2}\left[r_{0}^{2} \ln \frac{r_{0}}{r_{i}}-\frac{1}{2} \cdot\left(r_{0}^{2}-r_{i}^{2}\right)\right] \cdot \frac{1}{k_{0}\left[1+\frac{\gamma}{2}\left(T_{0}+T_{i}\right)\right]} .
$$

The $T_{i}$ was calculated through an iterative solution. The derivation of Eq. (IV-1) and the justification of the assumptions are given in Appendix A. For this experiment the maximum measured temperature drop through the tube wall was $4^{\circ}$ F.. Temperature drops through the liquid film were often as little as $7^{\circ} \mathrm{F}$. Thus an appreciable error would have been made in the heat-transfer coefficient if the temperature drop through the tube wall had been neglected. 


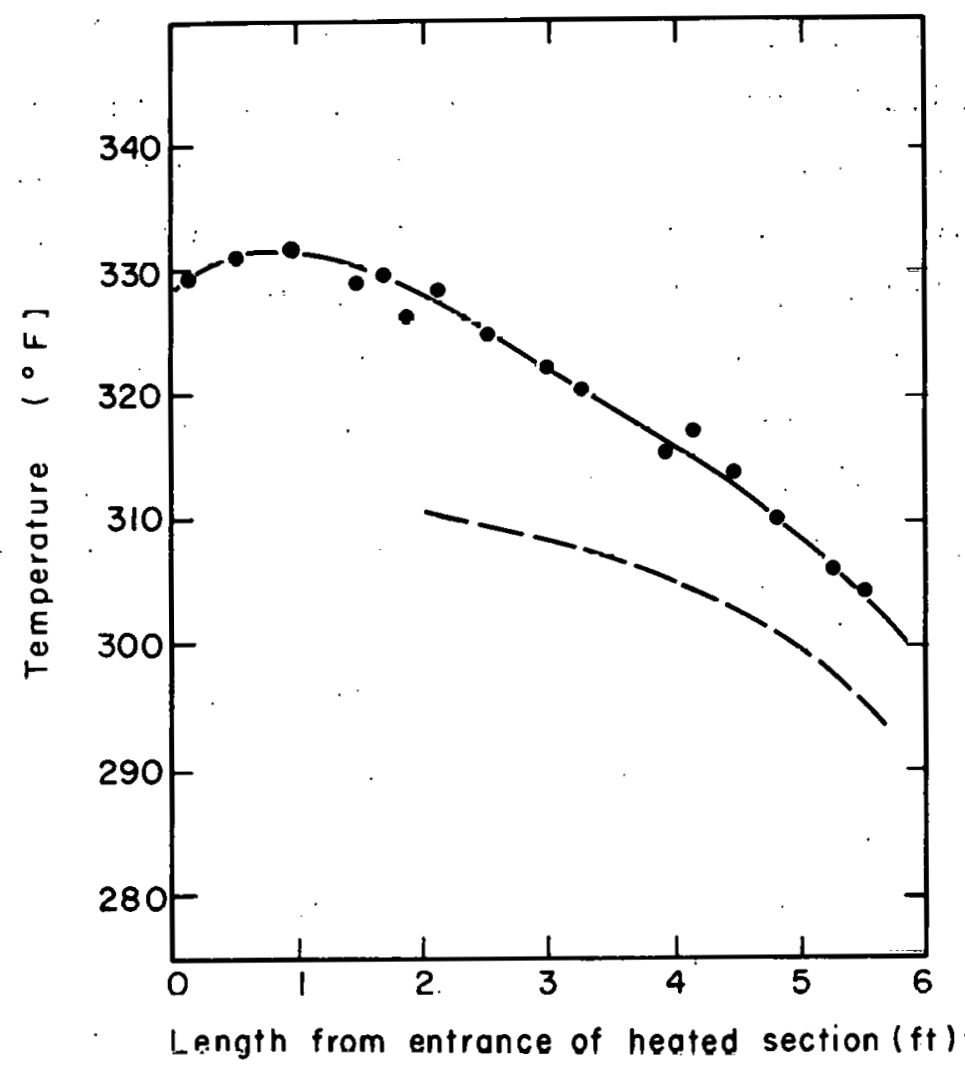

$M U .28759$

Fig. 8. Temperatures of outside tube wall for Run 25.0. - outside wall temperature

-.- bulk fluid temperature 
$-33-$

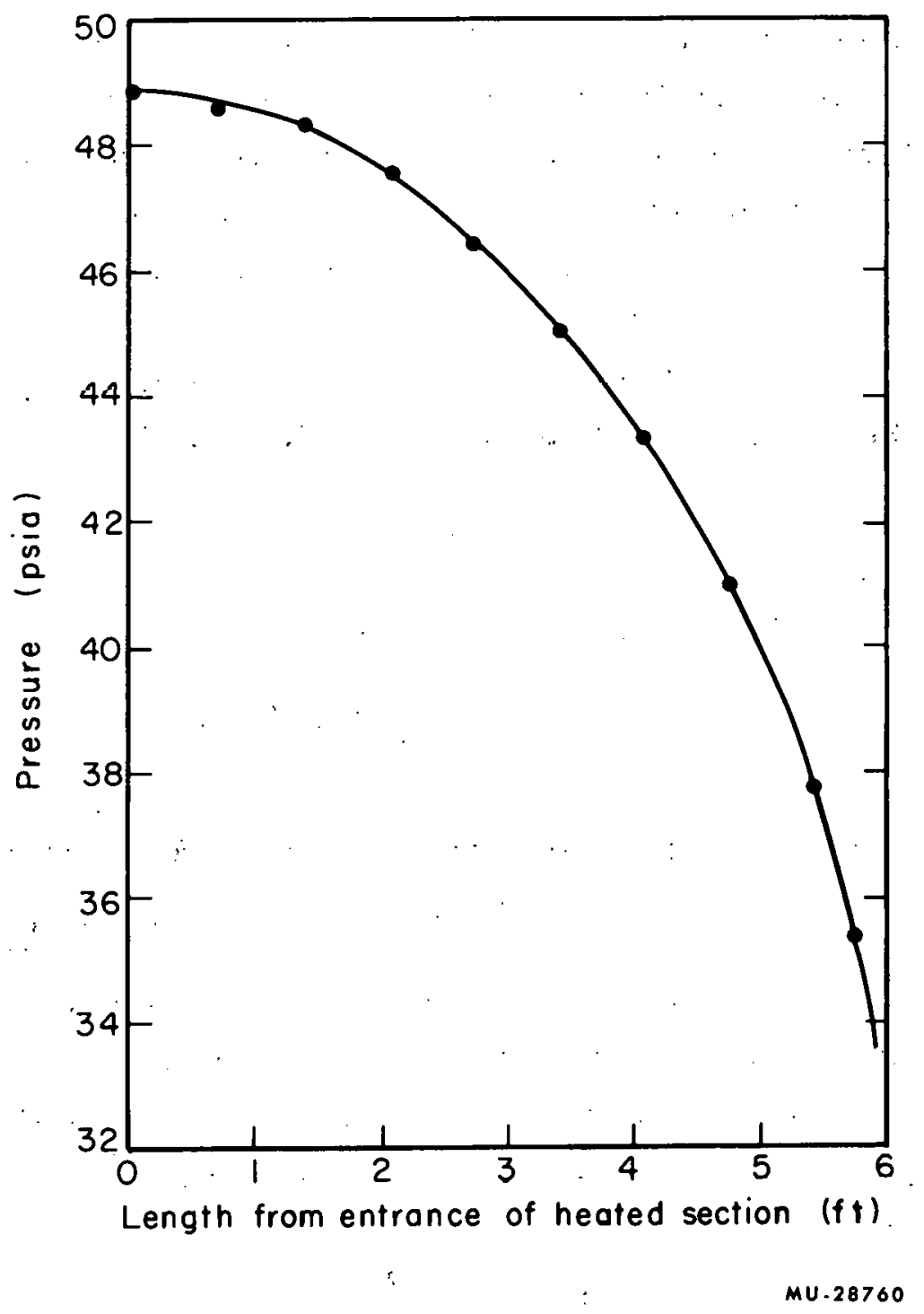

Fig. 9. Measured pressures for Run 25.0. 


\section{Bulk Temperature Measurement}

It was assumed that thermal equilibrium existed between the phases at any point in the test section where vapor and liquid were present simultaneously. When the pressure was known the saturation temperature was obtained from thermodynamic tables. The existence of thermal equilibrium is a very common assumption in two-phase: fluw prublenss, luwever, little discuooion or vorification of it has appeared in the literature.

With the inside-wall and bulk-fluid temperatures specified, the boiling heat-transfer coefficient is given by

$$
h_{b}=\frac{q}{T_{i}-T_{b}} \text {. }
$$

The heat flux $q$ is defined by

$$
q=\frac{3.41304 P w}{A_{h}} \text {, }
$$

where $A_{h}$ is the available heat-transfer area in $\mathrm{ft}^{2}$.

\section{Estimation of Vapor Quality}

The mass vapor fraction was obtained through an energy balance bctween any point in the boiling test fertion and station 1 . The latter was located before the flashing valve and was the primary reference point for the energy-balance calculations. The qualily, $x$, was estimated from

$$
\begin{aligned}
& x=\left[\frac{h_{1}-h_{f}+\frac{V_{l}^{2}}{2 g_{c} J}+\frac{Q}{W} \cdot \frac{\ell}{L}+\frac{1}{J} \cdot \frac{g}{g_{c}} \cdot\left(l+z_{l}\right)}{h_{g}-h_{f}}\right] \\
& -\left[\frac{\mathrm{v}_{\mathrm{g}}^{2}+(1-\mathrm{x}) \frac{\mathrm{v}_{\mathrm{f}}^{2}}{2 \mathrm{~g}_{\mathrm{c}} \mathrm{J}}}{\mathrm{h}_{\mathrm{c}} \mathrm{g} \mathrm{h}_{\mathrm{f}}}\right] \text {. }
\end{aligned}
$$


" Calculation of the latter term, which represents the kinetic energy of the fluid stream, requires a knowledge of the velocities of the vapor and liquid phases. Values of these quantities were not known, but they can be approximated from a.simple mass balance and the arbitrary specification of the slip ratio, $\psi$. Vapor and liquid velocities were obtained from Eqs. (IV-5), and (IV-6) respectively:

$$
\begin{aligned}
& v_{g}=\frac{W\left(\cdot(1-x) \psi \rho_{g}+x \rho_{f}\right.}{3600 A_{B} \rho_{g} \rho_{f}}, \\
& v_{f}=V_{g} / \psi .
\end{aligned}
$$

As the contribution of the kinetic energy terms is small, any reasonable value of $\psi$ can be used without introducing any serious error. A value of $\psi=2.0$ was used during the se calculations.

\section{E. Estimation of Total-Pressure Gradients}

The local total-pressure gradients were obtained graphically (see Section IV A) and put in a dimensionless form by division with the local frictional-pressure gradient. This latter quantity, defined as the gradient that would be expected if the liquid phase were flowing alone, was calculated from

$$
\left(\frac{\mathrm{dP}}{\mathrm{dl}}\right)_{\ell}=\frac{f G_{\ell}^{2}}{2.144 \mathrm{~g}_{\mathrm{C}} \bar{D}_{\mathrm{i}} \rho_{\ell}} .
$$

Values of $f$ were obtained from the Blasius friction-factor formula,

$$
\mathrm{f}=0.3164 \mathrm{Re}_{\ell}^{-0.25}
$$

When Eqs. (IV-7) and (IV-8) were combined, the liquid frictional-pressure gradient was expressed as

$$
\left(\frac{\mathrm{dP}}{\mathrm{dl}}\right)_{\ell}=0.1476 \frac{\left[(1-x) G_{T}\right]^{2}}{g_{C} D_{i} \rho_{\ell} R_{\ell}^{-0.25}} .
$$




\section{F: Thermodynamic and Physical:Properties: of:n-Butanol}

The thermodynamic and physical properties of $\mathrm{n}$-butanol were obtained from two sources. Where possible, experimental values were used; however, it was often necessary to employ an empirical method to estimate the desired property. Values of the thermodynamic and physical properties over the temperature range employed in this investigation are listed in Table $I$. The esperimental sources or empirical methods used for calculating the various properties are summarized below.

\section{Vapor Pressure}

The M。C. A. Research Project 28 suggests the following equation for pressures up to 1 atmosphere:

$$
\therefore \quad \because \cdots \log _{10} P=5.80336-\frac{2506.79}{296.79+\mathrm{T}} \quad \cdots \quad(\text { IV }-10)
$$

When extrapolated to 100 psia, Eq. (IV-10) was found to predict to within $0.5 \%$ the experimental data of Shemilt. 29 It was the refore used to estimate intermediate values of the vapor pressure. 2. Liquid and Vapor Enthalpy

Shemilt has published experimental values for the liquid and vapor enthalpies of $n$-butanol up to the critical point. Over the temperature range of interest his experimental data were fitted with a thirddegree polynomial, and intermediate values of the enthalpy were obtained from the resulting equations. The values of the enthalpy were considered to be accurate to within $1 \%$.

\section{Liquid and Vapor Specific Heat}

Values of the specific heat were obtained from the equations used in calculating the vapor and liquid enthalpies. The enthalpy: change in going from $0.5^{\circ} \mathrm{F}$ below the temperature in question to $0.5^{\circ} \mathrm{F}$ above was considered to be the specific heat at that temperature. 
TABLE I THERMODYNAMIC AND PHYSICAL PROPERTIES OF N-BUTANOL

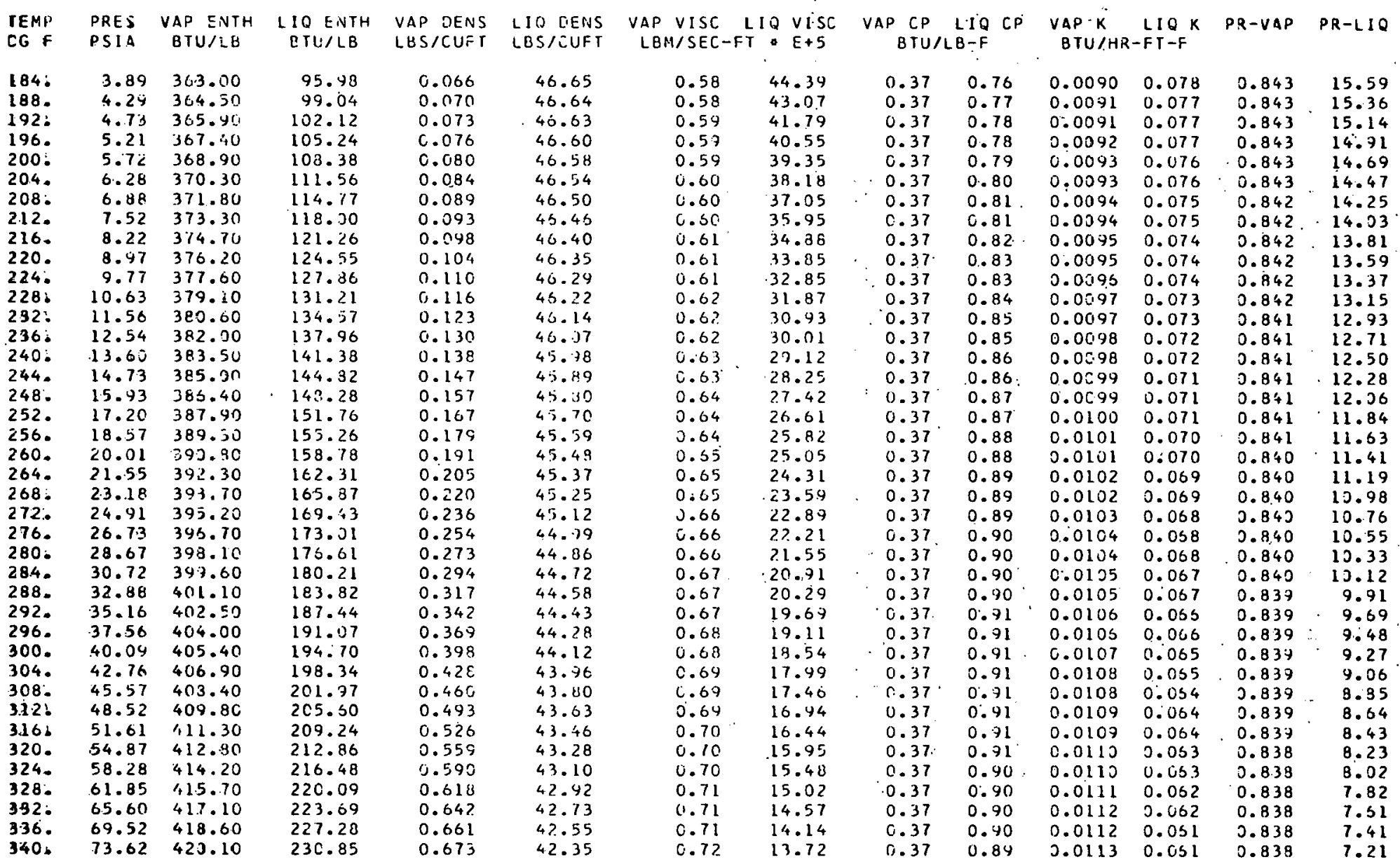




\section{Liquid and Vapor. Density}

The experimental data of Shemilt were fitted over the temperature range of interest with a second-degree polynomial. The resulting equations were used for predicting intermediate values of the density. The experimental values of the liquid density were considered accurate to within $0.1 \%$ and values of the vapor density to within $1 \%$.

5. Liquid and Vapor Viscosity

Liquid viscosity taken from the Handbook of Chemistry and Physics were fitted by a least-squares method. The resulting equation was extrapolated to obtain values of the liquid viscosity at higher temperatures. Values of the vapor viscosity were predicted by the method of Bromley and Wilke as outlined in Reid and Sherwood. 30

6. Liquid and Vapor Thermal Conductivity

The liquid the rmal conductivity was estimated by extrapolating the experimental data of Bates and Hazzard. 31 Vapor thermal conductivity was estimated by the method of Bromley as outlined in Reid and Sherwood. 30 


\section{V. . DISC.USSION}

\section{A. Boiling Heat Transfer}

\section{General}

Boiling heat transfer runs were made with the heat flux and mass flux as the controlled parameters. The reduced data are tabulated in Appendix B. All the experimental runs exhibited the same characteristic behavior: starting. from the test-section entrance the local heat-transfer coefficients decreased to a minimum at a location within the test section and then increased steadily to the test-section outlet. It is felt that this initial phenomenon can be attributed to a thermal entrance effect, and therefore all data in this region were ignored for the purposes of correlation. For this investigation the thermal entrance length was defined as that portion of the test section from the entrance to the point where the minimum heat-transfer coefficient: occurred. This length was found to vary from 6 to 48 pipe diameters.

From a rudimentary:inspection of the data several general observations can be drawn concerning the thermal entrance effect; however, it should be pointed out that these observations are based only on the data tabulated in Appendix B.

a. The entrance length decreases slightly with increasing heat flux. b. The entrance length appears to be independent of the mass flux. c. The entrance length decreases with increasing vapor fraction. Similar trends were also observed by:Wright for the forced-convection boiling of water. ${ }^{3}$

It was not possible to visually inspect the flow pattern within the test section; however, the flow could be examined immediately before and after the test section. The flow pattern at the test-section inlet closely approximated a bubble-flow model. The bubbles were large, distinct, and well defined. This might be expected, as for all runs the inlet mass vapor fraction was less than $1 \%$. The flow pattern 
at the test-section outlet could best be described as consisting of a highly turbulent mixture of vapor and liquid. Little variation in this pattern could be noticed between runs. No distinct vapor core-liquid annulus pattern could be noticed at the outlet. For the flow rates cono sidered in this experiment there was no evidence of "slugging. "This latter phenomenon would be less likely in a downflow than in an upflow experiment, as the liquid phase would be accelerated by gravity.

Within the test section, liquid must have been continuous at the heat-transfer. surface to account for the large coefficients.: The innes core, consisting of almost all the cross-sectional area, was probably a turbulent vapor-liquid mixture similar to that observed at the outlet. If the flow pattern within the test section approximated that observed in the inlet sight glass, the heat-transfer mechanism might have been one of nucleate boiling at the wall. However, it is felt that the exit flow pattern was more characteristic of conditions within the test section, so that most of the mass transfer would occur at the vapor-liquid interface.

These observations are similar to a mechanism proposed by Sachs and Long; who observed the forced-convection boiling of trichloromonofluormethane in a vertical glass annulus. 32 They reported that nucleate boiling occurred only in a short zone near the test-section entrance. After this short interval no nucleation could be observed a.1thnugh there was considerable vaporization. Downstream the flow pattern consister nf an annulus of vapor which surrounded a thin layer of liquid of the heater surface. From the results of their work it appears that the forced-convection effect suppresses nucleate boiling over the major portion of the tube length. Thus it would appear that very little nucleate boiling occurred in the investigation described here. 


\section{Comparison with Previous Correlations}

The forced-convection boiling data taken during this investi-. gation were compared with several correlations that had been developed for data taken with the steam-water system. This comparison was undertaken to see if any of these correlations could be used to predict heat-transfer coefficients for a system having different physical properties. From an examination of the results, listed in Table II, it can be seen that none of the correlations was satisfactory. Correlations 1 through 6 predicted values that were much too low, while correlations 7 and 8 predicted values that greatly exceeded the observed values. It appears that the previously suggested correlations were specific not only for the steam-water system, but--considering the large differences between the predictions of the various investigators--also specific for the range of variables covered by the individual experiments.

Despite the failure of the former correlations to predict heattransfer coefficients for $n$-butanol, the experimental data were plotted in a manner similar to the steam-water data of previous investigators. It was hoped this would serve a dual function:

a. it would give an indication of the standard deviation and scatter of the experimental data, and $b$. it would indicate whether the dimensionless groups suggested by the steam-water correlations were applicable to the data taken with $\mathrm{n}$-butanol.

Figure 10 shows the data correlated in the manner proposed by Dengler. The least-squares line for these data is

$$
\frac{h_{b}}{h_{0}}=7.55 x_{t t}^{-0.328}
$$

with a standard deviation in the heat-transfer coefficient of $\pm 11.8 \%$. Figure 11 presents the data in the manner suggested by Schrock and Grossman's second correlation. It can be seen that a correlation of this type provides a definite means of correlating the data for $\mathrm{n}$-butanol; 
cations in the glass do not contribute to the formation of a chemical bond at the interface because, again, the unsaturated state of the glass relative to the metal oxide causes solution of the metallic cations that become available.

If a molten glass is placed in contact with a metal having a definite oxide layer, then, as before, an interpenetration of the oxide surfaces occurs, with subsequent solution of the oxide. If the glass at the glassinxide interface becomes saturated with the oxide, this glass remains constant in composition (at constant temperature), and is in thermodynamic equilibrium with the oxide, resulting in a balance of bond energies and a chemical bond. In this case the ideal situation would be one in which this balance occurred with only chemisorbed oxygen remaining on the metal surface; it would result in the desired transition zone, free of a bulk oxide layer but with chemical bonding. However because the properties of an adsorbed oxide layer are different from those of the bulk oxide, and because of the metallic attractive forces due to the screening and bonding demands of the metal, it appeaxs that there is a certain amount of latitude and that this transition zone can occur even if the glass at the interface is not completely saturated. If the entire glass is saturated with the lowest-valence oxide of the metal, no difficulties are encountered in attaining this condition. If, however, the entire glass is not saturated with the oxide, then the critical requirement for maintaining saturation at the oxide-glass interface is that the rate of solution of the oxide at the interface is higher than the rate of diffusion of the dissolved oxide away from the interface. The appearance of good glass-to-metal seals seems to substantiate the existence of a saturated layer at the interface, as described earler for Kuvar seals. If a discrete oxide layer remained at the interface, then the critical question would be whether it was sufficiently strong and adherent to the 
Fig. 10. Comparison of boiling data from this experiment with Dengler ${ }^{i} \mathrm{~s}$ correlation.

$\mathrm{h}_{\mathrm{b}} / \mathrm{h}_{0}=7.55 \mathrm{x}_{\mathrm{tt}}^{-0.328}$

- D Dengler $\quad h_{b} / h_{0}=3.5 x_{t t}^{-0.5}$

Wright $\quad h_{b} / h_{0}=2.43 x_{t t}^{-0.562}$ 


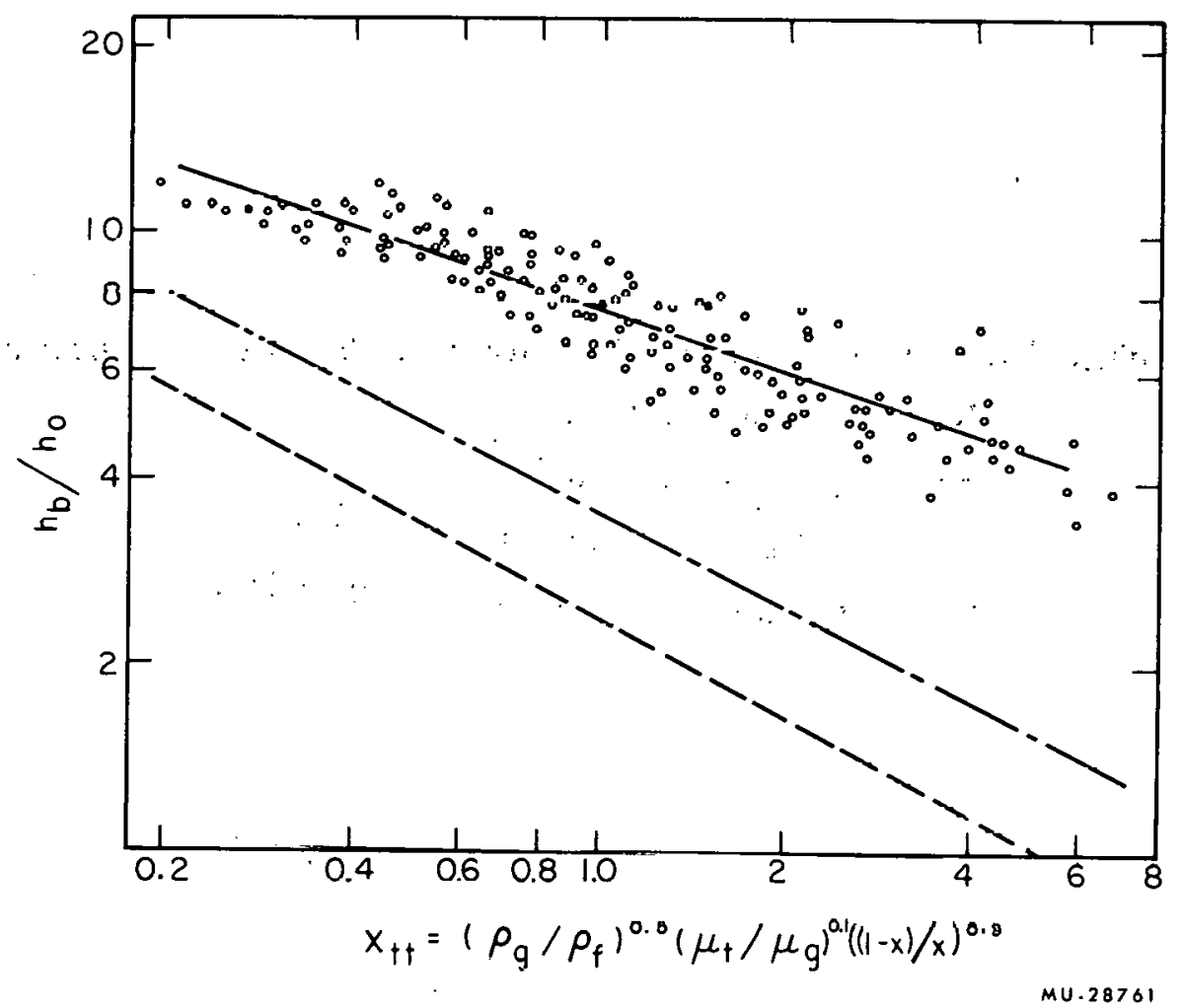


but, as seen in Fig. 11, the data lie above the steam-water correlations of Wright and.Schrock and Grossman. The equation for the data of the runs with $\mathrm{n}$-butanol was

$$
\frac{\mathrm{Nu}_{\mathrm{b}}}{\operatorname{Re}_{\ell}^{0.808} \operatorname{Pr}_{\ell}^{1 / 3}}=563 \cdot\left[\mathrm{Bo}+1.5 \cdot 10^{-4} \mathrm{x}_{\mathrm{tt}}^{-2 / 3}\right] \text {. }
$$

Wright obtained a coefficient of 320 and Schrock and Grossman one of 170. The standard deviation of the heat-transfer coefficient for $n$ butanol was $\pm 16.6 \%$, whereas Wright and Schrock and Grossman reported deviations of $\pm 21.3 \%$ and $\pm 35 \%$ respectively.

As the standard deviation of the data for $n$-butanol, based on these two correlations, compared favorably with deviations reported by other investigators using water, it was assumed that the experimental data were meaningful.

\section{Correlation of Experimental Data}

As none of the correlations developed from the steam-water data were successful in predicting boiling heat-transfer coefficients for $\mathrm{n}$-butanol, a project was initiated to study the variation of this quantity with flow variables and the physical properties of the fluid. Wright had used the same equipment to measure heat-transfer coefficients in the downflow boiling of water. ${ }^{3}$ Values taken from his experimental data were combined with an equal number of values taken during this investigation, and an attempt was made to develop a correlation that would be applicable to the two fluids.

The computations were performed on an IBM-7090 digital computer using a least-squares stepwise linear multiple-regression subroutine. This routine was written to include only significant variables in the final correlation. When a variable was not significant at a.specified tolerance level it was deleted from the correlation. Often this did not mean that the deleted variable was insignificant, but rather that its magnitude varied so little throughout the experiments that no dependence could be ascertained. 
$-46-$

Fig. 11. Comparison of boiling data from this experiment with Schrock and Grossman's second correlation.

$$
\begin{aligned}
& \longrightarrow \mathrm{Nu}_{\mathrm{b}} / \operatorname{Re}_{\ell}^{0.8} \operatorname{Pr}_{\ell}^{1 / 3}=563\left(\mathrm{Bo}+1.5 \cdot 10^{-4} \mathrm{X}_{\mathrm{tt}}^{-2 / 3}\right) \\
& \cdots-\quad \text { Wright, } \mathrm{Nu}_{\mathrm{b}} / \operatorname{Re}_{\ell}^{0.8} \operatorname{Pr}_{\ell}^{1 / 3}=320\left(\mathrm{Bo}+1.5 \cdot 10^{-4} \mathrm{X}_{\mathrm{tt}}^{-2 / 3}\right) \\
& \quad \text { Schrock and Grossman, } \\
& \mathrm{Nu}_{\mathrm{b}} / \operatorname{Re}_{\ell}^{0.8} \operatorname{Pr}_{\ell}^{1 / 3}=170\left(\mathrm{Bo}+1.5 \cdot 10^{-4} \mathrm{X}_{\mathrm{tt}}^{-2 / 3}\right)
\end{aligned}
$$




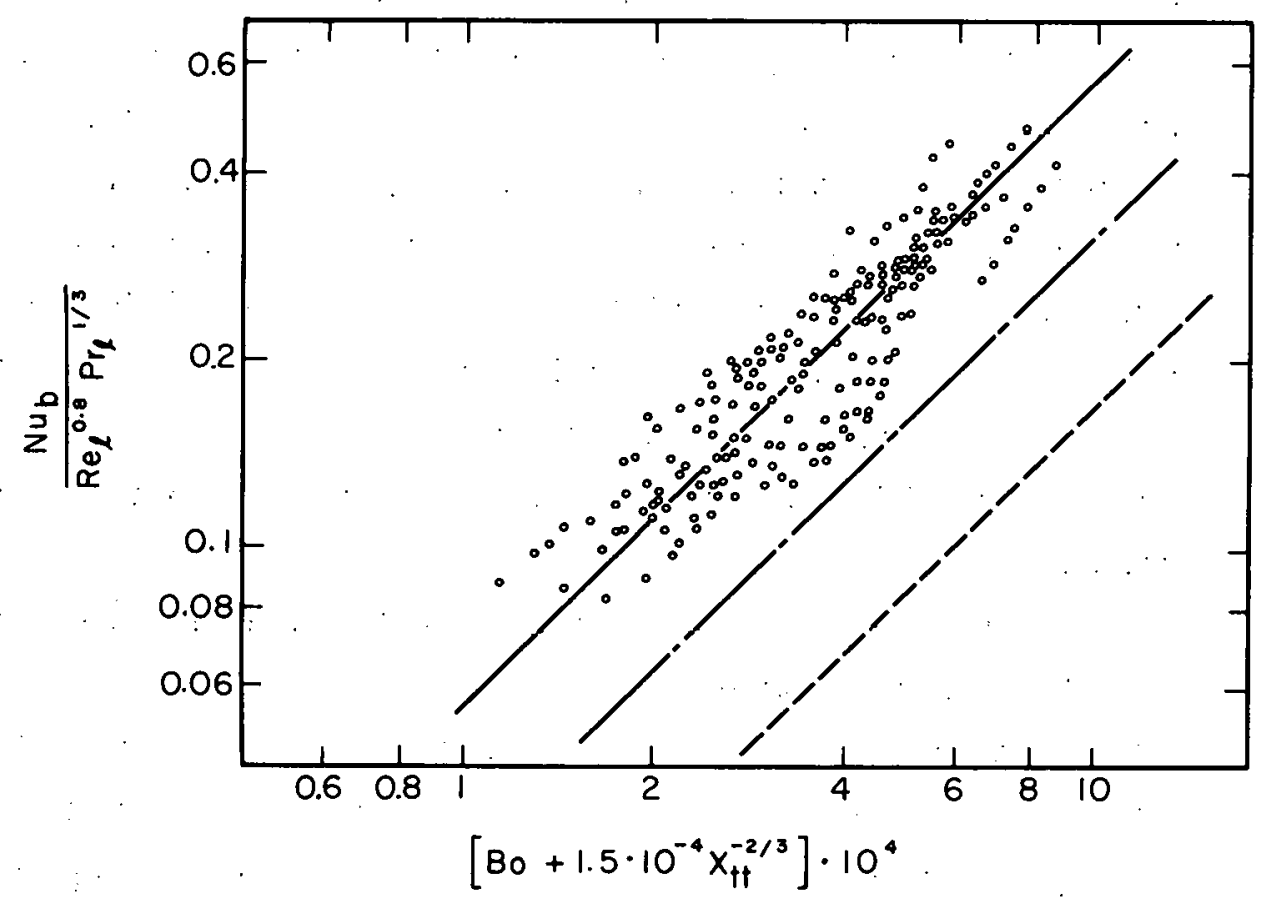

MU.28762

Fig. 11. Comparison of the present boiling data, with the second correlation of Schrock and Grossman.

$$
\begin{aligned}
& -\frac{\mathrm{Nu}_{\mathrm{b}}}{\mathrm{Re}_{\ell}^{0.8} \operatorname{Pr} 1 / 3}=563\left[\mathrm{Bo}+1.5 \cdot 10^{-4} \mathrm{X}_{\mathrm{tt}}^{-2 / 3}\right] \\
& -\mathrm{Wright} \cdot \frac{\mathrm{Nu}_{\mathrm{b}}}{\mathrm{Re}_{\ell}^{0.8} \operatorname{Pr}_{\ell}^{1 / 3}}=320 \cdot\left[\mathrm{Bo}+1.5 \cdot 10^{-4} \mathrm{X}_{\mathrm{tt}}^{-2 / 3}\right] \\
& \cdots \quad \text { Schrock and Grossman } \frac{\mathrm{Nu}_{\mathrm{b}}}{\operatorname{Re}_{\ell}^{0.8} \operatorname{Pr}_{\ell}^{1 / 3}}=170\left[\mathrm{Bo}+1.5 \cdot 10^{-4} \mathrm{X}_{\mathrm{tt}}^{-2 / 3}\right]
\end{aligned}
$$


During the initial stages of this study the data for $n$-butanol and water were examined separately by using both dimensionless and dimensional quantities. It became apparent that a better correlation was obtained with the dimensionless groups; thus the Reynolds number was a better correlating parameter than the mass flow rate, the boiling number a better correlating parameter than the heat flux. The quality, $x$, and the ratio of the vapor and liquid densities, $\rho_{g} / \rho_{f}$, were both found to be important correlating parameters. The Martinelli parameter was found to be equally successful, however, and it was decided to employ it rather than the quality and density ratio. In the final stages of this study the data for water and-n-butanol were combined into a single correlation. It was assumed that the Prandtl number would account for differences between the two fluids. The more successful correlations are summarized in Table IIl. Figures 12, 13, and 14 show graphically the comparison of the data with correlations Nos. 1,2, and 3 .

During the linear-regression analysis it was observed that the Martinelli parameter, which is strongly dependent on the quality, was the most important correlating parameter. The Reynolds number was always found to be a more important corrclating parameter than the boiling number or the heat flux. This was interpreted to mean that the forced-convection effects were more important than the nucleale builing cffccte.

The forced-cunvection boiling data of Mumm, ${ }^{11}$ Schrock and Grossman, ${ }^{13}$ and Bennett et al. ${ }^{14}$ wcre compared with the correlations summarized in Table IV. Of these correlations, Nos. 1 and 3 were the most successful in predicting values of the heat-transfer coefficient. The results of these predictions are summarized in Table IV and illustrated in Figs. 15 and 16. Both correlations were successful in correlating the data of the other investigators to within an average error of $\pm 30 \%$; however, correlation No. 3 appeared superior to correlation No. 1. Although the latter was successful in reducing the scatter of the data it did not predict the correct trend for the experimental water-steam data of other investigators (see Fig. 15). 
Table III. Boiling heat-transfer coefficient correlations

\begin{tabular}{|c|c|c|c|}
\hline Correlation & $\begin{array}{l}\text { Average error } \\
\text { in predicted } \\
\text { value of } h^{h} b_{\circ} \\
\left(B t u / h-\mathrm{ft}^{2}-{ }^{2}\right)\end{array}$ & $\begin{array}{l}\text { Standard deviation } \\
\text { of error in pre- } \\
\text { dicted value } \\
\quad\left(\mathrm{Btu} / \mathrm{h}-\mathrm{ft}^{2}-{ }^{\circ} \mathrm{F}\right) \\
\end{array}$ & $\begin{array}{l}\text { Average } \\
\quad \text { errora } \\
\quad(\%)\end{array}$ \\
\hline 1. $\mathrm{Nu}_{\mathrm{b}}=0.9273 \mathrm{Re}_{\ell}^{0.717} \mathrm{x}_{\mathrm{tt}}^{-0.345} \mathrm{Bo}^{0.194} \operatorname{Pr}_{l}^{0.800}$ & 653 & 552 & 14.5 \\
\hline 2. $h_{b}=294.9 \operatorname{Re}_{l}^{0.563} \mathrm{x}^{0.333} \mathrm{Bo}^{0.200} \operatorname{Pr}_{\ell}^{-0.241}$ & 639 & 706 & 13.6 \\
\hline 3. $S t=0.9005 \operatorname{Re}_{l}^{-0.286} \mathrm{X}_{\mathrm{tt}}^{-0.292} \mathrm{Bo}^{0.191} \mathrm{Pr}_{\ell}^{-0.233}$ & 668 & 555 & 15.0 \\
\hline 4. $\frac{N u_{b}}{\operatorname{Re}_{\ell}^{0.665} \operatorname{Pr}_{\ell}^{0.891}}=0.248 \cdot \mathrm{x}_{\mathrm{tt}}^{-0.42}$ & 707 & 618 & 16.2 \\
\hline 5. $\frac{\mathrm{Nu}_{\mathrm{b}}}{\operatorname{Re}_{\ell}^{0.665} \operatorname{Pr}_{\ell}^{0.891}}=45.84\left[\mathrm{Bo}+0.00528 \mathrm{x}_{\mathrm{tt}}^{-0.42}\right]$ & 697 & 605 & 15.9 \\
\hline
\end{tabular}

${ }^{\mathrm{a}}$ The average value of the boiling heat-transfer coefficients was $4549 \mathrm{Btu} / \mathrm{h}-\mathrm{ft}^{2}$. 


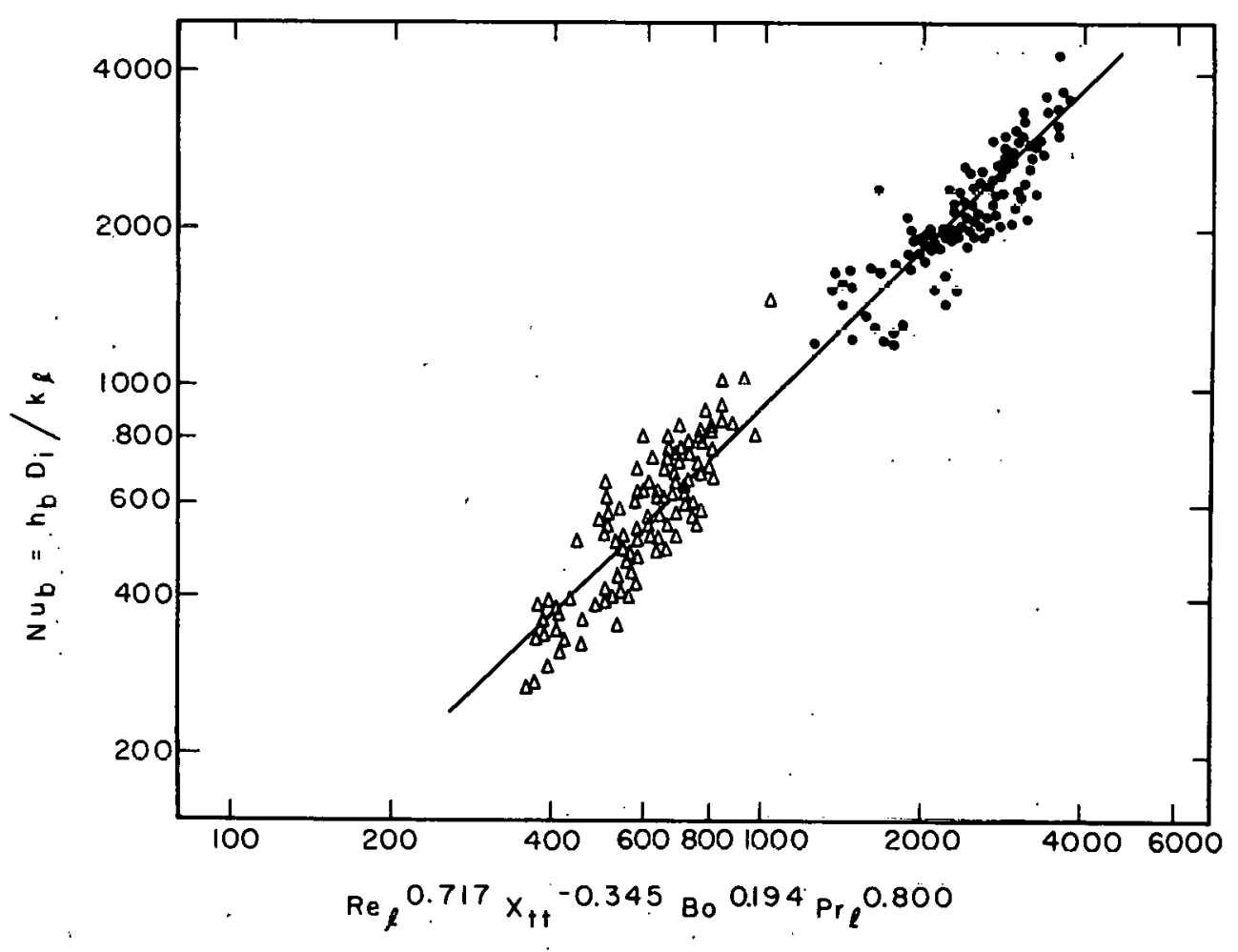

MU. 28763

Fig. 12. Graphical representation of boiling-heat-transfer correlation No. 1.

$\Delta$ water

n-butanol 


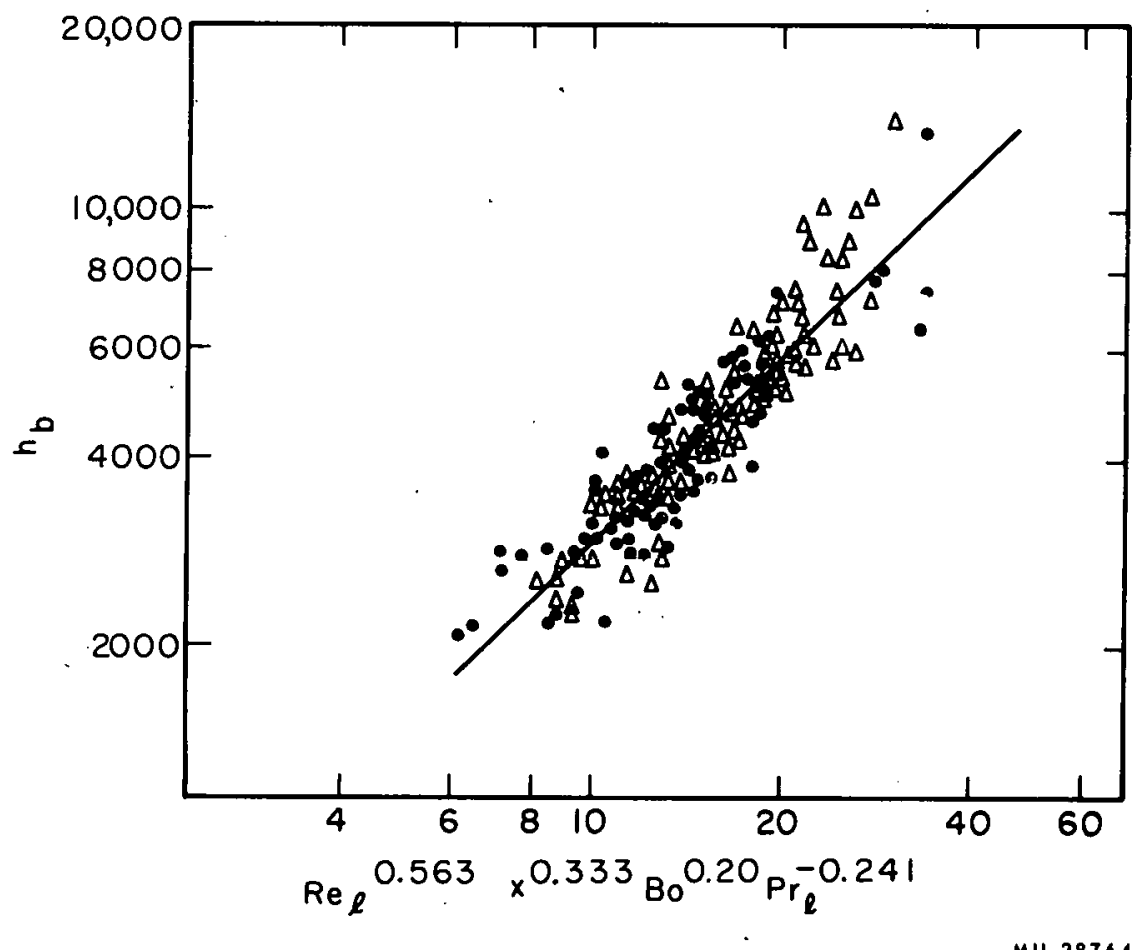

Fig. 13. Graphical representation of boiling-heat-transfer correlation No. 2.

$\Delta$ water

n-butanol 


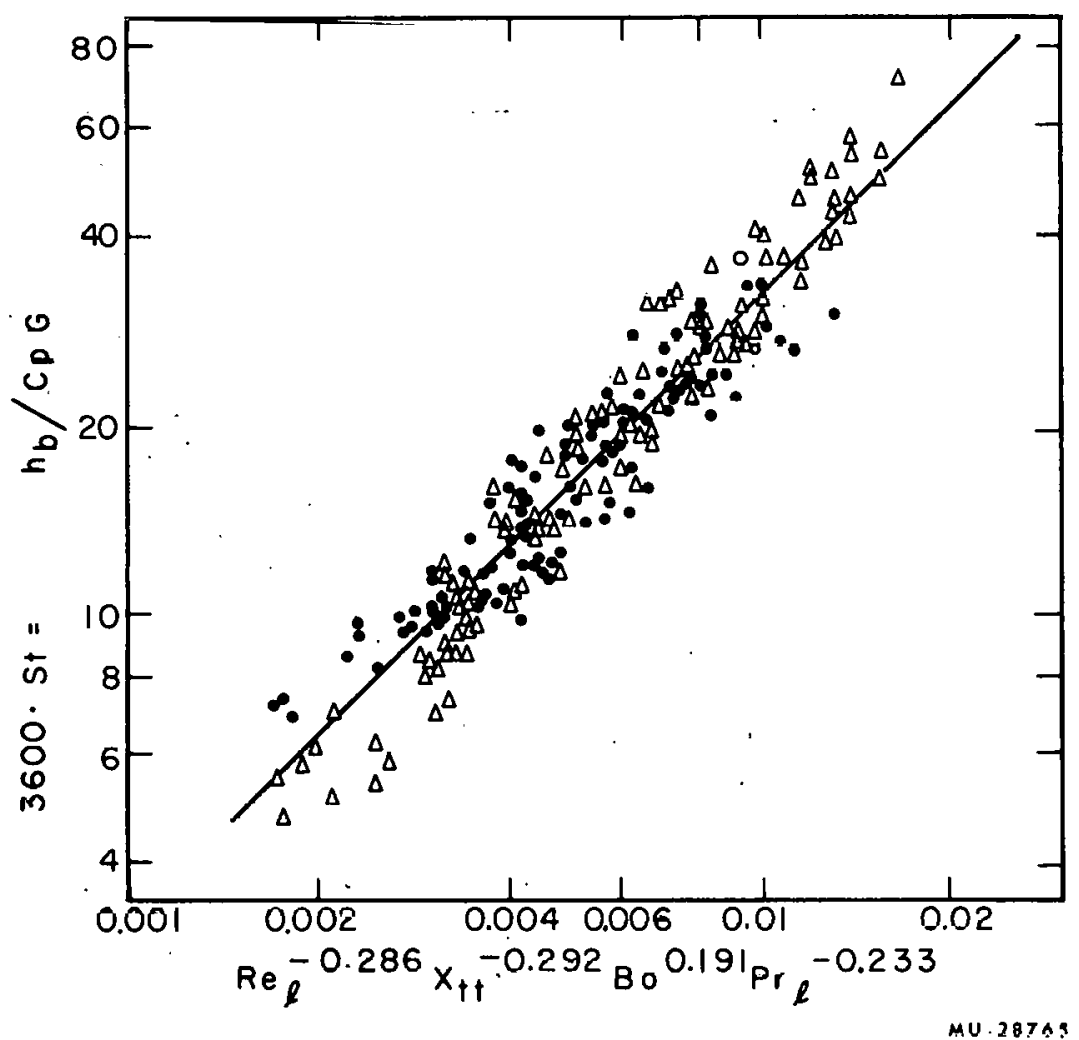

Fig. 14. Graphical representation of boiling-heat-transfer correlation No. 3.

$\Delta$ water

n-butanol 
Table IV. Comparison of boiling heat-transfer correlations with experimental data of other investigators

\begin{tabular}{|c|c|c|c|}
\hline \multicolumn{2}{|c|}{ Investigator (and reference) } & $\begin{array}{l}\text { Average error } \\
\text { in predicted } \\
\text { value of } h_{\mathrm{b}} \\
\left(\mathrm{Btu} / \mathrm{h}-\mathrm{ft}^{2}-\mathrm{F}\right)\end{array}$ & $\underset{(\%)}{\text { Average error }}$ \\
\hline \multirow{3}{*}{$\begin{array}{c}\text { Correlation } \\
\text { No. } 1\end{array}$} & Mumm (11) & 2390 & 29.6 \\
\hline & Schrock and Grossman (13) & 1947 & 22.0 \\
\hline & Bennett et al。(14) & 747 & 21.1 \\
\hline \multirow{3}{*}{$\begin{array}{l}\text { Correlation } \\
\text { No. } 3\end{array}$} & Mumm & 2153 & 26.9 \\
\hline & Schrock and Grossman & 1837 & 21.2 \\
\hline & Bennett et al. & 1183 & 27.8 \\
\hline
\end{tabular}

${ }^{\mathrm{a}}$ The average values of $\mathrm{h}_{\mathrm{b}}$ for the experiments of Mumm, Schrock and Grossman, and Bennett et al. were 7867,9425 , and $4298 \mathrm{Btu} / \mathrm{h}-\mathrm{ft}^{2}$ respectively. 


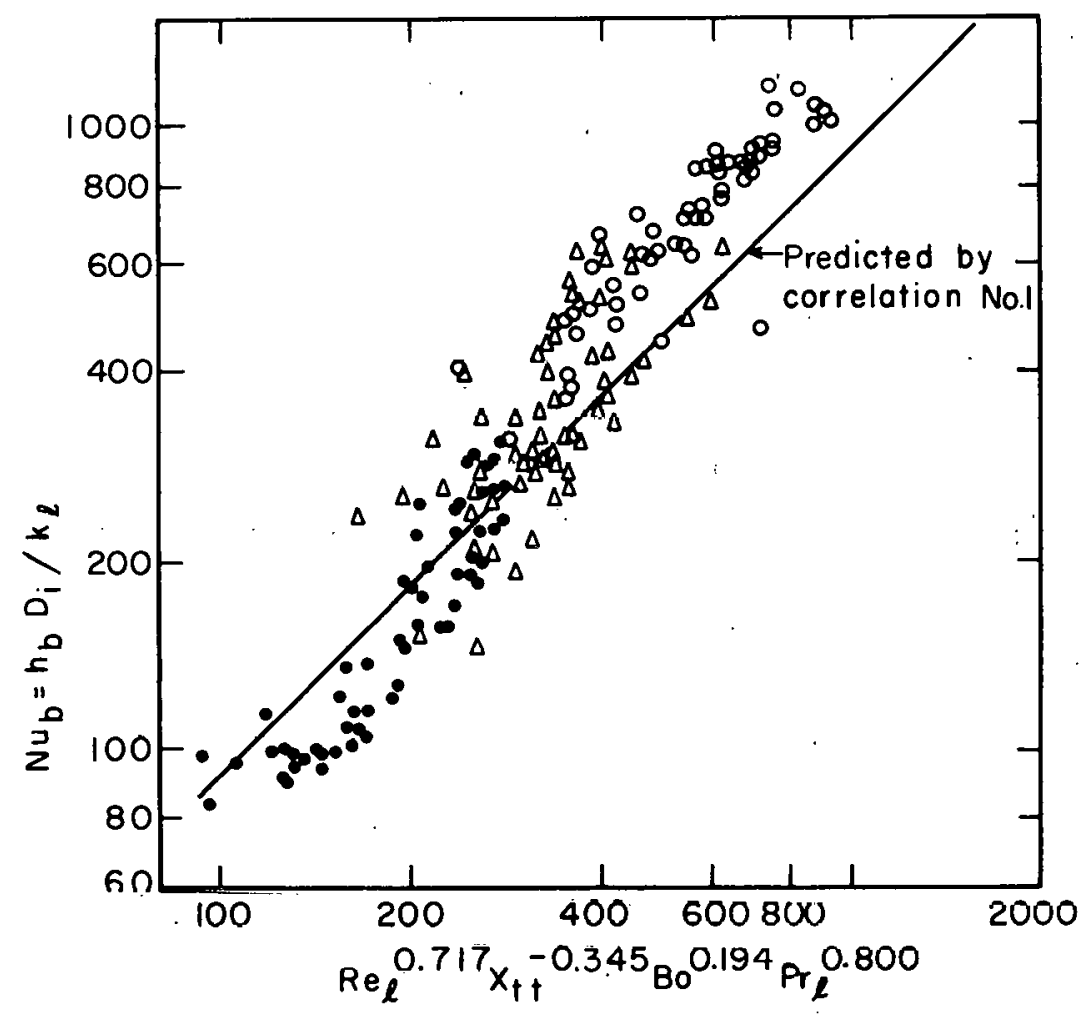

MU.28760

Fig. 15. Comparison of boiling-heat-transfer correlation No. 1 with data of other investigators.

Data of Bennett et al.

O Data of Mumm

$\triangle$ Data of Schrock and Grossman 


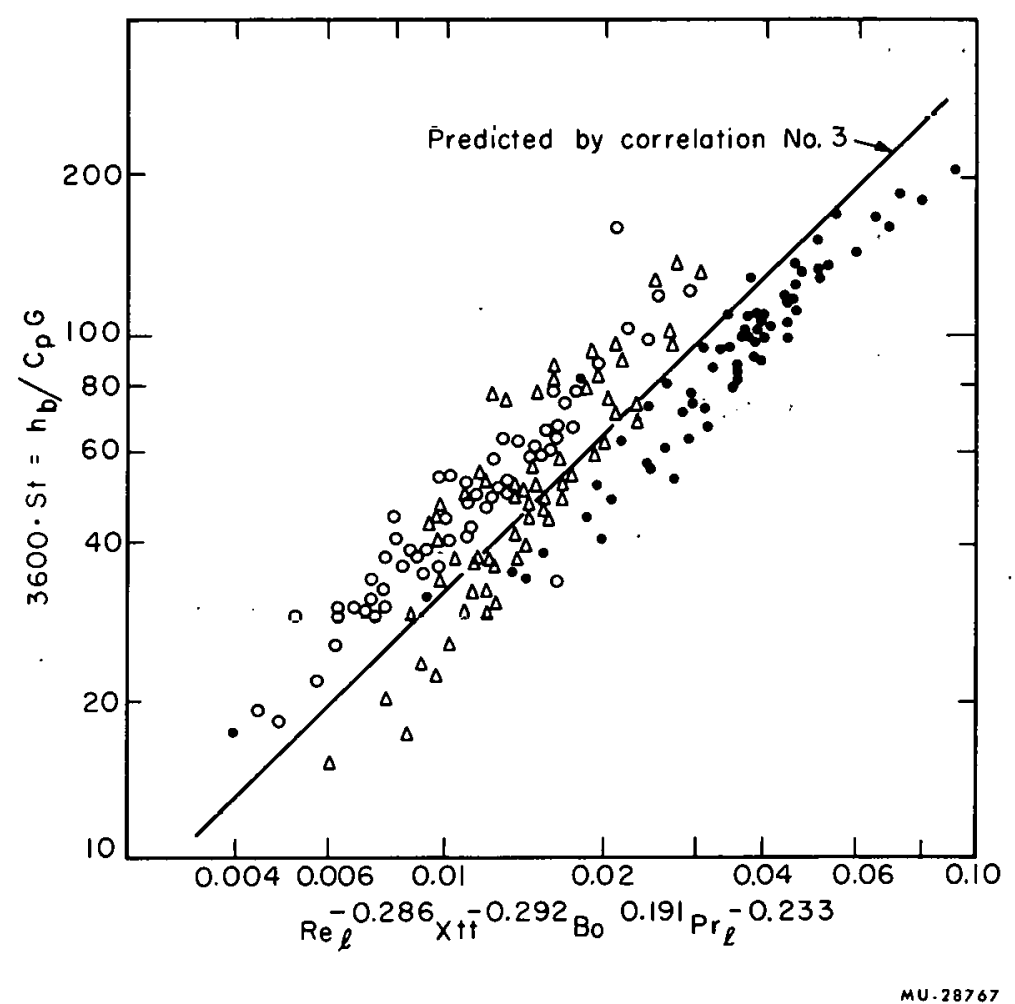

Fig. 16. Comparison of boiling-heat-transfer correlation No. 3. with data of other investigators.

Data of Bennett et al.

O Data of Mumm

$\Delta$ Data of Schrock and Grossman 
Correlation No. 3 appears to be the most successful of the correlations investigated. The experimental data of Mumm, Schrock and Grossman, Bennett et al。, and.Wright for the steam-water system were combined with the data for $n$-butanol taken during this investigation and plotted according to correlation No.3. The results are illustrated in Fig. 17. From an examination of this figure it can be seen that this correlation is successful in predicting boiling heat-transfer coefficients for various systems over a wide range of experimental conditions.

4. Burnout Heat Flux

Although measurement of burnout heat fluxes during forcedconvection boiling was not the purpose of this investigation, one value of this point was unintentionally obtained with test section No. 5 at a heat flux of $76,000 \mathrm{Btu} / \mathrm{h}-\mathrm{ft}^{2}$. The test section did not fuse, but the asbestos tape and glass wool insulation were severely charred, and it was estimated that the tube wall temperature must have exceeded $600^{\circ} \mathrm{F}$. For this run the inlet test-section pressure had been set at 30 psia and the mass flow rate at $292 \mathrm{lbm} / \mathrm{sec}_{-} \mathrm{ft}^{2}$.

Bonilla and Perry measured burnout heat fluxes for the pool boiling of $\mathrm{n}$-butanol on a polished copper surface electroplated with gold and chromium, and reported values of $140,000 \mathrm{Btu} / \mathrm{h}-\mathrm{ft}^{2} 33$ One would expect burnout heat fluxes in a forced-convection system to exceed those obtained in a ponl system. However, for the single value obtained this was certainly not the case. This difference may be attributed to several factors. The surface characteristics for the two systems were different; this could affect the peak heat flux. A small quantity of surface-active agent may have been picked up by the recirculating $\mathrm{n}$-butanol over the duration of six runs. This would lower the interfacial tension and cause an appreciable decrease in the burnout heat flux. ${ }^{34}$ Finally, there was a large amount of dissolved gas present in the $n-$ butanol at the time of burnout, as the equipment had just been turned on for the purpose of removing this gas. Kreith has reported that the 
Fig. 17. Comparison of boiling-heat-transfer correlation No. 3 with experimental data for water and $n$-butanol.

Data of Wright

Data of Bennett et al.

OData of Mumm

$\triangle$ Data of Schrock and Grossman

This investigation 


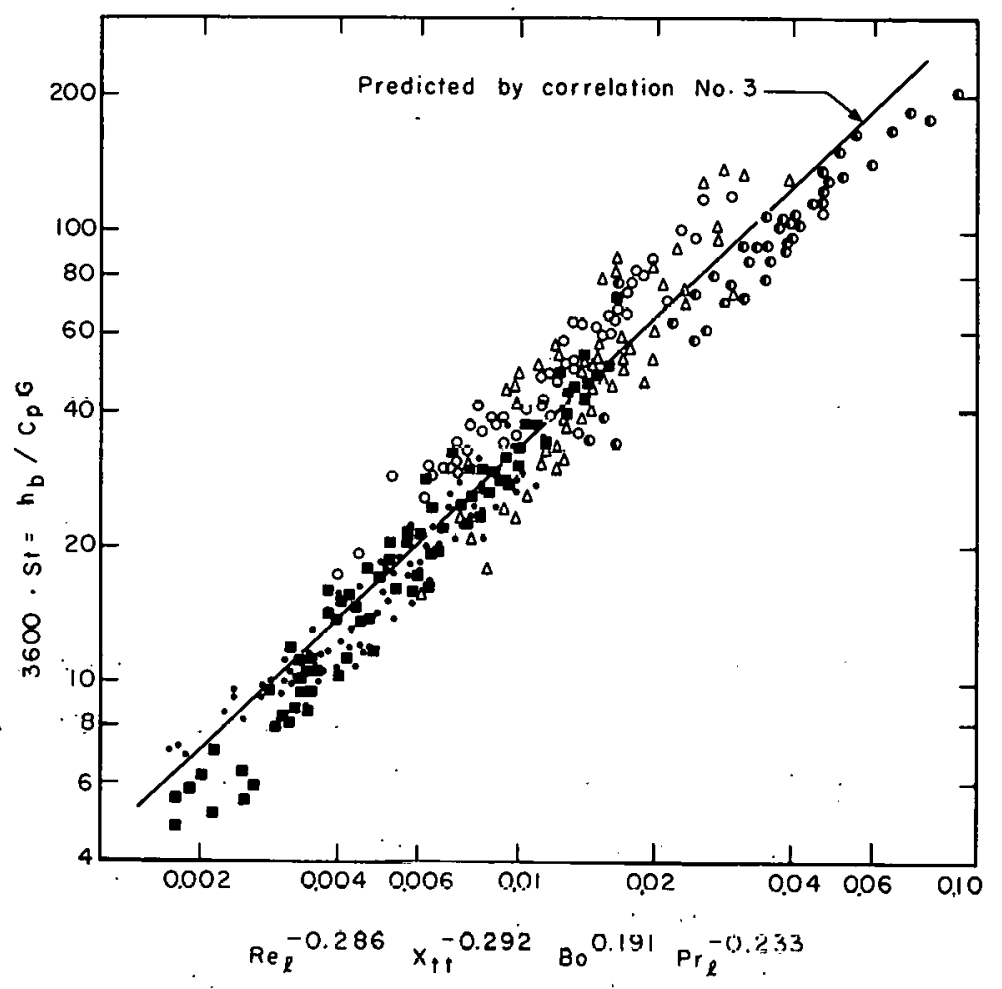

MU. 28708 
burnout heat flux is reduced by the presence of dissolved gases. ${ }^{35}$ One or all of these factors could account for the difference in heat flux between the forced-convection and pool boiling systems.

\section{B. Pressure Drop in Two-Phase Flow}

\section{Correlation of Total-Pressure Gradients}

Values of the local total-pressure gradient were obtained by graphically differentiating the curves of pressure versus test-section length. These were put in a dimensionless form by division with the liquid frictional-pressure gradient obtained from the Blasius frictionfactor formula (see Section IV.E). The results were correlated against the Martinelli parameter in a manner suggested by Schrock and Grossman. 7 Figure 18 shows this correlation as well as the curves obtained by Schrock and Grossman and by Wright for experiments with water.

It can be seen that the experimental data of this investigation lie between those of the other experimenters. One would not necessarily expect agreement among the three investigations, since the holdup and volume fractions would differ between the various studies. The leastsquares straight line for the data of this study is

$$
\left[\frac{(\mathrm{dP} / \mathrm{d} \ell)_{\mathrm{tpt}}}{(\mathrm{dP} / \mathrm{d} \ell)_{\ell}}\right]=37.02 \mathrm{x}_{\mathrm{tt}}^{-0.73 \dot{2}}
$$

although the best curve through the data is not a straight line.

Jenkins has reported a dependence of the two-phase pressure gradient on the total mass flux. ${ }^{22}$. For the data of this investigation a slightly improved correlation, having the form

$$
\left[\frac{(\mathrm{dP} / \mathrm{d} \ell)_{t p t}}{(\mathrm{dP} / \mathrm{d} \ell)_{\ell}}\right]=\frac{355.7}{G^{0.41}} \mathrm{x}_{\mathrm{tt}}^{-0.627},
$$

was obtained when the mass flux was taken. into account. Hughmark and Pressburg observed that for their experimental data the two-phase pressure drop was proportional to $\mathrm{G}^{-0.7} .23$ 


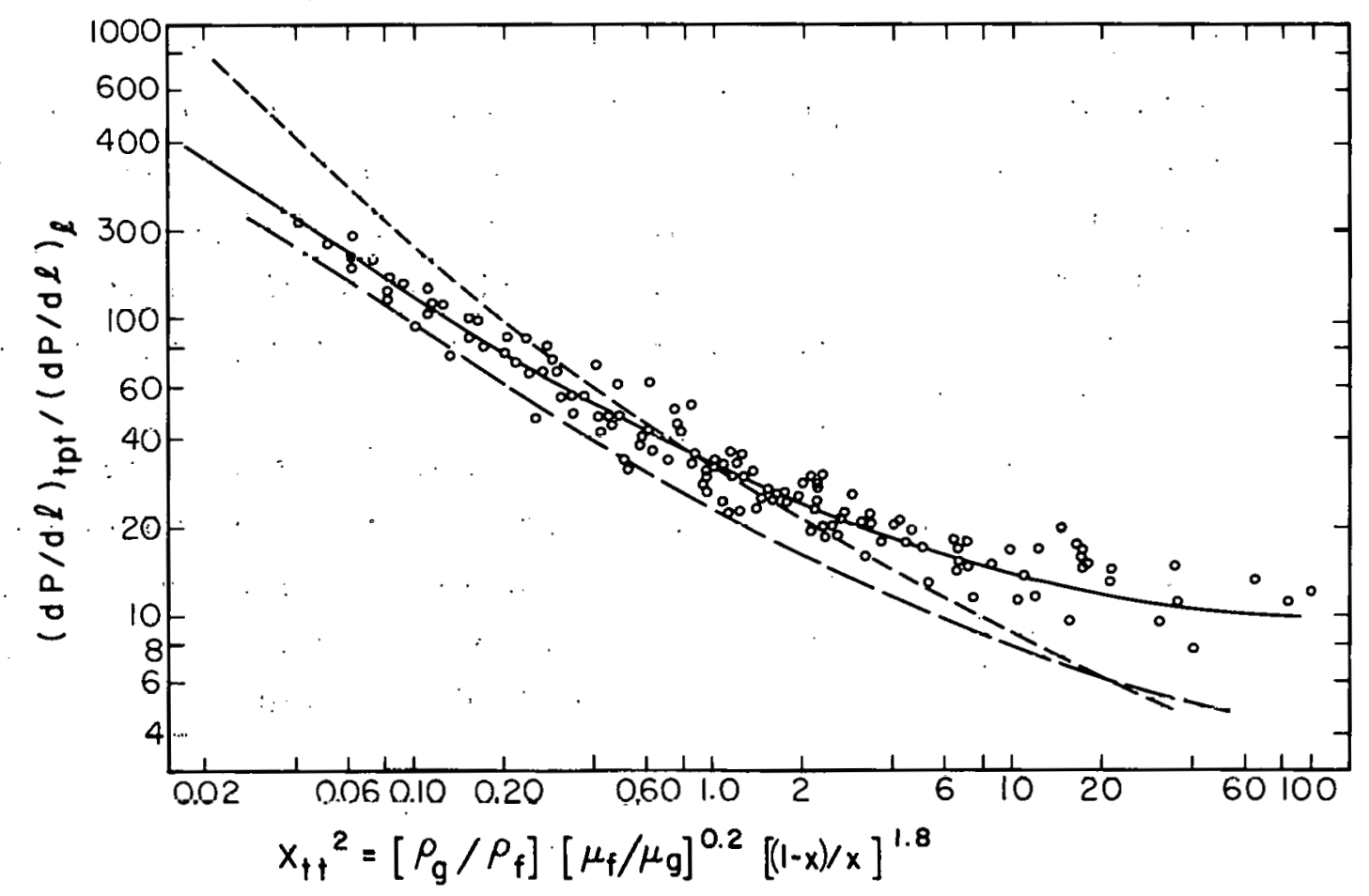

MU. 28769

Fig. 18. Forced-convection boiling total-pressure drop correlation using the Martinelli parameter. best curve (n-butanol, downflow)

-...- Schrock and Grossinar (water, upflow)

- Wright (water, downflow) 


\section{Prediction of Frictional-Pressure Losses}

The total-pressure loss in forced-convection boiling is the sum of three contributions: friction losses, momentum losses, and hydrostatic head losses. The frictional losses were obtained by subtracting these latter two losses from the observed total-pressure gradient. The losses in momentum and in hydrostatic head are dependent on the volumetric vapor fraction $a_{\text {o }}$. This latter quantity was obtained from the published correlations of a versus $X_{t t}$ by Lockhart and Martinelli and by Dengler. However for the range of $\mathrm{X}_{\mathrm{tt}}$ covered during this investigation both correlations gave nearly identical predictions of the volumetric vapor fraction for a particular value of $\mathrm{X}_{\mathrm{tt}}$.

Once a had been determined the pressure gradients due to losses in momentum and in hydrostatic head were calculated from force and momentum balances. The momentum loss was given by

$$
-\left(\frac{d P}{d l}\right)_{a}=\frac{G^{2}}{144 g_{c}} \frac{d}{d l}\left[\frac{x^{2}}{\rho_{g}^{a}}+\frac{(1-x)^{2}}{\rho_{f}(1-a)}\right],
$$

while the hydrostatic head loss was given by

$$
-\left(\frac{\mathrm{dP}}{\mathrm{d} \ell}\right)_{\mathrm{h}}=\frac{\mathrm{g}}{144 \mathrm{~g}_{\mathrm{C}}}\left[\rho_{\mathrm{f}}(1-a)+\rho_{\mathrm{g}}(a)\right] \text {. }
$$

Values of the frictional-pressure gradient were obtained by subtracting these two quantities from the experimental total-pressure gradient.

Figure 19 illustrates the results of this calculation and compares them with the experimental. results of some other investigators. At the lower values of quality (high values of $\mathrm{x}_{t t}$ ) the data taken during this investigation agreed.closely with the results reported by Stein et al. for the downflow vaporization of water in a heated annulus. 36 However, at the higher values of quality the experimental results agreed closely with the empirical correlation by Lockhart and Martinelli. 


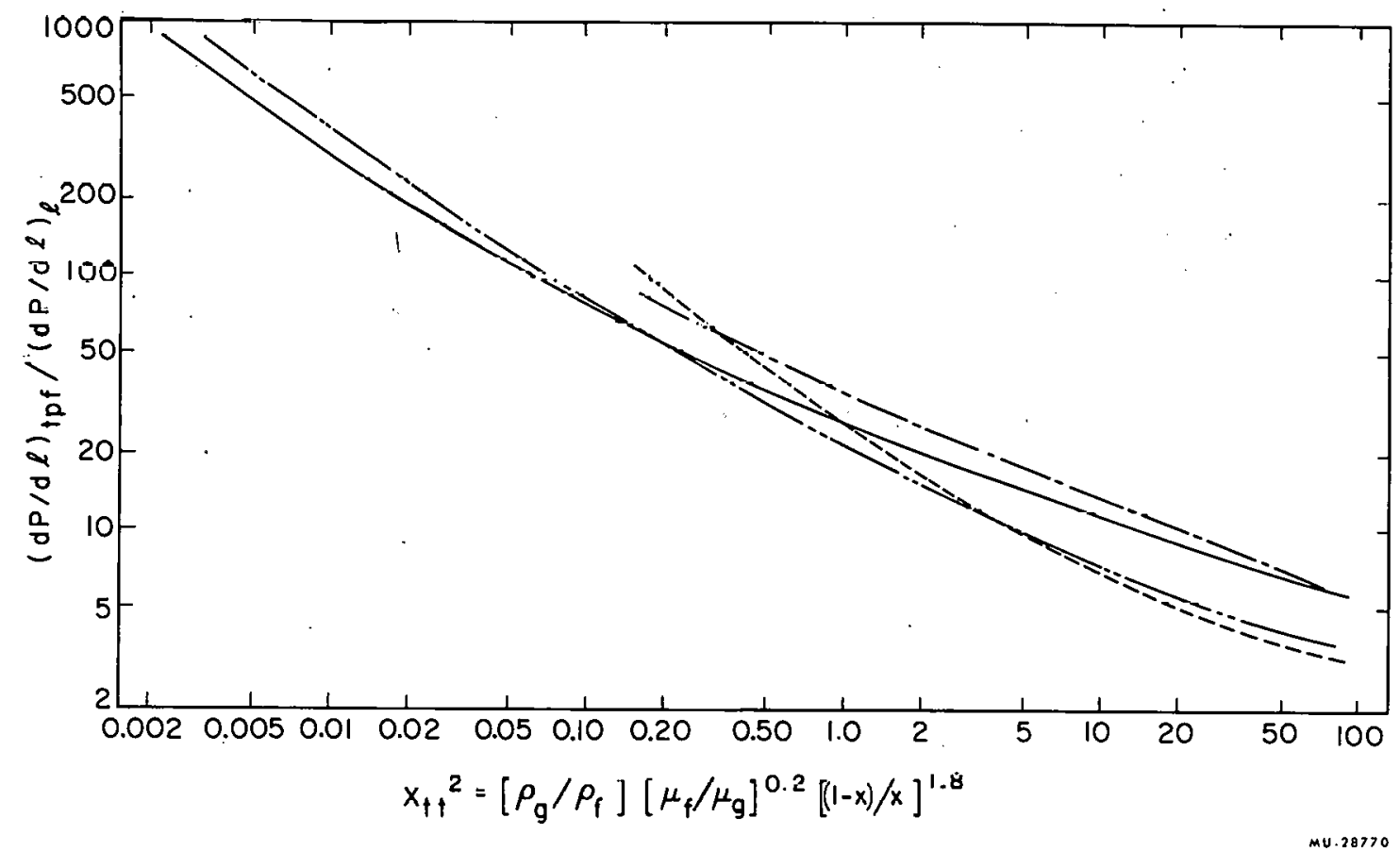

Fig. 19. Two-phase frictional pressure gradients. based on data from this experiment - - Lockhart and Martinelli: two-phase twocomponent flow

-... Dengler: vaporization in a $1-$ in. tube

-.-.-. Stein et al. : vaporization in a heated annulus. 


\section{Estimate of Experimental Error}

Local heat-transfer coefficients measured during this investigation were correlated to within $\pm 15 \%$, and were thought to be within the accuracy of the experiments. The calculation of the heat-transfer coefficient depends upon the measurements of power, wall thickness, test-section pressure, and outside-wall temperature. The probable error in each of these measurements is discussed below.

If losses occurring in the current transformer and powermeasuring circuits are neglected, the maximum error in the power measurement would be 150 watts, since the wattmeter was rated accurate to $0.5 \%$ of full scale. Though there was a large variation in the test-section wall thickness, calculations showed that even when the extreme values of the inside radius were used the deviation in the temperature drop through the wall was only $\pm 12 \%$. As $\Delta T_{w}$ was less than $4^{\circ} \mathrm{F}$ for all runs this amounted to an error of $\pm 0.5^{\circ} \mathrm{F}$. The values of the saturation temperature were obtained from the pressure measurements. As the standard deviation in the pressure transducer was less than $0.1 \mathrm{psi}$ it is believed that an error of $0.4 \mathrm{psi}$ in the pressure measured under run conditions would be conservative. This is equivalent to an error of $1^{\circ} \mathrm{F}$ in the saturation temperature and is of the same order of magnitude as the error in the equation used to predict the saturation temperature. The outside-wall temperature was the most uncertain of the measured quantitie's, as the thermocouples could not be calibrated under actual run conditions. Wright has presented a detailed discussion of the possible effects of ac current in the thermocouple leads, penetration of the thermocouple junction into the test section, and electrical heating of the thermocouple on the outside-wall temperature, and suggested that the value may be in error by $\pm 1^{\circ} \mathrm{F}^{3}$ A similar error has been assumed for calculations made during this investigation. 
The errors made in the determination of $T_{0}$ and $T_{b}$ are such that they could cancel each other or be additive. For small values of $T_{0}-T_{b}--i . e_{0}, 6^{\circ} \mathrm{F}$--the error in the heat-transfer coefficient could range from 1 to $5 \% \%$ depending on whether or not the individual errors were additive. At higher values of $\mathrm{T}_{0}-\mathrm{T}_{\mathrm{b}}--\mathrm{i} . \mathrm{e}, 10^{\circ} \mathrm{F}-$-the error in $h_{b}$ ranged from 1 to $19 \%$.

Many other investigators using electrically heated test sections to obtain values of the boiling heat-transfer coefficient have expressed difficulty in obtaining an accurate value of the temperature difference. Unfortunately they have often neglected to comment on the accuracy of their temperature measurements, and it is felt that much of the discrepancy among reported values of the heat-transfer coefficient is in part due to inaccuracies in temperature measurement.

It is thought that the errors in the calculated values of the frictional and total-pressure gradients arose from two sources: errors in the actual pressure measurements, and errors introduced by the graphical differentiation of the pressure-versus-length curves. It has been assumed that these errors were of the same order of magnitude and that the pressure gradients were accurate to within $\pm 25 \%$. 


\section{CONCLUSIONS}

Local heat-transfer coefficients and two-phase total-pressure gradients were measured for the downflow forced-convection boiling of n-butanol in electrically heated stainless steel tubes. The test sections employed had inside diameters of $0.4670 \mathrm{in}$. and heated lengths of 5.69 and $4.10 \mathrm{ft}$ respectively. Heat fluxes ranged from 2.8:10 4 to $6.6 \cdot 10^{4} \mathrm{Btu} / \mathrm{h}-\mathrm{ft}^{2}$ and mass fluxes from 136 to $440 \mathrm{lbm} / \mathrm{sec}^{2} \mathrm{ft}^{2}$. Exit qualities up to $31 \%$ were measured at pressures between 16.9 and 50.0 psia.

The experimental data were compared with previous correlations that had been based on the water-steam system; however, none of the correlations were successful in predicting values of the heat-transfer coefficient for $n$-butanol. Correlations similar to the types proposed by Dengler and by Schrock and Grossman were successful in correlating the experimental data to within $\pm 15 \%$.

New boiling heat-transfer correlations were derived and found to be successful in correlating data taken during this investigation and data taken for water by Wright to within $\pm 15 \%$. The most success ful correlations were

$$
\frac{h_{b}}{3600 C_{p} G}=S t=0.9005 \operatorname{Re}_{\ell}^{-0.286} X_{t t}^{-0.292} \mathrm{Bo}^{0.191} \operatorname{Pr}_{\ell}^{-0.273}
$$

and

$$
\mathrm{Nu}_{\mathrm{b}}=0.9273 \operatorname{Re}_{\ell}^{0.717} \mathrm{x}_{\mathrm{tt}}^{-0.345} \mathrm{Bo}^{0.194} \mathrm{Pr}_{\ell}^{0.800}
$$

They were successful in correlating the forced-convection boiling data of other investigators, taken at higher values of pressure and heat flux, to within $\pm 30 \%$.

Local two-phase total-pressure gradients were successfully correlated by the Martinelli $X_{t t}$ parameter. The least-squares straightiline for the data of this study was 


$$
\frac{(\mathrm{dP} / \mathrm{d} \ell)_{\mathrm{tpt}}}{\because(\mathrm{dP} / \mathrm{d} \ell)_{\ell}}=37.02 \mathrm{x}_{\mathrm{tt}}^{-0.732} \quad \therefore
$$

The data were found to lie between those of Wright and of Schrock and Grossman.: Local frictional-pressure gradients were obtained by subtracting the momentum and hydrostatic head los ses from the measured total-pressure gradient. Thcoo oalculated values of the frictionalpressure gradient when plotted against $\mathrm{X}_{\mathrm{tt}}$ agreed closely with experimental values obtained for other systems. 


\section{ACKNOW LEDGMENTS}

Grateful acknowledgment is due Professor LeRoy. A. : Bromley for his encouragement and helpful suggestions throughout the course of this work.

The author also wishes to thank the Lawrence Radiation Laboratory of the University of California for financial assistance during the course of this investigation.

This work was performed under the auspices of the United States Atomic Energy Commission. 
NOMENCLATURE

Letter Symbols

$A_{B} \quad$ cross-sectional area of the boiling test section

$f t^{2}$

$\mathrm{A}_{\mathrm{h}}$ heat-transfer area of the boiling test section

$f t^{2}$

Bo boiling number $=\frac{q}{3600 \mathrm{G} h_{f g}}$

${ }^{\text {Bo }}{ }_{\mathrm{m}}$ modified boiling number $=\mathrm{Bo}_{0} \frac{\rho_{\mathrm{f}}}{\rho_{\mathrm{g}}}$

$C_{p} \quad$ specific heat at constant pressure

Btu/1bin $=^{\circ}$ F

D diameter

$\mathrm{ft}$

$f \quad$ Blasius friction factor

dimensionless

Fr Froude number

$g$ acceleration due to gravity, 32.153

dimensionless

$\mathrm{ft} / \mathrm{sec}^{2}$

$g_{c}$ mass-force conversion factor, 32.1739

G mass flux

$\mathrm{ft} \mathrm{lbm} / \mathrm{sec}^{2}-\mathrm{lbf}$

$\mathrm{lbm} / \mathrm{sec}-\mathrm{ft}^{2}$

h enthalpy, or

$\mathrm{Btu} / \mathrm{lbm}$

heat-transfer coefficient

Btu $/ \mathrm{h}-\mathrm{ft}{ }^{2}-{ }^{\circ} F$

$\mathrm{J} \quad$ Joule's constant, 778.26

ft $\mathrm{lbf} / \mathrm{Btu}$

$k$ thermal conductivity

$\ell \quad$ length from entrance of heated test section

$\mathrm{Btu} / \mathrm{h}-\mathrm{ft}-{ }^{\circ} \mathrm{F}$

total length of test section

$\mathrm{Nu} \quad$ Nussult number

$P \quad$ pressure

Pr Prandtl number

$F_{W}$ electric power expended in test section

q heat flux

Q total heat input

$\mathrm{ft}$

$\mathrm{ft}$

fit

dimensionless

psia

dimensionless watts

$\mathrm{Btu} / \mathrm{h}-\mathrm{ft}{ }^{2}$

Btu/h 
radius

ft

Re Reynolds number

St Stanton number $=h_{b} / 3600 \mathrm{C}_{\mathrm{p}} \mathrm{G}$

$T$ temperature

$\triangle \mathrm{T} \quad$ temperature difference

V velocity

W flow rate

$x$ quality, vapor mass fraction

$\mathrm{X}_{\text {tt }} \quad$ Martinelli parameter

$$
=\left(\frac{\rho_{g}}{\rho_{f}}\right)^{0.5}\left(\frac{\mu_{f}}{\mu_{g}}\right)^{0.1}\left(\frac{1-x}{x}\right)^{0.9}
$$

dimensionless

dimensionless

${ }^{\circ} \mathrm{F}$

${ }^{O} \mathrm{~F}$

$\mathrm{ft} / \mathrm{sec}$

$1 \mathrm{bm} / \mathrm{hr}$

dimensionless

dimensionless

$z_{1}$ elevation difference between station $i$

and test-section inlet

$\mathrm{ft}$

\section{Greek Letters}

$\gamma$

volumetric vapor fraction

dimensionless

linear temperature coefficient of

thermal conductivity

$\mathrm{O}_{\mathrm{F}^{-1}}$

$\mu \quad$ viscosity

$\rho^{\prime}$ density

$1 \mathrm{bm} / \mathrm{ft}-\mathrm{sec}$

$\mathrm{lbm} / \mathrm{ft}^{3}$

$\sigma \quad$ surface tension (vapor-liquid)

$\phi_{\ell} \quad$ Lockhart-Martinelli friction-factor

$\mathrm{lbf} / \mathrm{ft}$ multiplier

$\psi \quad$ slip ratio

$\omega$ power generation per unit volume

dimensionless

dimensionless

$\mathrm{Btu} / \mathrm{h}-\mathrm{ft}^{3}$

\footnotetext{
Subscripts

a acceleration

b boiling, or saturation

e equivalent

$f \quad$ properties of saturated.liquid

fg difference in property between saturated vapor and saturated liquid
} 
g properties of saturated vapor

h. hydrostatic head

i inner wall, or inside

$\ell \quad$ liquid property, or evaluation on basis of local

liquid flow rate

- outer wall, or evaluation of a property at some bașe

T. total

tp two-phase

tpf two-phase friction-pressure loss

tpt . two-phase total-pressure loss

1 refers to station 1 


\section{APPENDICES}

A. Solution for the Inside-Wall Temperature

Consider...a cylindrical tube of inner radius $r_{i}$ and outer radius $r_{0}$ in which heat is being generated at a uniform rate $\omega$ $\mathrm{Btu} / \mathrm{h}-\mathrm{ft} \mathrm{H}^{3}$ with the following assumptions:

1. steady-state conditions,

2. circular symmetry,

3. negligible longitudinal heat flow,

4. adiabatic outer wall,

5. uniform heat generation,

6. negligible inductance or capacitance effects,

7. linear dependence of thermal conductivity with temperature. The equation for radial heat conduction is

$$
\frac{1}{r_{i}} \frac{d}{d r} \cdot\left[r k(T) \frac{d T}{d r}\right]=-\omega_{\text {., }}
$$

with the following boundary conditions (assumption 4):

$$
\begin{aligned}
& \mathrm{r}=\mathrm{r}_{0} ; \cdot \mathrm{T}=\mathrm{T}_{0}=\text { constant, } \\
& \mathrm{r}=\mathrm{r}_{0}, \quad \frac{\mathrm{dT}}{\mathrm{dr}}=0 .
\end{aligned}
$$

We_can define a variable (T) such that

$$
\begin{gathered}
\xi(T)=\int_{0}^{T} k(T) d T, \\
\frac{d \xi}{d T}=k,
\end{gathered}
$$

and

$$
\frac{\mathrm{d} \xi}{\mathrm{dr}}=\frac{\mathrm{d} \xi}{\mathrm{dT}} \cdot \frac{\mathrm{dT}}{\mathrm{dr}}=\mathrm{k} \frac{\mathrm{dT}}{\mathrm{dr}}
$$

Substituting Eq. (A-6) into Eq. (A-1) and integrating gives

$$
\xi=-\frac{\omega r^{2}}{4}+C_{1} \ln r+C_{2} .
$$


From as sumption $7, \ldots$

thus

$$
\mathrm{k}=\mathrm{k}_{0}\left(\mathrm{i}+\gamma_{T} \mathrm{~T}\right)
$$

$$
\xi=k_{0}\left[T+\frac{\gamma T^{2}}{2}\right]
$$

Substituting Eq. (A-9) into Eq. ( $\mathrm{A}-7)$ and applying the boundary conditions gives

$$
\begin{gathered}
c_{1}=\frac{\omega \mathrm{r}_{0}^{2}}{2}, \\
\mathrm{C}_{2}=\mathrm{k}_{0}\left[\mathrm{~T}_{0}+\frac{\gamma \mathrm{T}_{0}^{2}}{2}\right]+\frac{\omega \mathrm{r}_{0}^{2}}{4}-\frac{\omega \mathrm{r}_{0}^{2}}{2} \ln \mathrm{r}_{0} .
\end{gathered}
$$

Substituting Eqs。( $A-9),(A-10)$, and $(A-11)$ into Eq. $(A-7)$ and rearranging, one has

$$
\mathrm{T}_{\mathrm{i}}=\mathrm{T}_{0}-\frac{\omega}{2}\left[\frac{\mathrm{r}_{0}^{2} \ln \frac{\mathrm{r}_{0}}{\mathrm{r}_{\mathrm{i}}}-\frac{1}{2}\left(\mathrm{r}_{0}^{2}-\mathrm{r}_{\mathrm{i}}^{2}\right)}{\mathrm{k}_{0}\left[\mathrm{r}_{1}+\frac{\gamma}{2}\left(\mathrm{~T}_{0}+\mathrm{T}_{\mathrm{i}}\right)\right]}\right]
$$

The assumptions used in the derivation of Eq. $(\mathrm{A}-\mathrm{I} 2)$ can be justified through an examination of the experimental data. It is be lieved that a steady-state condition was reached, because the tubewall temperatures fluctuated around a steady mean value. Although the condition of circular symmetry was not maintained, the heat generation along the test section was presumably uniforin. This is borne out from an examination of the power dissipation along the test sertinn. This quantity was always linear for a variety of heat fluxes (see Fig. 20). The longitudinal heat flux was calculated to be less than $1 \cdot 10^{-5} \%$ of the radial heat flux, while the heat losses were less than $1 \%$ of the total heat input. "Since the lowest measured power factor was 0.980 , it was assumed that induction and capacitance effects were negligible. Over the small temperature range of interest, less than $40^{\circ} \mathrm{F}$, the thermal conductivity of stainless steel was assumed to be a linear function of temperature, and could be expressed as

$$
\hat{k}=8.44\left[1+5.32\left(10^{-4}\right) \mathrm{T}\right]\left(\text { in Btul } / \mathrm{h}-\mathrm{ft}-{ }^{\circ} \mathrm{F}\right) \text {. }
$$




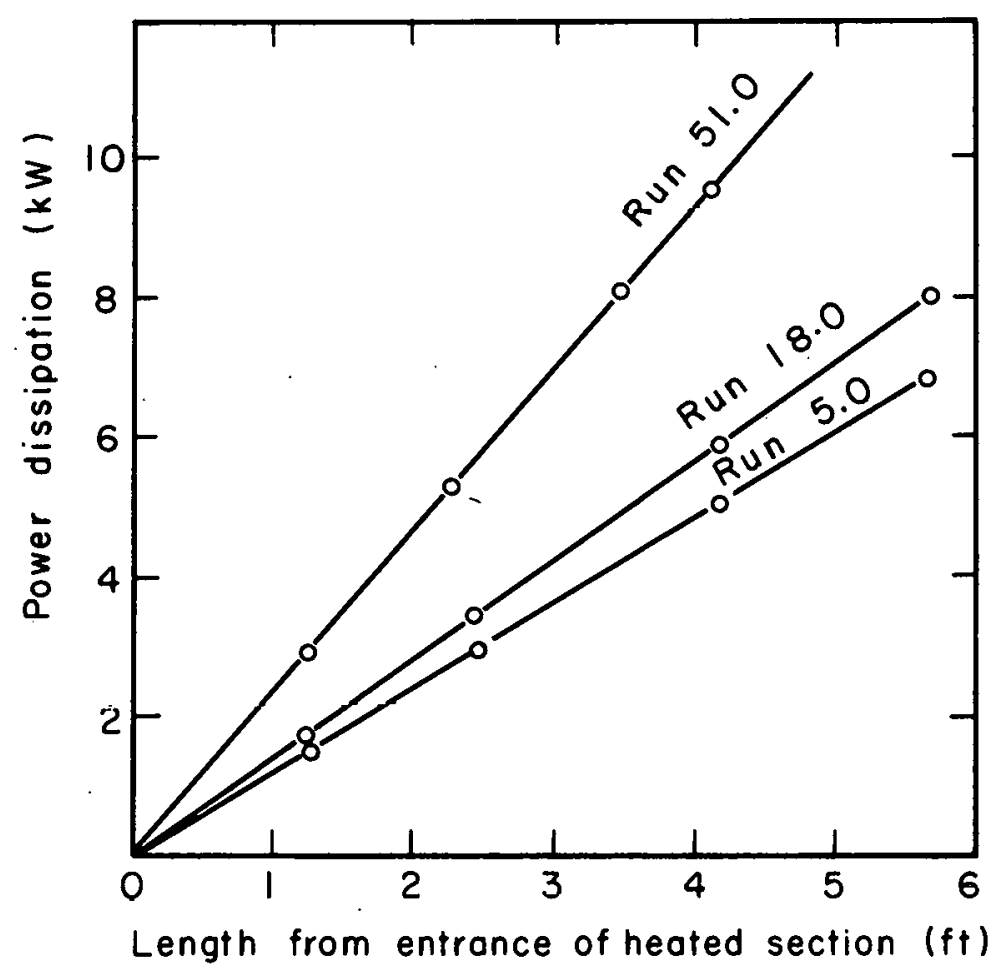

$M U .28771$

Fig. 20. Power dissipated along tube. 


\section{B. Forced-Convection Builing. Data}

The following table (Table V) lists the reduced experimental data for the boiling of $\mathrm{n}$-butanol. The units employed are those given in the Nomenclature. The symbols that may not be self-explanatory are:

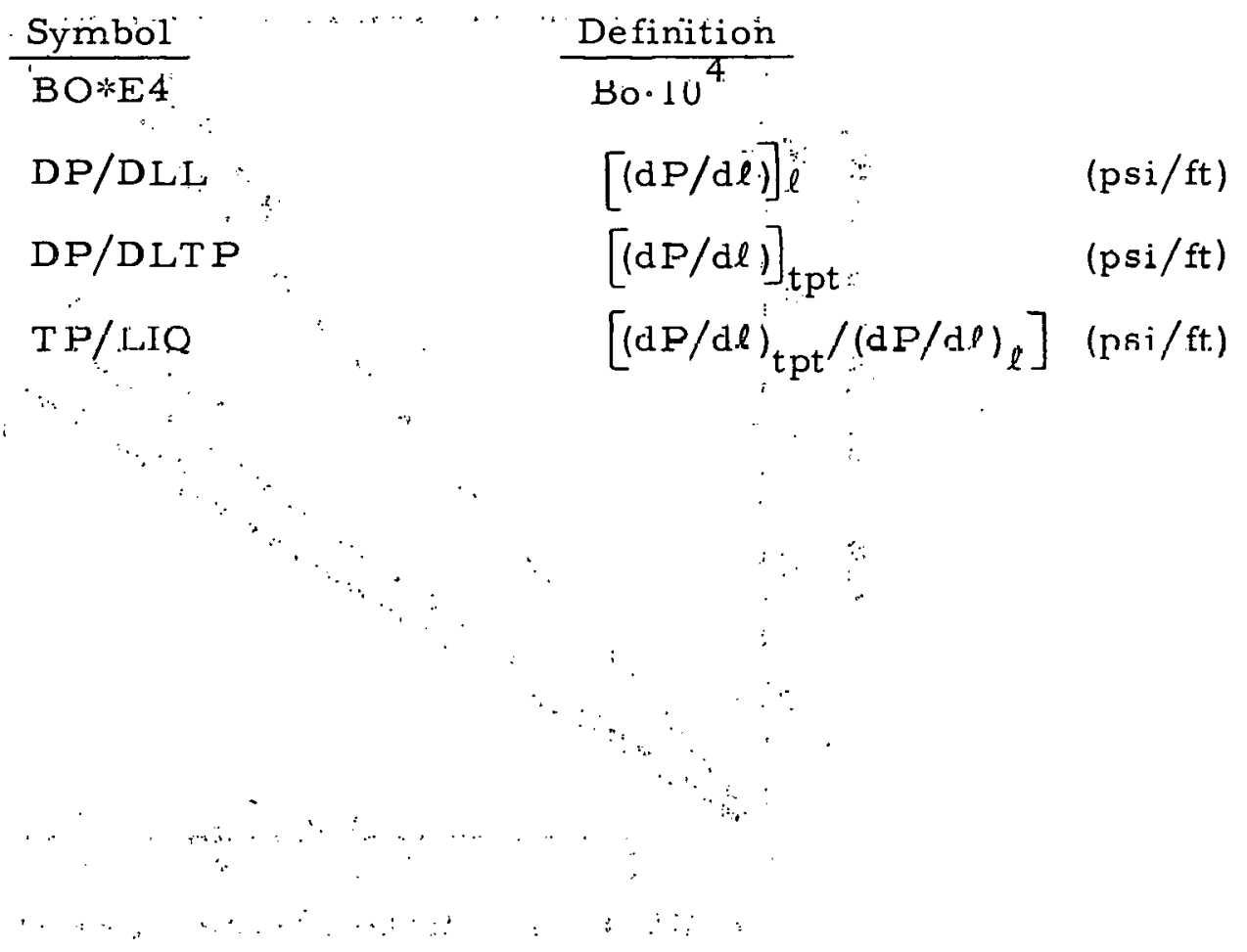


TABLE $V$ FORCED CONVECTION BOILING RUN NO. 2.0 N-BUTANOL TEST SECTION NO. 4 INSIDE DIAMETER,DI=0.038917 FT.

FLOW R.TE, $W=670$. LBSAHR MASS VELOCITY,C $=156.5$ LCS/SEC.SQFT POWER $=7.52$ KILOWATIS HEAT FLUX, $Q=36877$. BTU/AR.SQFT TEMPERATURE BEFORE FLASH $=277.4 \mathrm{~F}$ VELJCITY BEFORE FLASH $=1.1 \mathrm{FT} / \mathrm{SEC}$

\begin{tabular}{|c|c|c|c|c|c|c|c|c|c|c|c|c|c|c|c|c|c|}
\hline LEFT & PSIA & To & TI & $T B^{\circ}$ & DELT & HBOIL & HL 10 & $x$ & $X T T$ & NUB & RENOL & $B D \cdot E 4$ & STANTIN & PFNOL & $D P / D L L$ & $D P / D L T P$ & TP/LIO \\
\hline 0 & 24.6 .5 & 287.8 & 285.5 & 271.4 & $14 \cdot 10$ & 2616 & 340 & .0238 & .905 & 487 & 25854 & 1960 & .00520 & 16.79 & .0358 & .300 & 3.39 \\
\hline 0.50 & 2.4 .4 .1 & 288.7 & 286.4 & 270.9 & 15.55 & 2371 & 335. & 408 & 2 & 346. & 297 & .8924 & .00472 & $c .82$ & 0347 & 325 & .37 \\
\hline $1: 00$ & 24.16 & 288.1 & 285.9 & 270.3 & 15.58 & 2367 & 329. & .0578 & 253 & 1342. & 739. & .8886 & .00471 & $1 C .85$ & .0337 & 375 & 14 \\
\hline 1.50 & 23.89 & 286.4 & 284.1 & 269.1 & 14.45 & 2551 & 324 & .0750 & .971 & $\because 445$. & 24175 & .8845 & .00508 & 10.89 & .0326 & 440 & 9 \\
\hline .00 & 23.61 & 284.4 & $282: 1$ & 269.0 & 13.10 & 2815 & 319 & .0922 & 0.788 & 1593. & 23611 & .8802 & .00561 & 10.92 & .0316 & 520 & 46 \\
\hline 2.60 & 23.29 & 281.9 & 279.7 & 268.3 & 11.39 & $323 \%$ & 313 & .1096 & 0.659 & 1830 & 23030 & .8754 & .00645 & 10.96 & $: 0306$ & 0.650 & 21.27 \\
\hline $3 \pm 00$ & 22.90 & 2.79 .3 & 277.0 & 267.3 & 9.67 & 3812 & 308 & .1277 & 0.559 & c151. & 22402 & .8691 & .00760 & 11.01 & .0295 & 0.850 & 28.80 \\
\hline $9: 40$ & $22: 55$ & 277.0 & 274.7 & 266.5 & 8 & 48 & 30 & .1425 & 496 & 2525. & 21880 & .8633 & .00895 & 11.06 & .0287 & 50 & 40.11 \\
\hline 3.80 & 2. & 2 & 2 & 0 & & & & .1573 & 5 & 28 & & .8534 & .01 & 14 & & .575 & 77 \\
\hline .20 & 2 & & 2 & & 7 & & & .1739 & 376 & 2 & 9. & .8383 & .0 & 26 & .0267 & 75 & 72 \\
\hline 4.60 & 1 & 2 & 2 & 7 & 7 & 4 & 2 & .2003 & 24 & 2742 & 2. & .8199 & .00990 & 43 & .0256 & 10 & .01 \\
\hline B. 00 & 18.58 & 2 & 204.3 & 256.1 & 8.29 & 4447 . & 272 & .2235 & 0.278 & 246 & 19319. & .7977 & .00899 & 11.63 & .0244 & 3.230 & 132.28 \\
\hline 5.40 & 16.95 & 263.7 & 261.4 & 251.2 & 10.23 & 3606. & 261. & .2497 & 0.235 & 1786 & 17068 & .7680 & .0 & 11.88 & .0231 & 3.950 & 170.68 \\
\hline
\end{tabular}


TABLE $:$ (CONTOI. FORC:ED CONVECTION BOILING

RUN NO. 3.0 N-BUTANOL TEST SECTION NO. 4 INSIDE OIAMETER,DI=0.038917 FT.

FLOW RATE, $W=868$. LASIHR MASS VELOCITY, G $=202.7$ LBS/SEC.SOFT POWER = 9.98 KILJWATTS HEAT FLUX,Q= $43941.3 T U / H R . S Q F T$ TFMPERATURE BEFORE FLASH $=263.7 \mathrm{~F}$ VELOCITY BEFURE FLASH $=1.4 \mathrm{FT} / 5 E \mathrm{C}$

\begin{tabular}{|c|c|c|c|c|c|c|c|c|c|c|c|c|c|c|c|c|c|}
\hline EIFN & SIA & ro & TI & $T B$ & DELIT & HBOIL & HL IG & $x$ & XIT & NUB & RENOL & $B 0 \cdot E 4$ & STANTN & PRNOL & DP/DLL & DP/DLIP & TP/LIO \\
\hline o. & 26.32 & 298.7 & 295.7 & 275.1 & $20.59^{\circ}$ & 2377 & 30. & - & $0:$ & 359. & 5276. & .9920 & .00363 & 10.60 & .0534 & 0.475 & .13 \\
\hline .50 & 26.08 & 300.4 & $297: .4$ & $274.0^{\circ} t$ & 22.81 & 2145. & 429. & - & 0. & 25. & 35136. & .988 .3 & .00323 & 0.62 & .0585 & .475 & 12 \\
\hline .00 & 25.78 & 300.5 & 297.5 & 273.9 & 23.62 & 2072 & 429 & . & 0. & 82. & 34962 & .9838 & .01 & .66 & 285 & 625 & 38 \\
\hline 50 & 25.43 & 9.2 & 896.2 & 273.2 & 23.03 & - & 425. & .0087 & .405 & • & 4460 & .9785 & $.00325^{\circ}$ & 0.70 & & & \\
\hline 00 & 25.02 & 7.0 & 244.0 & 272.3 & 21.73 & 225 & 417. & .0275 & 1 & 282. & 3581. & .9724 & .00346 & 10.75 & $0 \leq 58$ & 35 & \\
\hline .50 & 24.56 & 294.6 & .291 .6 & 271.2 & 20.37 & 2403 & 410. & .0463 & .546 & 365. & 32655 & .9553 & .00369 & 10.80 & $.3 \leq 40$ & 990 & 8.16 \\
\hline .00 & 24.02 & 1.7 & 288.7 & 270.0 & 18.71 & 2615 & 402. & .0067 & .091 & 1482 & 1673. & .9569 & .00402 & 10.87 & $.0 \leq 21$ & .55 & 36 \\
\hline 0 & 2 & 9.0 & 2 & 268 & 1 & 2843. & 395 & 183 & 0.870 & 60 & 30831 & .9488 & .00437 & .94 & & 150 & 6.70 \\
\hline 80 & & . & 2 & 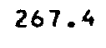 & & 3140. & 38 & .100 & 0.715 & 1712 & 24945. & 95 & .0 & 1 & 0 & 30 & \\
\hline & & & & & & & 3 & & & & & & & & & & \\
\hline 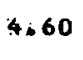 & & & & & & & & & & & & & 3 & & & 90 & \\
\hline $6: 00$ & & & 2 & 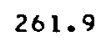 & 9.82 & 4982. & 26 & • & 6 & 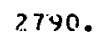 & . & - & .0 & & & 15 & 33 \\
\hline 6.30 & 19.11 & 270.5 & 207.5 & 257.5 & 9.93 & 4927 . & 351. & .1817 & 0.355 & 2739 & 25287 & $.375 C$ & .00768 & 11.55 & .2720 & 3.240 & 77.09 \\
\hline
\end{tabular}




\section{TABLE $V$ (CONTO) FGRCED CONVECTION BOILING}

RUN NO. 4.0 N-BUTANOL TEST SECTION NU. 4 INSIDE DIAMETER,DI=0.038917 FT.

FLOW RATE,H=1530. LBS/HR MASS VELOCITY,G $=357.3$ LBS/SEC.SQFT POWER $=9.81 \mathrm{~K}$ ILOWATTS HEAT FLUX,Q= 481O7. BTU/HR.SOFT TENPERATURE BEFORE FLASH $=287.0 \mathrm{~F}$ VELOCITY BEFORE FLASH $=2.6 \cdot \mathrm{FT} / \mathrm{SEC}$

\begin{tabular}{|c|c|c|c|c|c|c|c|c|c|c|c|c|c|c|c|c|c|}
\hline FT & SIA & TO & TI & $T B$ & $E L T$ & BOIL & 1610 & $x$ & $X T T$ & NUB & ENOL & O.E4 & STANTN & RNOL & $O P / D L L$ & $P / D L T P$ & $P / L$ \\
\hline 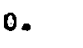 & 36.25 & 13.4 & $300: 5$ & 293.8 & 6.60 & 219. & 706 . & - & 0 & - & 85. & 10 & .00619 & 59 & 1544 & 100 & 0.5 \\
\hline 0 & .20 & 16.3 & 303.4 & 293.7 & .6 & 984. & 706 & - & 0. & . & 1541. & 6 & - & 60 & 44 & 100 & 0.6 \\
\hline 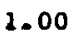 & 36.1 .5 & 08.6 & $305: 7$ & 293.7 & 1.9 & 4013 & 706. & - & 0. & 363. & 71496. & .7463 & .00344 & 9.60 & 1544 & .00 & 6 \\
\hline 50 & 36. & 9.9 & 307.0 & 293.6 & 13.4 & 4. & 706 . & • & 0 & - & 71452 & & .0 & 9.61 & & & 0.8 \\
\hline 00 & 36. & 10.6 & 30 & 293.5 & & . & 701 &.$c$ & & . & 70806 . & 55 & .0 & & 522 & & .3 \\
\hline 60 & 35.82 & 3.10 .4 & 307.5 & 293.1 & 14. & 3. & 695. & .0 & & & 69852. & .7439 & & .63 & & & . 1 \\
\hline .00 & 3.5 .37 & $30 y .3$ & 306.4 & 292.4 & 4.04 & 27 & 687 & .031 & 30 & 013. & 68612 & .7406 & 294 & 9.67 & & & 1.2 \\
\hline 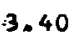 & 34.72 & 307.9 & 305.0 & 291.2 & $\cdot$ & $50 \mathrm{~s}$ & 618 & .0428 & .004 & 058. & 67212 & -7 & & 9.73 & 34 & & 15.5 \\
\hline 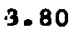 & -3 & 3 & & 2 & & & $t$ & & & & . & 35 & & & & & 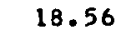 \\
\hline 20 & & & & & & & & & & & & & & & & & 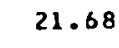 \\
\hline 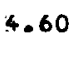 & & & & & & & & & & & & & & & & & . \\
\hline .00 & 3 & 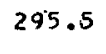 & 2 & 2 & & 4897 . & 6 & & & • & & 5 & • & & & & $2 \cdot 4$ \\
\hline .40 & 28.30 & 290.2 & $287: 2$ & 279.3 & .98 & 6032 . & 615. & .1241 & 0.638 & 4699 & $56198^{\circ}$ & .6855 & .00521 & 10.37 & .1244 & 5.375 & 43.2 \\
\hline
\end{tabular}


TABLE $Y$ (CONTD) FURCED CONVECTION BOILING
RUN NO. 5.0 N-BUTANOL
TEST SECTION NO. 4
INSIDE DIAMETER, DI $=0.038917 \mathrm{FT}$.

FLOW RATE,W $=1490$ : L3S/HR MASS VELOCITY,G: 343.C. LBS/SEC.SQFT POHER = 6.82 KILOWATTS HEAT FLUX,Q= 33469. 8TJ/HR. SQFT TENPERATURE BEFORE FLASH: $289.4 \mathrm{~F}$ VELOCITY BEFORE FLASH $=2.5$ FTISEC

\begin{tabular}{|c|c|c|c|c|c|c|c|c|c|c|c|c|c|c|c|c|c|}
\hline $2 . F .1$ & PSIA & TO & $T \cdot I$ & $T B$ & DELT & BOIL & L L 10 & $x$ & $T T$ & NUB & RENOL & $B O \cdot E_{4}$ & STANTN & RNOL & $D P / D L L$ & DP/OLTP & $T P / L I O$ \\
\hline 0. & 37.69 & 303.0 & $301 . c$ & 296.2 & 4.77 & 010. & 695. & . & 0 & $\$ 7$ & 9977 & .2555 & .00617 & .47 & 1470 & . & . \\
\hline .50 & 3.7 .38 & 303.9 & 301.8 & 295.7 & 6.13 & 460. & 694. & 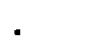 & 0 & 227 & 0708 & .2539 & .00481 & .49 & 1471 & - & - \\
\hline .00 & .37 .00 & 304.5 & 307.5 & 295.1 & 7.41 & 514. & 693. & - & 0 . & 605. & 70370 & $.2519^{\prime}$ &. $\mathrm{CO39B}$ & 9.53 & 1472 & . & - \\
\hline 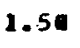 & -36.58 & 304.9 & $30=.8$ & 294.4 & $8.40^{\circ}$ & 954. & 692. & - & 0 & 2331 & 70001 & .2498 & .60348 & 9.56 & .1473 & 0.950 & .45 \\
\hline .06 & 38.08 & $305.0^{\circ}$ & 302.9 & 293.5 & 9.4 & 561. & 587. & .0079 & 9.633 & 2097 & 69015 & .2472 & .00314 & 9.61 & .1654 & 420 & .17 \\
\hline 50 & 35.41 & 304.8 & $302: 7$ & 292.4 & 10.31 & 245. & 679. & .0190 & .297 & 1906. & 67682 & .2437 & .00286 & 9.67 & $.1<27$ & 00 & 2.61 \\
\hline 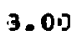 & 34.63 & 304.2 & 302 & 291.1 & l & 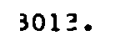 & - & .0309 & .708 & 1756. & & & .00265 & 4 & .1599 & & 08 \\
\hline 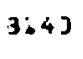 & 3 & 30.3 .9 & 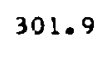 & 9.7 & 12.1 & 744. & • & .041 & & 160 & 3. & .2351 & .00242 & & .1574 & & 6.60 \\
\hline 83 & 31.90 & 301.6 & 29.7 .6 & 288.1 & L & 900. & 654. & .0534 & 79 & 1692. & 02. & .2275 & .00256 & 1 & .1347 & 70 & 18.34 \\
\hline .23 & 31.80 & 298.8 & $296: 8$ & 286.0 & 10.77 & $10 \%$ & 643. & $.06 t 5$ & 1.257 & 1807 & 01374 . & $.223 \varepsilon$ & .00275 & 10.01 & .1317 & 80 & 20.34 \\
\hline 4.63 & 30.69 & 295.5 & 293.4 & 284.0 & 7.48 & 531. & 633. & .0755 & 1.037 & 2048 & 59594. & . $217 \pi$ & .00313 & 10.12 & .1288 & 2.980 & 23.13 \\
\hline.$\infty$ & 29 & 2 & & & & $406:$ & & & 59 & 2344 & & .2105 & & 25 & .1256 & 3.430 & - 30 \\
\hline 40 & .8 & $T .1$ & 5.0 & 8.2 & 7 & $2 ?$. & . & .1110 & .708 & 829 & 5118. & 2011 & .004 .38 & 10.43 & $.1 \geq 20$ & 4.250 & 34.84 \\
\hline
\end{tabular}




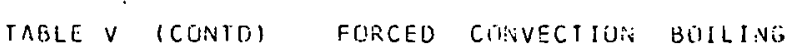

RUN NO. 11.1 V-BUTANTLL TEST SECTIGV JU. 4 INSIDE DIAMETER,DI=0.038917 FT.

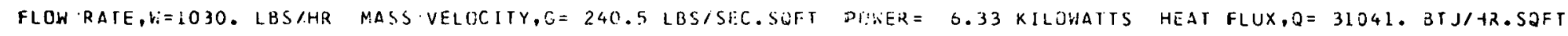
TENPERATURF EEFORE FLASH:= 235. $2 \mathrm{~F}$ VELUCITY LIFFORE FLASH= 1.7 FI/SES

\begin{tabular}{|c|c|c|c|c|c|c|c|c|c|c|c|c|c|c|c|c|c|}
\hline$L, F T$ & PSIA & TO & $\mathrm{rl}$ & IB & DELT & $110 \mathrm{Jl} \mathrm{L}$ & $h L I G$ & $x$ & $x I t$ & Nue & RENDL & $80 * 5: 4$ & STANTN & PE.NOL & $D P / D L L$ & JP/OL RP & TP/LIQ \\
\hline 0. & 34.31 & 300.2 & 298.3 & 290.5 & 7.79 & 3987 & 511. & . & 0. & 2335 & 47013 & .6500 & .00508 & 0.77 & . & 0.840 & 10.84 \\
\hline .50 & 34.31 & $3 \cup 0.2$ & 298.3 & $29 \mathrm{C.}=$ & 7.79 & 3387 & 511. & - & 0 & 2.335 & 47013 & .0506 & .00508 & 5.77 & .0775 & 0.995 & 12.71 \\
\hline 1.00 & 33.37 & 249.4 & $24 \% .5$ & 2390 & e. 66 & 3583. & 507 & .0000 & 11.651 & Pusi. & $4515 \%$ & .6530 & .00457 & 9.85 & .0758 & 1.140 & 14.34 \\
\hline 1.50 & 32.73 & 148.3 & 200.4 & 237.7 & 8.65 & $3 \ddot{3} 8 \%$ & 500. & .0142 & 4.042 & 2043. & 45160 & .6488 & .00453 & 9.92 & .0751 & 1.275 & 17.24 \\
\hline 2.00 & 31.94 & $246 . t$ & 242.7 & $28 C .3$ & 8.41 & 3630. & 492 & .0336 & 2.4192 & $7 i 48$. & 44006 & .6430 & .00472 & 10.00 & .0733 & 1.455 & 19.84 \\
\hline $2: 50$ & 31.06 & 274.8 & 2.42 .9 & 284.6 & 8.24 & 3767. & 484 & $.04 i t$ & 1.675 & 2107 & 42798 & .6365 & .00482 & 10.07 & .0715 & 1.635 & 22.37 \\
\hline 3.00 & 30.15 & 292.8 & 290.9 & 282.9 & 7.98 & $33+1$. & $47 t$ & .0638 & $i .272$ & 2252. & 41.562 & .62 .97 & .00493 & 10.13 & .0696 & 1.830 & 26.29 \\
\hline 3.40 & 24.33 & $2 \div 1,1$ & $23 \cdot 3.2$ & 281.3 & 7.88 & 3941. & 404 & $.07 i, 7$ & 1.049 & $2 ! 74$. & 40497 & .6235 & .0 .0505 & 10.25 & .3691 & 2.035 & 29.46 \\
\hline 3.80 & 28.45 & $2 x y .1$ & 237.4 & $\angle 79.0$ & $7 .: 12$ & $3 \rightarrow 71)$. & 40.2 & .0701 & 0.383 & 2294 & 39394 & .6167 & .00510 & 10.35 & .0665 & 2.220 & .39 \\
\hline 4.20 & 2 & 23 & 23 & 277.7 & 7.40 & 4194. & 455 & .1038 & $0.754_{4}$ & $2406=$ & 38244 & .6092 & .00539 & 10.46 & .0649 & 2.435 & 38.30 \\
\hline 4.60 & 26.46 & $284 . \therefore$ & 282.5 & 3.75 .4 & 7.07 & 4.391. & $14 i$ & .1138 & $0.2 \div 5$ & 2,11 . & 36974 & .6004 & .00566 & 10.58 & .0632 & 2.840 & 44.97 \\
\hline 5.00 & 25.23 & $23: .1$ & 213.2 & 272.7 & 0.50 & $477 ?$. & 435. & .1300 & 0.552 & 2.18 & 35362 . & .5904 & .00617 & 10.72 & .0613 & 3.355 & 54.87 \\
\hline 5.40 & 2.3 .74 & 276.7 & 275.0 & 269.3 & 5.70 & 5442. & 426 & .1535 & $0.4 i 5 y$ & $36,81$. & $33 \% 20$ & .5782 & .00705 & 10.91 & .0573 & 4.220 & 71.18 \\
\hline
\end{tabular}


TABLE $\vee$ (CONTD) FORCED CONVECTION BOILING

RUN NO. 12.0 N-BUTANOL TEST SECTION NO. 4 INSIDE DIAMETER.DI=0.038917 FT.

FLOW RATE,W=105.5. LHS/HR MASS VELOCITY,G $=246.4$ LBS/SEC.SQFT POWER $=9.50$ KILOWA:TS HEAT FLUX,O= 46587. BTU/HR. SOFT TENPERATURE BEFORE FLASH $=292.5 \mathrm{~F}$ VELOCITY REFORE FLASH $=1.8$ FIISEC

\begin{tabular}{|c|c|c|c|c|c|c|c|c|c|c|c|c|c|c|c|c|c|}
\hline$=$ :F.T & S.IA & TO & TI & $T B$ & ELT & BOLE & L 10 & $x$ & T T & UB. & RENOL & $B O * E_{4}$ & STANTN & RNOL & $D P / D L L$ & $D P / D L T P$ & $P / 110$ \\
\hline . & 39.69 & 16.0 & 319.2 & 9.4 & 1 & 82. & 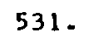 & - & 0 . & 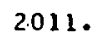 & 1. & 8 & 0420 & 30 & 0801 & 125 & 05 \\
\hline 0 & 39.12 & 5.6 & 31.2 .8 & 8.5 & 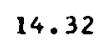 & . & 30. & - & 0 . & 31 & 119. & 29 & 4 & 35 & 802 & 55 & 55 \\
\hline 0 & 38.45 & 14.4. & .311 .6 & 297.4 & 14.1 & 96. & 27. & .0044 & 17.000 & 1954. & 0487 & $.4760^{\circ}$ & .00410 & 9.41 & .0796 & 400 & .58 \\
\hline 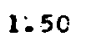 & 37.668 & 2.5 & 309.7 & 296.2 & that & 464. & 18. & .0223 & 45 & 2050 & 9131. & .4681 & .00431 & .47 & .0773 & & 20.26 \\
\hline 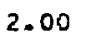 & 36. & 0.1 & 307. & 294.8 & 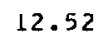 & 723 & 08. & .0408 & 2. & 2196. & & .4593 & & 54 & .0748 & & 39 \\
\hline 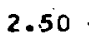 & 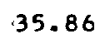 & 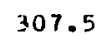 & 3 & 293.2 & 1 & . & - & .0600 & & 391 & & .4495 & & & & & \\
\hline . & . & . & i & 3 & 1 & $46 E$. & $\bullet$ & .0 & & & & & & & & & \\
\hline 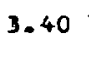 & $:$ & . & 2 & 6 & 9 & & . & .0968 & & & 43190 & .42 & : & & & & \\
\hline 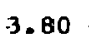 & 32.69 & 249.5 & 290.6 & 287.7 & c & 174 & . & .1 .142 & 48 & 3029 . & 2. & $.415 c$ & & 3 & & & \\
\hline 20 & 31.54 & 296.7 & 293.8 & 285.5 & 8.2 & 2016. & $46 \mathrm{C}$ & .1321 & 632 & 3265 & 40253 & .4030 & .30 & 04 & & & \\
\hline 60 & $30 . .21$ & 3.8 & 2 & $\cdot 0$ & 7.90 & 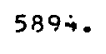 & $44 c$ & $.15 \div 3$ & & 3412 & 38629 & .3888 & .00737 & 7 & .06 & .45 .5 & .56 .50 \\
\hline & & & & & & & - & & & & & .3719 & & & .0588 & & \\
\hline$: 40$ & 0.93 & 0 & 284.4 & c. & 1.90 & 3 & 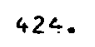 & 939 & 386 & $3=30$ & 916. & .350 .3 & 0.913 & 0.52. & .0563 & 5.130 & 91.15 \\
\hline
\end{tabular}


THBLE V (CTINTE) FORCED CUMVECTION BOILING

FIIN NO. 13.0 N-BUTANUL TEST STCTION HU. \& IMSIDE DIAMETER,DIFÖ.038917 Fr.

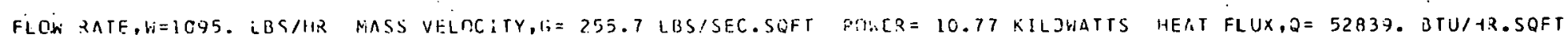
TENPERATURE BEFURE FLASH:'233.1 F VELOCITY BEFURE FLASH= $1.8 \mathrm{FT} / \mathrm{FE}=$

\begin{tabular}{|c|c|c|c|c|c|c|c|c|c|c|c|c|c|c|c|c|c|}
\hline L.FT & PSIA & . TO & 11 & $T B$ & OELT & HOCIL & $\mathrm{HLIO}$ & $x$ & XIT & $: 003$ & RENOL & $B O \cdot E 4$ & STA!ITN & PRVOL & $J P / D L L$ & $D P / D L T P$ & $P / L I Q$ \\
\hline $0:$ & 34.94. & 319.4. & 316.7 & 258.2 & 12.48 & 2850 & 545 & - & i. & 1690. & 52942 & .7113 & .00342 & 9.36 & .0856 & 0.590 & 6.39 \\
\hline 0.50 & 38.46. & 319.7 & 3.16 .5 & 297.4. & 19.04 & 2775 & 544. & - & 0. & lくぐ. & ${ }^{\circ} 52039$. & .7058 & .00332 & 9.40 & .0857 & .022 & 11.73 \\
\hline 1.00 & 37.87 & 319.1 & 315.9 & $2 \hookrightarrow t .5$ & 19.37 & 2727 & 5,43 & - & 0. & $\ln 14$ & 52272 & .6992 & .00327 & 9.45 & .0857 & .330 & 15.51 \\
\hline 1.50 & 37.14 & 318.8 & 315.6 & 295.3 & 20.26 & 2600 & 542 & - & 0. & 1540 & 51006 . & .6911 & .00312 & $9: 52$ & $.0858^{\circ}$ & $1: 575$ & 8 \\
\hline .00 & 36.30 & 315.9 & 312.7 & 293.5 & 18.76 & 2817 & 536. & .0094 & 8.240 & 1659 & 50780 & .6817 & .00338 & 9.59 & .0845 & 51 & 1 \\
\hline .50 & 35.36 & 313.1 & $3 u+4.9$ & 292.3 & & - & - &. & & - & 49 & & - & .67 & 17 & 1.835 & 23.08 \\
\hline .00 & 34. & 307.8 & 305.6 & 290.6 & 15.0 & 29?. & 515. & .0506 & 1.700 & $1+32$ & 41476 & .6593 & .00396 & 9.77 & .0738 & 2.040 & 25.70 \\
\hline 40 & 33.53 & 307.0 & 303.9 & 289.2 & 14.6 & $01:$ & 506. & .0673 & 1.278 & 2115. & 46142 & .6495 & .00434 & 9.85 & .0755 & 2.215 & 28.96 \\
\hline 3.80 & 32.61 & 303.8 & 3011.6 & 237.5 & 13.04 & 052. & 497 & .0846 & .008 & $2363:$ & 14733 & .6386 & .00487 & 9.94 & .3741 & 2.455 & 33.12 \\
\hline 4.20 & 31.55 & $3 i 0.5$ & 297.3 & 285.6 & 11.70 & 4517. & 486 & .1010 & 0.815 & 202.6. & 1,3189 & .6261 & .00543 & 10.04 & .0717 & 30 & 39 \\
\hline 4.60 & 32 & $2:$ & 29 & 2 & 1 & 981. & 475 & .1225 & .009 & $\cos 3$ & 41520 & .6115 & .00600 & 10.16 & .0692 & 3 & 40 \\
\hline 5.00 & & & & & & & 463 & $\cdot$ & .552 & 5. & 39630. & .5435 & .00634 & 10.31 & .0055 & 4.055 & 61.17 \\
\hline 40 & .9 & 2 & 86.5 & $27 \leq .5$ & 30 & 31 & 449. & .1680 & .453 & 2939. & 37427 & .5574 & .00621 & 10.52 & .3635 & 5.470 & 86.16 \\
\hline
\end{tabular}


TABLE V ICOATDI FGRCE COEVECTION BOILINO
(U)! No. 14.0
VI-BUTANCL
TEST SECTIOA Nï. 4
I.VSIDE DIAMETER, DI $=0.038917 \mathrm{FT}$.

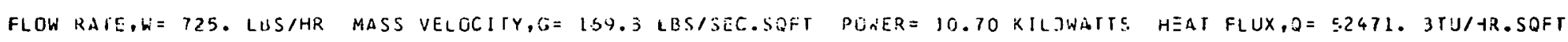
TENPERATURE BEFORE TLASH= 2HC.5F VELOCITY BEFORE FLASH= 1.2 FT/SEC

\begin{tabular}{|c|c|c|c|c|c|c|c|c|c|c|c|c|c|c|c|c|c|}
\hline FT & PSIA & TO & TI & IB & ELT & BÜLL & L1. & $x$ & It & NUE & REIVEL & $30 * \Xi 4$ & S-ANTV & RNUL & $D P / D L L$ & $D P / D L T P$ & $P / L I Q$ \\
\hline 0 . & 3.3 .15 & 304.1 & 300.9 & $28 E .5$ & 12.317 & 235. & 334 & - & 0. & 73. & 2592. & 7571 & .00768 & .88 & .3920 & 1.315 & 31.30 \\
\hline 50 & 32.45 & 303.7 & 300.5 & 287.2 & 13.31 & 945. & 3.33. & - & - & 295 & $3 ? 282$ & $.954 \epsilon$ & .50715 & 9.45 & $.0 \cdot+21$ & .355 & 32.45 \\
\hline 00 & 3.1 .78 & 302.3 & 29.1 & $28 t \cdot c$ & 13.13 & 39: & 376. & .0170 & 4.282 & 2325 & 31407 & .9425 & .00726 & 10.02 & $.0 \div 38$ & .425 & 34.92 \\
\hline .50 & 31.03 & $3 i 3.6$ & 277.4 & 284.6 & 12.78 & 105 & 367. & .0434 & 1.345 & 2.383. & 30265 & .9290 & .20746 & 10.09 & $.03 \div 0$ & 510 & 38.71 \\
\hline .00 & 30.26 & 298.7 & 295.5 & 283.1 & 12.40 & $423:$ & $35 \varepsilon$ & $.069 i$ & $1.17 \mathrm{C}$ & 2456. & 29113. & $.915^{\circ}$ & .707 a 0 & 10.17 & .0372 & 10 & 43.24 \\
\hline .50 & 27.46 & 296.5 & 293.3 & 281.5 & 11.70 & 463. & $34 \subseteq$. & .0952 & .345 & 2576 & 27.559. & .4512 & .90813 & 10.25 & .0355 & 745 & 49.17 \\
\hline .00 & 28.50 & $29 \% .1$ & 790.9 & 279.7 & 11.25 & $46 \leq 5$. & 335. & .1234 & 0.640 & 2034 & 25748 . & .8930 & $.003 \leq 1$ & 10.35 & .0337 & 925 & 57.09 \\
\hline 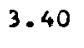 & 27.66 & $29 \%$ & $28 ?$. & 277.7 & $10.7 ?$ & 4807. & 33 & $.145 ?$ & 0.535 & 275 & 25726 & .856 .7 & $.008: 8$ & 10.44 & .0323 & 2.150 & 36 \\
\hline 3.80 & 26. & $2 B y$ & 285 & $27 \%$ & 10. & 43 & 32 & $-1 \in B ?$ & 0 & $28 \div 2$ & 2466 & .8480 & .02903 & 53 & 39 & 55 & 77 \\
\hline 20 & 2 & 2 & 284.1 & 27 & & 5043. & 313 & 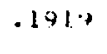 & & 287 & 23 & $.8<77$ & .004 & 67 & 4 & 20 & \\
\hline .60 & .44 & 284.5 & $\therefore 4.3$ & 270.9 & 1 & -6 & . & .2154 & 0.325 & 2875 . & 22363. & .8037 & .00931 & 10.82 & .3279 & 3.185 & 14 \\
\hline .00 & 3.07 & 281.4 & $>75.2$ & 267.8 & 10.31 & 5047. & 2.3. & .2427 & 0.277 & 2351. & 21111 & .7764 & .00430 & 10.99 & .0254 & .635 & 137.48 \\
\hline 5.40 & 21.58 & 277.3 & 274.0 & 264.1 & 9.94 & 5278. & $i n 2$ & .2630 & 0.237 & 2904. & 17812 & $.744 j$ & . JU987 & 11.18 & .2249 & 4.120 & 165.24 \\
\hline
\end{tabular}




\section{TABLE $\checkmark$ (CONTD) FOKCED CONVECTION BOILING}
RUN NO. 15.0
i. BUTANOL
TEST SECTION NO. 4
INSIDE DIAMETER,DI=0.038917 FT.

FLOW RATE,W= 7.50. LUS/HR MASS VELOCITY,G = 175.1 LBS/SEC.SQFT POWER=7.79 KILJWATTS HEAT FLUX,Q= 38201. BTU/4R.SQFT TENPERATURE BEFORE FLASH $=285.8 \mathrm{~F}$ VELOCITY BEFORE FLASH $=1.3 \mathrm{FT} / \mathrm{SEC}$

\begin{tabular}{|c|c|c|c|c|c|c|c|c|c|c|c|c|c|c|c|c|c|}
\hline$\therefore F T$ & $51 \mathrm{~A}$ & ס ד & TI & $T B$ & DELT & HBOIL & HLIV) & $x$ & KT & vus & IENUL & $B O: E 4$ & STANTN & RNOL & $D P / D L L$ & DP/DLTP & {$[P / L$} \\
\hline a. & 31.92 & 298.5 & 296.1 & 286.2 & 9.89 & 3863. & 393. & - & 0 . & 248 & 33148 & .7765 & .00678 & o & 7 & 5 & 20.25 \\
\hline 50 & 31.45 & 298.7 & 296.4 & 285.4 & 11. & 46.3 . & 87. & 0 & & 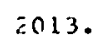 & 4. & & & & 5 & 00 & 30 \\
\hline .00 & 0.93 & 298.5 & 290.2 & 34.4 & .78 & • & - & & & 841. & & .7543 & 0 & & 1 & 35 & \\
\hline 50 & .34 & 297.7 & 295.4 & 283.3 & 12 & 152. & 7 & .0528 & 8 & 82 & 706 & .7568 & .00554 & 0.16 & .0428 & 75 & .27 \\
\hline 00 & .70 & 296.2 & 29.3 .6 & 282.0 & 11.79 & 241 . & 66. & .0719 & 25 & 873 & 9805 & .7486 & .00570 & 10.22 & .0374 & 30 & 29 \\
\hline 50 & .88 & 294.3 & $272 . C$ & $8 C .4$ & 11.54 & 311. & 359. & .0921 & .870 & 1908. & 28807 & .7382 & .00583 & 10.31 & .03 & & 53 \\
\hline .00 & .00 & 292.1 & $28 \% .8$ & 278.6 & 11.1 & 423. & 35 & .1129 & 0.698 & 1906 & 277 & .7261 & .00 & 10 & & & \\
\hline .40 & 5 & 290.2 & 2 & 77.1 & $\mathrm{t}$ & 549 . & 344. & . & & & & & & & & & \\
\hline 80 & 37 & 288 & & 2 & & & & & & & & & & & & & \\
\hline 20 & & 2 & & & & & & & & & & & & & & & \\
\hline 60 & ra & & & & $\because$ & & & & & & . & . & & & & & \\
\hline 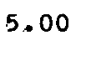 & 07 & 2 & & & 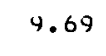 & & 312. & . & & $2 \geq 27$. & . & 577 & .0 & & & 0 & 11 \\
\hline .40 & 21.65 & 276.1 & 273.7 & 264.3 & 7.44 & 4048 & 303. & .2268 & .289 & $2 \geq 74$. & 21667 & .6360 & .00724 & $11.18^{\circ}$ & $\therefore 2271$ & 4.045 & 139.05 \\
\hline
\end{tabular}


TASLE V FORC EO CONVECTION BOILING

RUN NO. 16.0 N-BUTANOL TEST SECTION NO. 4 INSIDE DIAMETER,DI=0.038917 FT.

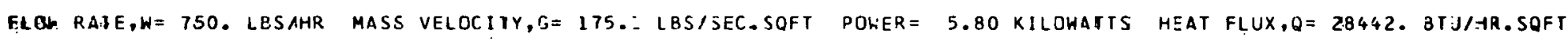
TEMPERATURE BEFORE FLASH $=285.1 \mathrm{~F}$ VELOCITY BEFORE FLASH $=1.3 \mathrm{FT} / \mathrm{SEC}$

\begin{tabular}{|c|c|c|c|c|c|c|c|c|c|c|c|c|c|c|c|c|c|}
\hline$f \pi$ & SIIA & TO & I T: & TB & ELT & BOIL & IL 10 & $x$ & $T$ & NUB & ENOL & $O \cdot E_{4}$ & SIANTN & PRNOL & $D P / C L L$ & $D P / D L T P$ & $P / L I O$ \\
\hline & 30.39 & 34.8 & 93.1 & 283.4 & .69 & 935. & 88. & 071 & 2 & . & 213. & 530 & .50516 & 0.15 & $.0<43$ & 145 & 25.86 \\
\hline & 29.80 & 3.7 & 92.0 & 282.2 & .77 & $91 \mathrm{C}$. & 182. & 0223 & .390 & 682 . & 1444 & .0474 & .00512 & 0.21 & .0431 & 1.66 & .88 \\
\hline$v$ & 29. & 292.5 & 290.7 & 281.1 & te & $94 C$. & 376. & .03 & 76 & 696. & 91. & .0418 & & 27 & .0420 & & 9 \\
\hline & 2 & 1.0 & 3 & 2 & 9.46 & $00 \epsilon$ & 71 & .052 & 484 & 730 & 22. & & .00530 & 34 & & & \\
\hline & & 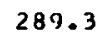 & 6 & 2 & 1 & & 364. & .0684 & & 744. & 7. & & & & & & \\
\hline & 2 & 7.5 & $5: 7$ & 277.1 & $8.6 t$ & & 58. & .08 & & . & 1. & & & & & & \\
\hline & 26 & 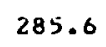 & $33: 4$ & 275. & 2 & & 52. & .10 & & 967. & 2. & $.014 c$ & & & & & \\
\hline o & 2 & 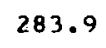 & 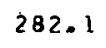 & 274 & .00 & & $34 t$ & • & 0.664 & G 1 & 794. & 76 & & & & & \\
\hline b & 2 & 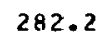 & 10 & 272 & (1) & . & $34 \bar{C}$ & .1 & 381 & • & 26042 & .0000 & .0 & & & & 8 \\
\hline & & & & & & & 334 & & & & & $.9900^{\circ}$ & & & & & \\
\hline & & & & & & & & & & & - & & & & & & \\
\hline 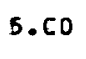 & & & & & & & 318 & & & & & & & & & & \\
\hline $0 .-40$ & 20.0 & $0 .<$ & 268.5 & 200.3 & 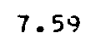 & 148. & 309. & 0194 & 0.321 & . & 200 & 4882 & 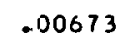 & & 2 & 4.020 & \\
\hline
\end{tabular}




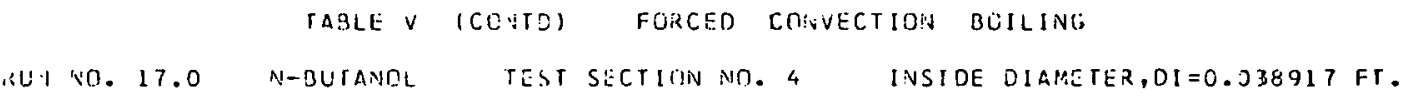

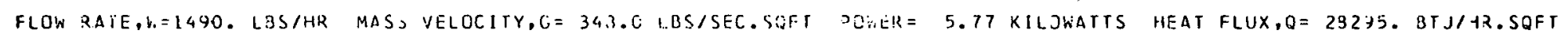
TENPERATURE BEFORE TLASH= $286.0 \mathrm{~F}$ VELIJCITY BEFORE FLASH= $2.5 \mathrm{FT} / \mathrm{SEC}$

\begin{tabular}{|c|c|c|c|c|c|c|c|c|c|c|c|c|c|c|c|c|c|}
\hline$L, F T$ & PSIA & $T C$ & $\cdot 11$ & I B & DELT & HLOIL & HLIO) & $x$ & $x \mathrm{rr}$ & iN1):3 & RENCL & $80: E 4$ & STANTN & PANOL & $D P / D L L$ & DP/DLTP & TP/LIQ \\
\hline 0. & $3 \% .72$ & 309.3 & $307 . t$ & 296.3 & 11.35 & 2493 & 695. & - & 0. & 475. & 71002 & .0510 & .00219 & 9.47 & .1470 & 0.235 & 1.39 \\
\hline 50 & 31.54 & 311.7 & 310.0 & $2 * t .0$ & 13.97 & 2026 . & 694. & - & i. & 1 s. & 10851 & .0508 & .00178 & 9.48 & .1471 & . 430 & 2.72 \\
\hline .00 & 37.27 & 310.3 & 305.9 & 295.6 & 13.43 & $? 049$. & 694. & . & 0. & 240. & 70627 & .0597 & .00185 & 9.50 & .1471 & .635 & 4.11 \\
\hline .50 & 36.95 & 309.0 & 307.2 & .245 .0 & 12.23 & 2314. & 693. & - & 0. & 366. & 70326 & .0582 & .00204 & 9.33 & .1472 & .815 & 5.54 \\
\hline .00 & 36.48 & 207.1 & 305.3 & 294.2 & 11. & 547. & 692. & - & a. &. & 14. & .0561 & .00224 & 9.57 & .1473 & 75 & 7. \\
\hline .50 & .35 .82 & 305.1 & 303.3 & 2.73 .1 & 10.23 & 766. & 690. & . & . & 627. & 69343. & .0532 & .00244 & 9.63 & .1475 & 1.330 & 9.02 \\
\hline .00 & 3.5 .04 & 303.7 & 302.2 & 291.8 & 10.35 & 2735 & 68.4. & .0000 & 4.42 .1 & $1<.5 .5$ & 69.123. & $.04 \forall 8$ & .00241 & 9.70 & .1456 & 20 & 12 \\
\hline-40 & 34.35 & 301.4 & 300.2 & 290.5 & 9.6 & 2942. & $67 \%$ & .0173 & 4.601 & $17: 4$. & 06366 & .0405 & .00259 & 9.77 & .1434 & 0 & 2.97 \\
\hline .80 & 33.49 & 298.6 & 295.4 & 283.1 & 7.77 & 3641 . & (si). & .0278 & 2.435 & 2128 & 65408. & .0425 & .00321 & 9.85 & .1410 & 130 & \\
\hline .20 & 32.48 & $2 \div 5.8$ & $2+4$ & 287.3 & 6 & 4161 . & 6600 & .0 & 2.056 & $24 \lambda$ & 63 & 78 & - & 9.75 & 33 & 50 & 19 \\
\hline .60 & 31.38 & $2+3.0$ & $2 \neq 1.3$ & $285 . ?$ & 6. & 634. & $\csc$ & .0518 & 3 & $2 \pi i$ & 01972 & .0327 & . & 10.05 & .1 & 350 & 11 \\
\hline .00 & 30.11 & 290 & $238 . ?$ & $282 .:$ & 5.46 & 17 & 6.39 & $.065 c$ & 1.239 & $2: 3<7$ & $57 y 77$. & .0267 & .00459 & 10.18 & .1324 & 3.440 & 25.78 \\
\hline .40 & 25.50 & 285.5 & 234.8 & 279.7 & 5.08 & 5568. & 626 & .0819 & 0.970 & 3204. & 57542. & .0190 & .00494 & 10.35 & .1283 & 4.42 .3 & 34.31 \\
\hline
\end{tabular}


tABLE $V$ (CONTD) FORCED CONVECTION BOILING

RUN NO. 18.0 N-BUTANOL TEST SEETION NU. 4 INSIDE DIAMETER.DI=0.038917FT.

FLOW RATE,W=1490: LBS/HR MASS VELOCIT , G= 34B.0 LBS/SEC.SQFT POWER = 8.00 KILOWATTS HEAT FLUX,Q= 35231. BTU/HR. SOFT TEMPERATURE SEFQRE FLASH $=286.2 \mathrm{~F}$ VELOCITY BEFORE FLASH $=2.5 \mathrm{FT} / \mathrm{SEC}$

\begin{tabular}{|c|c|c|c|c|c|c|c|c|c|c|c|c|c|c|c|c|c|}
\hline $\mathrm{E}: \mathrm{FT}$ & PSila & TO & $\bar{i} \mathbf{i}$ & $T B$ & OELT & HBOIL & HLIQ & $x$ & $x T^{T}$ & NUB & RENOL & $B D=E 4$ & STANIN & PRNOL & $D P / D L L$ & DP/DLTP & $P / L I O$ \\
\hline 0. & 37.35 & 315.4 & $313: 0$ & 298.8 & 14.14 & $2>75$ & 699. & • & c. & 648. & 72396 & .4819 & .00244 & 9.33 & .1486 & 0.500 & 3.41 \\
\hline .50 & 39.23 & .317 .4 & 315.1 & 298.7 & 16.40 & 2392 & 699. & - & c. & 1420 & 72291 & .4811 & .00210 & 9.34 & .1467 & .340 & 2.32 \\
\hline .00 & 39.06 & 317.05 & 315.1 & 298.4 & 16.72 & 2346 & 698. & - & a. & 1393. & 72144 & .4301 & .00206 & 9.35 & .1467 & 520 & 3.54 \\
\hline .50 & 38.81 & .316 .5 & .314 .1 & 298.0 & 16.13 & $2 \div 31$ & 697. & - & a. & 1442 & 71928 & .4785 & .00214 & 9.38 & .1408 & 765 & 5.21 \\
\hline .00 & 38.47 & 3.15 .4 & 313.0 & 297.5 & 15.53 & 2526. & 697. & - & 0 . & 1447 & 71537 & .4765 & .03222 & 9.40 & $.14: 38$ & 045 & 7.12 \\
\hline .50 & 37.86 & 313.5 & 311.1 & 296.5 & 14.6 & 585 & 695. & - & 0. & 1589. & 71120 & .4727 & .05236 & 9.45 & .1470 & 75 & 9.49 \\
\hline 3.00 & 36.98 & 310.7 & 308.3 & 295.0 & 13.25 & 2.961 & 689. & .0077 & 10.001 & 1748 & 69809 & .4673 & $.0 J 261$ & 9.53 & .1452 & 1.790 & 12.33 \\
\hline 40 & 36.18 & $308 . \lambda$ & 305.8 & 293.7 & 12.07 & $3: 250$ & 681. & .0193 & +.2 .77 & 1414. & 68306. & .4625 & .03285 & 9.60 & .1424 & 2.170 & 15.23 \\
\hline 3.80 & 35. & 305 & 302 & 292.1 & 10 & 362 & 671. & .0321 & 2.644 & 2130 & 65617. & .4566 & .00320 & 9.68 & .1375 & 35 & 54 \\
\hline 20 & 7 & & 2 & 2 & & 4 & 66 & 462 & & 2346. & 64665 . & .4492 & .00 & 79 & .1362 & 0 & \\
\hline 4.60 & 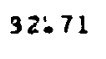 & 2 & 2 & 2 & 9.09 & & 643. & 17 & 1 & - & 62 & .4404 & - & 93 & .1327 & 15 & 14 \\
\hline 6: 00 & 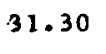 & 2 & 23 & 2 & . & $<76$ & 635. & .0779 & 1.070 & 276 & 60206 & .4313 & .00 & 10.06 & .1291 & 0 & 30.84 \\
\hline $5: 40$ & 24.43 & 291.5 & $28 \% .1$ & 281.5 & 7.58 & E 17.3. & 620. & .0975 & 0.830 & 2989. & 57353. & .4190 & .00457 & 10.25 & .1248 & 4.310 & 34.53 \\
\hline
\end{tabular}


TABLE $V$ ICUNTDI FORCED CONVECTION BOILING

RUN NU. 19.0 N-BUIANOL TEST SECTION NO. 4 INSIDE DIAMETER,DI=0.038917 FT.

FLOW RATE,H=1490. LBS/HR MASS VELOCITY,G $=348.0$ LBS/SEC.SOFT PIJWER $=10.30 \mathrm{KILJWATTS} \mathrm{HEAT} \mathrm{FLUX,Q=} \mathrm{505IO.} \mathrm{BTU/AR.SQFT}$ TENPERATURE BEFORE FLASH $=285.5 \mathrm{~F}$ VELOCITY BEFORE FLASH $=2.5 \mathrm{FT} / \mathrm{SEC}$

\begin{tabular}{|c|c|c|c|c|c|c|c|c|c|c|c|c|c|c|c|c|c|}
\hline L, F.T & HSIA & ro & I I & IB & DELT & HBIIL & $H L 1 Q$ & $x$ & $x I T$ & NUB & RENOL & $B D \cdot E 4$ & STANTN & PFINOL & $D P / D L L$ & $D P / D L T P$ & TP/LIO \\
\hline 0. & 41.42 & 321.4 & $31 \dot{a} .3$ & 302.0 & 16.34 & 3092 . & $70 \%$ & - & 0. & 1945. & 74142 & .9235 & .00272 & 9.16 & .1462 & 0.200 & 1.37 \\
\hline 0.50 & 41.29 & 322.0 & 318.9 & 301.8 & 17.11 & 2951. & 703 & - & 0. & 1761. & 74033 & .9226 & .00259 & 9.17 & .1462 & 0.380 & 2.60 \\
\hline 1.00 & 4.1 .06 & 322.4 & 319.3 & 301.5 & 17.84 & 2832 & 703 & - & 0. & 2089. & 73842 & .9209 & .00249 & 9.19 & .1463 & 0.635 & 4.14 \\
\hline 1.50 & 40.64 & 322.4 & $31 \% .3$ & 300.9 & 18.42 & $27<2$ & 702 & - & 0. & 1634 & 73537 & .9182 & .00241 & 9.22 & .1463 & 0.865 & 5.91 \\
\hline 2.00 & 40.18 & 322.1 & $319 . c$ & 300.1 & 15.86 & 2679 & 701 & - & 0. & 1594. & 73119 & .9145 & .00235 & 9.26 & .1464 & 1.145 & 7.82 \\
\hline 2.50 & 39.48 & 320.5 & 311.4 & 299.1 & 18.36 & 2751 & 699 & - & 0. & 1634. & 72509 & .9090 & .00242 & 9.32 & .1466 & 1.480 & 10.10 \\
\hline 3.00 & 38.60 & 318.2 & 315.1 & 297.7 & 17.46 & 2893 & 693. & .0067 & 11.615 & 1715. & 71266 & .9020 & .00255 & 9.39 & .1451 & 1.825 & 12.58 \\
\hline 3.40 & 37.80 & 316.0 & 312.9 & 296.4 & 16.52 & 3057 & 684. & .0199 & 4.274 & 1809 & 69657 & .8957 & .00269 & 9.46 & .1419 & 2.160 & 15.22 \\
\hline 3.80 & 36.86 & 313.6 & 310.5 & 294.8 & 15.66 & 3225 & 674 & .0341 & 2.559 & 1403. & 67852 & .8883 & .00284 & $9.54^{\circ}$ & .1386 & 2.470 & 17.83 \\
\hline 4.20 & 35.75 & 310.9 & 307.9 & $293 . \bar{C}$ & 14.86 & 3399 & 663. & .0494 & 1.776 & 1799. & 65857. & .8796 & .00299 & 9.64 & .1350 & 2.750 & 21.48 \\
\hline 4.60 & 34.50 & 307.5 & 304.4 & 290.9 & 13.55 & 3729 & 651. & .0658 & .326 & 2185 & 63696 & .8694 & .00329 & 9.75 & .1312 & 3.220 & 24.54 \\
\hline 5.00 & 32.94 & $3 c 2.4$ & 294.3 & 288.1 & 11.18 & 4520 & 637 & .0842 & .017 & 2038. & 61174. & .8564 & .00399 & 9.90 & .1271 & 4.480 & 35.25 \\
\hline .5 .40 & 30.84 & 275.4 & 292.3 & 284.2 & 8.05 & 5276 & 618 & .1067 & 0.777 & 3041 . & 57953 & .8390 & .00555 & 10.11 & .1222 & 6.890 & 56.39 \\
\hline
\end{tabular}




\section{TABLE V ICUNTD) FIJRCED CINVECTIGN EOILINE}

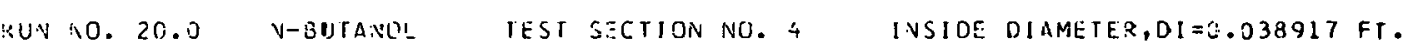

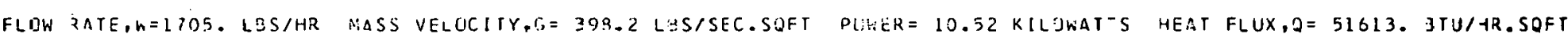
TENPERATURE BEFCFE FLASH= $235.9 \mathrm{~F}$ VELUCITY BEFORE FLAST $=2.5 \mathrm{FT} / \mathrm{SEC}$

\begin{tabular}{|c|c|c|c|c|c|c|c|c|c|c|c|c|c|c|c|c|c|}
\hline$L,=T$ & PSIA & ru & $\mathrm{ri}$ & TB & OEL $r$ & HEOIL & HLIS & $x$ & $x T r$ & NUB & RENUL & $B \bar{E} \cdot E_{4}$ & STAMTH & PRIVOL & $D P / O L L$ & $D P / D L T . P$ & $T P / L I O$ \\
\hline 0. & 4.3 .22 & $3 i 7.6$ & 116.5 & $304 . ?$ & 11.70 & $44: 2$ & 783 & - & 0. & 2645 & 86615 & .7248 & .00339 & 9.02 & .1845 & 0.035 & 0.46 \\
\hline .50 & 43.19 & 321.7 & 313.6 & 304.0 & 13.93 & 3692. & $7 E 8$. & - & 0. & 213 & 86533 & $.72: 43$ & .00283 & 9.03 & .1846 & 0.180 & .98 \\
\hline .00 & 43.03 & 322.9 & 319.8 & 304. & 15.31 & 3371 & 788 & - & 0. & 020. & 80432. & .7230 & .00257 & 9.04 & .1846 & 0.325 & .76 \\
\hline .50 & 42.80 & 323.4 & $3: 0.3$ & $304 . \bar{c}$ & 16.10 & 3205. & 788 & - & 0 & เ919. & $86<32$ & .72 .72 & .20245 & 9.05 & .1847 & 553 & .98 \\
\hline 2.00 & 42.51 & 32.3 .3 & 320.1 & 302.6 & 10.48 & 3132. & 727. & - & 0. & P 74. & $858: 36$ & .7249 & .00240 & 9.08 & .1848 & 0.835 & .52 \\
\hline .50 & 41.47 & 322.4 & 31.9 .3 & 302.9 & 10.45 & 3138. & $7 \pm 5$ & - & 0. & 875. & 65339. & .7213 & .00241 & 9.12 & .1847 & 90 & .44 \\
\hline 3.00 & 41.27 & 320.7 & 317.3 & 301.8 & 15.75 & 3276 & 734 & - & 0. & $195 \%$ & 846.97 & .7167 & .00252 & 9.18 & .1851 & +35 & .75 \\
\hline 3.40 & 40.48 & 313.3 & 315.7 & $300 . \dot{n}$ & 15.11 & $3<17$ & $7 n 1$ & - & 0 . & 035. & 83950 & .1116 & $.002 t 2$ & 9.24 & .1853 & 2.340 & 1.01 \\
\hline 3.80 & 31.51 & 316.6 & 313.5 & 249.1 & 14.35 & 3596. & 773 & .0100 & 8.207 & 2137 & 87174 & .7549 & .00276 & 9.32 & .1824 & 520 & 32 \\
\hline .20 & 38.32 & $3+1.9$ & 310.7 & 247.2 & 13 & 3329. & 750. & .6249 & 95 & 2264. & 79737 & 5 & .00244 & 42 & 9 & 95 & 4 \\
\hline .50 & $36 . c 1$ & 310.1 & & $2+4.8$ & 12.18 & 4239. & 745 & .0421 & 2 & 2501 & $76 \geqslant 54$ & .6559 & .00326 & 54 & .1 .729 & 75 & 3 \\
\hline .00 & 35.29 & 305.1 & $30 \% . \mathrm{C}$ & 292.2 & 9.72 & i309. & 731. & .0593 & 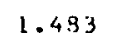 & 3118. & 74158 & .6753 & .00407 & 9.68 & .1679 & 660 & 27.75 \\
\hline$=.40$ & 33.20 & 299.1 & $4 \%$ & $288 .:$ & 7.35 & 225. & 712 & 8305 & .060 & 4102 & 70514 & .0597 & $.005 \div 1$ & 9.88 & .1619 & 5.935 & .35 \\
\hline
\end{tabular}




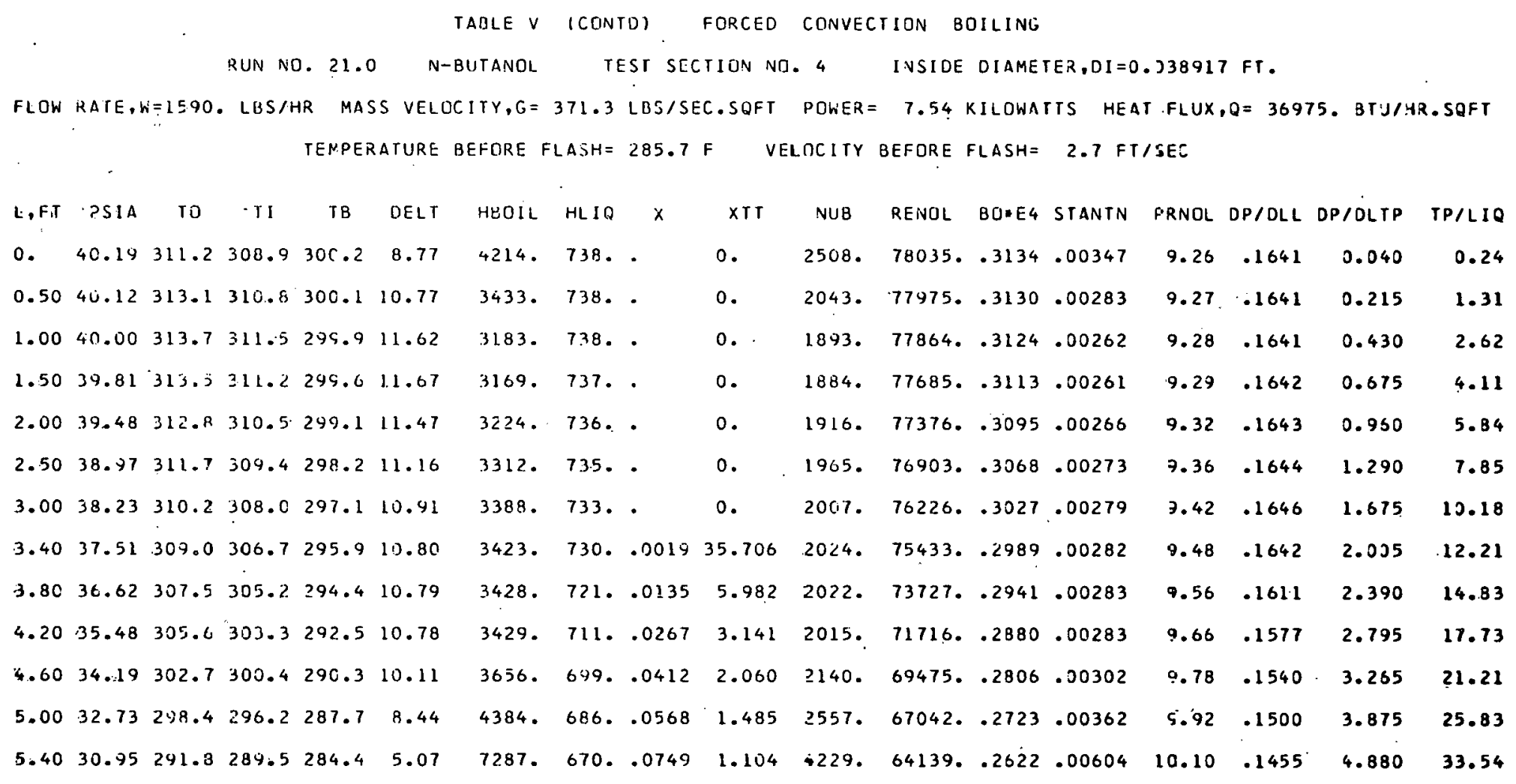


TABLE V FURCED CONVECTION BOILING

RUN NO. 22.0 M-BUTAVOE IEST SECTICN NO. 4 INSIDE DIAMETER,DI=0.038917 FI.

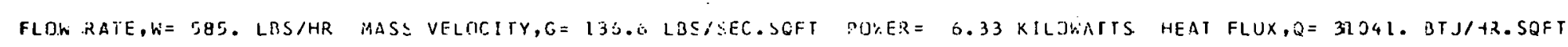
TENPERATURF BEFJRE FLASH $286 .+\mathrm{F}$ VILLUC:TY BEFOZE FLGSH $=1.0$ FT/SEC

\begin{tabular}{|c|c|c|c|c|c|c|c|c|c|c|c|c|c|c|c|c|c|}
\hline F 1 & PSIA & 10 & $\mathrm{II}$ & IU & $E L T$ & roth & LIS & $x$ & I & vids & $\because \mathrm{V} \cap \mathrm{L}$ & $O: E 4$ & SIANTV & RVOL & $D P / C L L$ & DQ/JLTP & $P / L I Q$ \\
\hline G. & 20.76 & 243.5 & 291.6 & 280.6 & 11.05 & $\therefore 2$ & 12. & 237 & 2 & $6: 0$. & 170. & 36. & 37 & 33 & $\int \overline{79}$ & .615 & 2.03 \\
\hline 50 & 23.57 & 242.4 & 290.5 & 279.8 & $10.6 \%$ & 706. & 67 & .0414 & .864 & 072. & 23614 & .6433 & .50657. & 10.34 & $2: 71$ & 760 & 39 \\
\hline 00 & 28.05 & 291.1 & 289.2 & 279.7 & 13.43 & 917. & 201 & $.050 x$ & $.2+5$ & 716. & 22961 & .3407 & .006673 & 10.40 & . & 5 & 42.24 \\
\hline 5.3 & 27.4 & $28 \cdot .5$ & $=37.6$ & 277.5 & $\therefore 0.1$ & $0<:$ & 95 & .074 & .470 & 754. & 2.2 .257 & .4317 & .00694 & 10.47 & .0253 & 325 & 2.46 \\
\hline .0J. & 20.71 & 287.7 & $135 .:$ & 276.0 & . & 155 & 99. & $\therefore a c:$ & .771 & $10 i 4$ & $2: 537$ & $.82 .1=$ & .00715 & 10.55 & 3 & 525 & 2.57 \\
\hline 5 & 25.89 & 285.6 & 28.3 .7 & 274.2 & 9 & $32=5$. & 12 & .1211 & .526 & 1852 & 23747 & .8095 & .20737 & 0.65 & .0234 & & .09 \\
\hline 3.0 .5 & 24.95 & 283.4 & 781. & 272.1 & 3. & $\because 300$. & 275 & .1430 & .317 & $n a \mathrm{~L}$. & $149 ? 2$ & .7463 & .00753 & 5 & 2 & & 2.57 \\
\hline .20 & 24.19 & 281.4 & > & 273.4 & 9.14 & $33+7$. & 265 & .1600 & .431 & . & 19234 & .7352 & $.2: 3774$ & 83 & .0217 & & 90.86 \\
\hline$\infty 0$ & 23.39 & $27 \div \cdot 4$ & $27 \% .5$ & $26: .5$ & 3.05 & $: 472$ & $2 a c$. & $.17: 3:$ & $\cdot 3 \cdot ; 6$ & 1962 & 18535 & .7735 & .0 .0792 & 10.95 & $.0: 2$ & 10 & 00.33 \\
\hline .20 & 23.50 & $27 \% .3$ & $2.7 r_{1.4}$ & 265.4 & 9.0 & 345.7 & $25.1 \%$ & .1071 & 0.348 & lys $1 ;$ & 17564. & .7545 & .007 & 11.07 &.$a$ & 320 & $1 ?$ \\
\hline .60 & 50 & 274.9 & $a$ & 2 & 1.07 &, 421. & 23 & $.213: \cdot$ & 0.307 & $\mid y-1$ & 17119 & $.7 \div 37$ & .20795 & 20 & $.31+4$ & כ & 34.27 \\
\hline$c 0$ & & & . & & ' & $32:$ & “哽 & 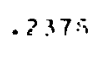 & 3 & $12: 5$ & 4. & .1231 & 65 & 37 &.$\approx 185$ & 135 & 160.03 \\
\hline$c_{c}$ & .0 & 3 & $\therefore 6 t$. & 257 . & 1 & 9 & 2350 & 257 & 235 & $2.0^{\circ}$ & 6. & 1347 & .30734 & 1.56 &.$=177$ & 3.390 & 191.73 \\
\hline
\end{tabular}




\section{tABLE $V$ FORCED COINVECTION BOILIING \\ RUN NO. 23.0 N-BUTANOL TEST SECTION NO. 4 INSIDE DIAMETER,DI=0.238917 FT.}

FLLW RAIE,W $=585$ : LBS/HR MASS VELOCITY,G $=136.6$ LBS/SEC.SOFT POWER = 9.05 KILOWATIS HEAT FLUX,Q= 44395. 8TU/TR. SOFT TEMPERATURE BEFORE FLASH $=285.9 \mathrm{~F}$ VELOCITY BEFORE FLASH $=1.0 \mathrm{FT} / \mathrm{SEC}$

\begin{tabular}{|c|c|c|c|c|c|c|c|c|c|c|c|c|c|c|c|c|c|}
\hline$L G F T$ & SIA & ro & rI & $T B$ & DELT & HEOIL & HLIO & $x$ & $x T$ & NUJB & ENOL & $30 * E 4$ & STANTN & RNOL & DP/OLL & OP/OLTP & P/LIO \\
\hline $0:$ & $? .44$ & 304.9 & 302.2 & 283.5 & 18.72 & 371. & 317 & 0102 & 015 & 374. & 5066. & .1093 & .00535 & 0.15 & .0285 & .170 & 1.05 \\
\hline .50 & .78 & 4.8 & 302.1 & 282.2 & 19.90 & 31 & 310 & .0364 & 147 & 289. & 4164. & .0967 & .00503 & 0.22 & .0272 & 210 & .44 \\
\hline .00 & 29.16 & 303.3 & 300.6 & 281.0 & 19.61 & 264 & 302 . & .0622 & 1.281 & 306. & 3304. & .0849 & .00511 & 0.28 & .0250 & 255 & .35 \\
\hline 50 & 8.50 & 301.0 & $298: 3$ & 9.7 & 18.6 & 336 & 295. & .0863 & 901 & 373. & & .0721 & 39 & 35 & .0248 & & 20 \\
\hline .00 & 27.79 & 298.5 & 295.0 & 278.2 & 17.6 & 521. & 287 & .1147 & 685 & 447. & 1544. & .0573 & .00570 & 43 & .0236 & 50 & 90 \\
\hline .50 & 27.01 & 295.9 & 293.2 & $27 t .6$ & 16. & 8. & 279. & .1414 & 44 & 534. & 641. & .0412 & 07 & & & & 12 \\
\hline .00 & 26.16 & 293.2 & 290.5 & 274.8 & 15.7 & 26. & 270 & .1687 & .444 & 614 & 9712. & .0238 & .00641 & 62 & .0212 & 10 & .34 \\
\hline .40 & 25.37 & 290.9 & 288.2 & 273.0 & 15.17 & 2926. & 263. & .1912 & 0.381 & 1667. & 8929. & .0077 & .00665 & 1 & .0203 & 00 & .75 \\
\hline 80 & 6 & 2 & 285 & 271.0 & 14.5 & 3057 & 256 & .2140 & 0.329 & 1736 & 18101 & .9890 & .00696 & 82 & 3 & 70 & 56 \\
\hline 4.20 & 3 & 2 & 2 & 38.7 & 13 & 2( & 248 &. & 5 & 82 & 5. & & .00 & & & 25 & 36 \\
\hline 4.60 & 2 & 2 & 2 & 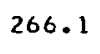 & 1 & • & 2 & • & 6.40 & 1871 . & • & 46 & . & & & 0 & 98 \\
\hline . & 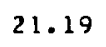 & $\dot{2}$ & 2 & 3 & 12 & • & 23 & .288 & 0.216 & 192 & 2. & .9170 & .0 & 4 & .0 & 985 & 82.26 \\
\hline re & 19.86 & 2.74 .7 & 271.9 & 259.6 & 12.33 & 3600 . & 223. & .3150 & .187 & 2308. & 14493. & .8870 & .00830 & 11.43 & .0154 & 3.335 & 214.59 \\
\hline
\end{tabular}


TABLE V ICCN'O: Fi:RCED CCINYECTION GOILING

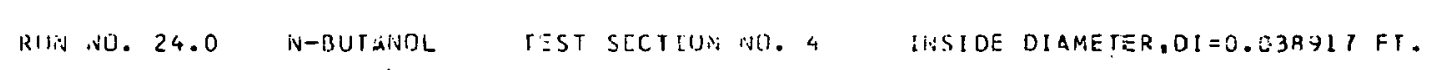

FLOW RATE,W=1E35. LÜSIHR NASS VELOCITY,G= 428.5 LBS/SEC.SOFT PFHER = 9.7T KILOWATTS HEAT FLUX,Q= 4IB91. BTJ/TR.SQFT

TENPERATURE BEFJRE FLASH= $297.8 \mathrm{~F}$ VELITCLTY BEFURE FLASH $=3.1 \mathrm{FT} / \mathrm{FEC}$

\begin{tabular}{|c|c|c|c|c|c|c|c|c|c|c|c|c|c|c|c|c|c|}
\hline$L, F T$ & PSIA & 70 & $\mathrm{TI}$ & IB & OELT & H.3OIL & HLI: & $x$ & $x \mathrm{xr}$ & sulis & REVOLL & $E 0 * E_{4}$ & STANTN & PRNOL & $D P / D_{-} L$ & $D P / D L J P$ & TP/LIO \\
\hline 0. & 47.47 & 328.3 & 325.4 & $31 \mathrm{c} .6$ & $14.79^{\circ}$ & 3233 & 845 & • & 0. & 1962. & 97402. & .5145 & .03231 & 8.71 & .2033 & 0.050 & 0.24 \\
\hline 0.50 & 47.40 & 132.3 & $3<9.4$ & 310.5 & 19.94 & 2523 & 845. & • & 0. & $L \leq: 2$. & 97331. & .5141 & .30180 & 8.72 & .2038 & 0.150 & 0.77 \\
\hline 1.00 & 47.28 & 333.0 & $3 \times 0.1$ & 310.3 & 19.73 & 2427 & 845 & • & $\therefore$ & 1470. & 97211. & .5134 & .00173 & 8.73 & .20088 & 0.330 & 1.82 \\
\hline 1.50 & 47.01 & 332.4 & $32 \% .5$ & 310.2 & 19.53 & $\overline{2} 452$ & Bi41. & • & $n$. & $1 / 814$ & 36942 & .5119 & .00175 & $8: 75$ & $.2 \operatorname{Cyg}$ & 0.650 & 3.16 \\
\hline 2.00 & 46.60 & 331.5 & $3 z: 6$ & 3119.4 & 19.15 & $=-500$. & 1343 & . & 0. & $1: 12$. & 45537 & .5097 & .30178 & 8.78 & .267. & 1.020 & 4.88 \\
\hline 2.50 & 46.00 & 330.0 & $32 \because .1$ & 3118.6 & 19.45 & $25,96$. & $34 \therefore$ & • & $n$. & $1: 88$. & 95949. & .5063 & .20185 & 8.82 & .2571 & 1.312 & 3.26 \\
\hline 3.00 & 43.19 & 327.7 & 324.8 & 307.5 & 17.36 & 275.9 & $83 \%$ & .0039 & 20.501 & $1 \therefore 53$ & 94769 & .5314 & .00197 & 8.88 & .26 .79 & 1.710 & 9.19 \\
\hline 3.40 & $4: .35$ & 325.6 & 322.7 & $3 i 26.3$ & 16.36 & 2927 . & $42 !$ & $.01 r_{3}$ & 5.420 & $1 \% 00$ & 92843 & .4972 & .00209 & 9.94 & .2040 & 2.320 & 11.37 \\
\hline 3.80 & 43.32 & 322.8 & 319.9 & 304.8 & 15.07 & 317. & $31:$ & .0279 & 3.381 & lus. & 90664. & $.91 t$ & .30227 & 9.02 & .1098 & 2.790 & 13.96 \\
\hline 4.20 & 42.02 & $3: 9.5$ & 315.6 & 332.4 & 13.31 & $34: 76$. & 805. & .0 .420 & 2.262 & z') & 88071 & $.484 \equiv$ & .00249 & 9.12 & .1351 & 3.330 & 17.07 \\
\hline 4.50 & 40.51 & 315.6 & 312.7 & $30 \mathrm{C} .6$ & 12.07 & $346^{\circ}$. & 731. & .0575 & 1.646 & 23033. & 95182 . & .4755 & .020283 & 9.24 & .1300 & 4.000 & 21.05 \\
\hline 5.00 & 38.82 & 311.3 & $30 r . .4$ & 298.0 & 10.39 & 4608. & 775 & .0743 & 1.206 & 2134 & 32007 & $.455^{\circ}$ & .20329 & 9.37 & .1346 & $4.71 J$ & 25.52 \\
\hline 5.40 & 36.75 & 306.7 & 303.8 & 2.34 .7 & 9.11 & $525 \equiv$ & $75 \%$ &. $\cos 37$ & 11.972 & 3102. & 78300 & $.453:$ & .00376 & 9.55 & .1795 & 5.530 & 30.78 \\
\hline
\end{tabular}




\begin{tabular}{|c|c|c|c|c|c|c|c|c|c|c|c|c|c|c|c|c|c|c|}
\hline & $96 \cdot 2 \varepsilon$ & $0 \mathrm{c} 6^{\circ} \mathrm{s}$ & C6L ${ }^{\circ}$ & $\angle B \cdot S$ & $\rightarrow Z \rightarrow O C^{\circ}$ & $6 \mapsto \varepsilon 1^{\circ}$ & •Oてヤ6L & $\cdot 8 z \operatorname{sic}$ & BSt $0^{\circ} 0$ & $\varepsilon 960^{\circ}$ & • ט9L & $\cdot 1,965$ & $82 \cdot 9$ & $2 \cdot 962$ & $5 \cdot 205$ & $8 \cdot b \cdot J \xi$ & $69 \cdot 18$ & $0 \rightarrow \cdot 5$ \\
\hline & $\angle S \cdot s Z$ & $022^{\circ}$ & $7 \nrightarrow 81^{\circ}$ & $C \varepsilon \cdot 5$ & $\varepsilon: \& 00^{\circ}$ & டタガ・ & $\cdot 92088$ & •90天६ & $\angle O Z \cdot I$ & $58 \angle 0^{\circ}$ & $\cdot \because \angle L$ & - ZEES & $5 t \cdot 9$ & 5.562 & 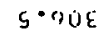 & $2 \cdot(81) \varepsilon$ & $L 1 \cdot \omega \varepsilon$ & $00 \cdot s$ \\
\hline & $5 E \cdot 02$ & $0 \angle 6^{\circ} \mathrm{L}$ & $5 \in 81^{\circ}$ & $91^{\circ}$ & $\epsilon \ni \varepsilon 00^{\circ}$ & $2251^{\circ}$ & • 8Т098 & $\cdot 6 \varepsilon 6 \bar{c}$ & AIS. I & $\hbar \varepsilon .0^{\circ}$ & $\because 62$ & $\cdot \overrightarrow{2 \varepsilon}, \vec{n}$ & $19^{\circ} \mathrm{L}$ & $I \cdot 20 \varepsilon$ & $L \cdot 60$ s. & $\theta^{\circ}$ I Is & $5 \cdots 17$ & $09^{\circ}=$ \\
\hline & $5 * \cdot 21$ & $C \& \varepsilon^{\circ} \varepsilon$ & $\angle E G 1^{\circ}$ & $90^{\circ} t$ & $81 \varepsilon C 0^{\circ}$ & $185^{\circ}$ & •દヤৎุ8 & $\cdot \varepsilon 3 n z$ & $928 \cdot 1$ & $8.050^{\circ}$ & $\cdot 500$ & ・18カ7 & $9 \varepsilon \cdot a$ & $0 \cdot$ म & ש & $L \cdot$ •IS & 81.24 & $0 z \cdot \rightarrow$ \\
\hline & Sか・わ & $058^{\circ} 2$ & $6 \angle 61^{\circ}$. & $96 \cdot 8$ & $16220^{\circ}$ & S\&S. & - $3960 t$ & $\cdot 29+2$ & $n 9 S \cdot 2$ & $\angle \angle E 0^{\circ}$ & •91? & - sol' & $\varepsilon I^{\circ} \bullet$ & G.5O\&. & 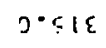 & $\Phi \cdot L I r$ & $80^{\bullet} \gg 7$ & $08^{\circ} \varepsilon$ \\
\hline & $S t=11$ & $010 \cdot 2$ & $9102^{\circ}$ & $88 \cdot \varepsilon$ & $29200^{\circ}$ & $0891^{\circ}$ & . GIOEA & •とてくる & $995 \cdot \zeta$ & $\angle 920^{\circ}$ & $\cdot 923$ & $\cdot 1.89 E$ & $91 \cdot 01$ & $b \cdot\langle 0 \varepsilon$ & $S \cdot L I S$ & $\mathrm{~B}=6$ If & OIימ⿰亻 & $0 \rightarrow \cdot \varepsilon$ \\
\hline & $06^{\circ} 6$ & $010^{\circ} 2$ & OSOz' & $2.8 \cdot \varepsilon$ & $\dagger \varepsilon 200^{\circ}$ & $\angle T \angle 1^{\circ}$ & $\cdot 0+8 b 6$ & $\cdot \varepsilon$ Gt I & $2 \theta: 5 \cdot 5$ & $9910^{\circ}$ & •म६! & - ODEe & Sו & $9 \cdot 80 \varepsilon$ & $3.51 \varepsilon$ & $2 \cdot 2 z \varepsilon$ & $20^{\circ} \mathrm{CB}$ & $00 \cdot \varepsilon$ \\
\hline 1 & $9 S \cdot L$ & $\cos 5^{\circ} \mathrm{I}$ & $1002^{\circ}$ & $S L^{\circ} \varepsilon$ & $\$ 0200^{\circ}$ & $6521^{\circ}$ & .62696 & ・リ1 & $095^{\circ} \angle I$ & $4+\mathrm{CO}^{\circ}$ & ・カガ & $\cdot \angle L E Z$ & $20^{\circ}=1$ & $6 \cdot 508$ & 6.225 & $2 \cdot 526$ & $\rightarrow(5 \cdot)$ & $05^{\circ} 2$ \\
\hline & $3 L \cdot 5$ & $0120^{\circ}$ & $\angle \mathrm{Cl} 2^{\circ}$ & $0 L \cdot g$ & $8 \angle 100^{\circ}$ & $06 \angle 1^{\circ}$ & - $\rightarrow 018 s$ & - LISI & $\cdot 0$ & $\cdot$ & $\cdot \bullet \gg 3$ & •"vs: & $96 \cdot+1$ & \& & $\theta^{\circ} \sin$ & $1 \cdot 6 i \varepsilon$ & $\rightarrow 9 \cdot 1 \rightarrow$ & $00 \cdot 2$ \\
\hline 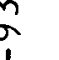 & $\angle \varepsilon^{*}{ }^{\prime}$ & $\mathrm{c} 2 t^{\circ} \mathrm{C}$ & $9 \mathrm{CI} 2^{\circ}$ & $19 \cdot 8$ & $09100^{\circ}$ & II & • દI986 & - ธง\& & $\cdot 0$ & $\cdot$ & - 158 & -ys:2 & $19 \cdot 91$ & $s$ & $1 \cdot 42 \varepsilon$ & $\forall \cdot 0 F \varepsilon$ & $7 i \cdot 8$, & $05^{\circ} 1$ \\
\hline & $B Z \cdot E$ & $\operatorname{cts} 5^{\circ} \mathrm{C}$ & $\operatorname{set} 2^{\circ}$ & $\mapsto 9 \cdot 8$ & ESTOC & $\angle 281^{\circ}$ & $\cdot 2 L t .86$ & •IT\& & $\cdot c$ & $\cdot$ & $: 158$ & -isiz & $\varsigma \varepsilon^{\circ} L 1$ & $0 \cdot 21 \varepsilon$ & $\varepsilon \cdot ค 3 \%$ & $9 \cdot I 5.5$ & $G \rightarrow \cdot P B$ & $00 \cdot 1$ \\
\hline & $\angle D \cdot 2$ & $025^{\circ} \mathrm{C}$ & $\rightarrow \mathrm{Cr}^{\circ}$ & $29 \cdot 8$ & $29100^{\circ}$ & $6 \varepsilon 81^{\circ}$ & - S९乙66 & •દ๙\& & $\cdot 0$ & • & $\cdot \cos$ & $\cdot 212 z$ & $\varsigma+, 91$ & $\mapsto \bullet \measuredangle 1 \varepsilon$ & $\partial^{\circ} \varepsilon \subset \varepsilon$ & $I \cdot I \varepsilon \varepsilon$ & $08 \cdot 84$ & $05 \cdot 0$ \\
\hline & $s t \cdot 1$ & $01 H^{\circ} \mathrm{C}$ & $\rightarrow \mathrm{CIZ}^{\circ}$ & $C 9 \cdot 8$ & $20200^{\circ}$ & $\leftrightarrow \rightarrow 81^{\circ}$ & • $\varepsilon \bullet \mapsto \in \epsilon$ & •Iรג & 0 & $\cdot$ & - t5a & $\operatorname{ringz}$ & $S I \cdot \varepsilon I$ & $L \cdot 2 I E$ & $3 \cdot \varsigma 2 \varepsilon$ & $1 \cdot 8>\varepsilon$ & 70.64 & $\cdot 0$ \\
\hline & $017 / d 1$ & dד/40/d & סגה/ סרר & רกแ18-1 & N.N.71S & ว & $70 n$ & gnt. & $11 x$ & $x$ & $\mathrm{OI} \mathrm{TH}$ & רIO:H & $17 \exists 0$ & 31 & 11. & נו & VISA & $\left.1 t^{\prime}\right]$ \\
\hline
\end{tabular}

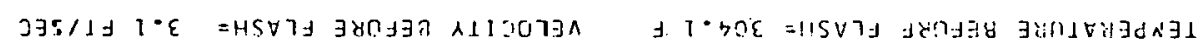

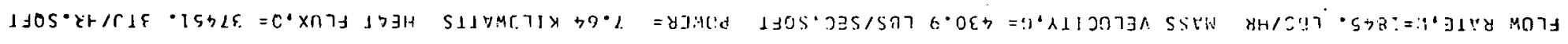

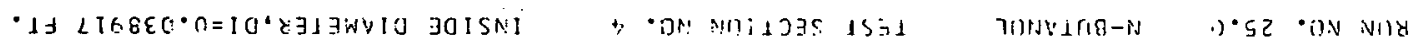

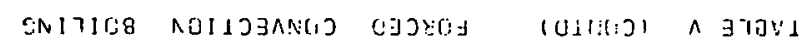


THBLE V (CLNTJ) FORCED CONVECTION BUILING

BUN NO. 26.0 N-EUTAINOL TEST SECTION NU. 4 INSIDE DIAMETER,DI=0.038917 FT.

FLOW RATE, $:=1885$. LBS/HR MASS VELOCITY, $=4 \% 0.2$ LES/SEC.SQFT POWFR= 5.71 KILONATIS HEAT FLUX,Q $=28001$. BTU/HR.5QR, TENPEF.MTURE EEFCRE ELLSH= $308.3 \mathrm{~F}$ VRLLOCITY BETORE FLASH= 3.? FI/SEC

\begin{tabular}{|c|c|c|c|c|c|c|c|c|c|c|c|c|c|c|c|c|c|}
\hline$L, F T$ & SIA & To & TI & $T B$ & DELT & MOIL & LI:I & $x$ & it & ue & RENOL & $B D=E 4$ & STAVTN & RNOL & $D P / D L=$ & DP/OLTP & TP/LIO \\
\hline 0. & 49.69 & 324.8 & 323.1 & 313.5 & 9.55 & 31. & 69. & . & 0. & 84. & 102287 & .8588 & .00204 & B. 56 & .2182 & 0.683 & 3.12 \\
\hline 0.50 & 49.31 & 26.5 & 324.8 & 313.0 & 11.80 & $\equiv 72$. & 68. & . & $n$. & $1,42$. & 101914 & .8677 & .00155 & 8.59 & 218.3 & 0.810 & 3.71 \\
\hline 1.00 & 48.87 & 325.5 & 3.? & 312.5 & 11.32 & c73. & 867. & . & 0. & 503. & 101485 & .8564 & & 8.61 & .2184 & 970 & 4.44 \\
\hline 1.50 & 48.36 & 323.9 & 322.2 & 311.8 & 10 & 6.96. & ist & . & $c$. & 6.36 & 981. & .8549 & 87 & 8.65 & 2186 & 70 & .35 \\
\hline 2.00 & 47.77 & 322.1 & 320.4 & 311.0 & 9.38 & 986. & $\varepsilon s r$. & $.005 \%$ & 14.529 & 1810. & 99772 & .8630 & .60208 & .69 & $.21 \in 5$ & 00 & 0.47 \\
\hline 2.50 & 47.04 & 320.1 & 318.4 & $31 c .0$ & 8.34 & 356. & 52. & .0147 & .346 & 2031 & 92152. & .8305 & .00233 & 8.74 & $.21 \equiv 3$ & 90 & 7.92 \\
\hline 3.00 & 46.12 & 317.3 & 310.1 & 309.3 & 7.29 & +41. & 843. & .0245 & 3.423 & 2320 & 95264 . & .8577 & .00267 & .81 & .2009 & 240 & 9.72 \\
\hline 3.40 & 4.5 .72 & 315.8 & 314.1 & $30 \mathrm{e} . ?$ & 3 & 76.1. & 38. & .0304 & & 2974. & 95299. & .8565 & .0 & 8.84 & & & 11.50 \\
\hline 3.80 & 4 & 313.7 & 312.0 & 305 & 5.48 & $458 \mathrm{BC}$ & $32 t$. & - 4 ase & 2 & 2813 & . & .8517 & .01 & 95 & & & .72 \\
\hline .20 & 42. & 3 & 309 & & & 5nodo. & 1 & .0546. & & 03 & 1. & .8479 & & & & & 32 \\
\hline .60 & & 3 & & & & & & & & & & 4 & & & & & 37 \\
\hline 5.00 & 3 & 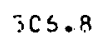 & 3 & 2 & 5.43 & 5154. & $i 90$. & $.68 \mathrm{C} 2$ & - & 3066 & 5. & .8378 & . & & 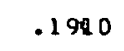 & & 35 \\
\hline $5.4 \mathrm{C}$ & 37.80 & 30.3 .6 & 301.9 & 296.4 & 5.49 & $=103$. & 773 & $.0900^{\circ}$ & 0.957 & $36 \div 0$. & 81222 & .9307 & .000355 & 9.46 & .1857 & 5.330 & 28.70 \\
\hline
\end{tabular}




\section{table V ICONTO) Force[ CONVECTION BOILING}

RUN NO. 51.0 N-BUTANOL TEST SECTION NO. 5 INSIDE DIAMETER,DI=0.038917 FT.

FLOW RATE, W=1130. LES/HR MASS VELOCITY,G $=263.9$ LBS/SEC.SQFT POWER = 9.55 KILOWATTS HEAT FLUX,Q= 65J24. BTJJHR.SOFT TENPERATURE BEFURE FLASH $=287.5 \mathrm{~F}$ VELOCITY BEFORE FLASH $=1.9 \mathrm{FT}$;SEL

\begin{tabular}{|c|c|c|c|c|c|c|c|c|c|c|c|c|c|c|c|c|c|}
\hline$\therefore, F T$ & SIA & 10 & TI & TB & DELT & HBOIL & HLIQ & $x$ & $x T T$ & NuB & RENOL & $B D=E 4$ & STANTN & PRNOL & $D P / D L L$ & $D P / D L T P$ & TP/LIO \\
\hline .25 & 35.39 & 318.2 & $314 . ?$ & 292.4 & 21.84 & 978. & 553. & . & 0 . & 749 & 2310. & .1859 & .00346 & .67 & .0910 & .840 & .23 \\
\hline .50 & 35.11 & 15.6 & 312.6 & 291.9 & 20.70 & 141. & 552. & - & - & 843. & 2128. & .1821 & .00365 & 9.69 & .0910 & 180 & 2.97 \\
\hline .00 & 34.42 & 315.0 & 312.1 & 290.7 & 21.36 & 044 . & 542. & .0191 & .209 & 783. & 6665. & .1722 & .00354 & 9.76 & .0881 & 580 & 17.93 \\
\hline .50 & 33.54 & 313.5 & 309 & 289.2 & 20. & 195 & 30. & .0417 & .015 & 1868 & 48929 & .1597 & .00372 & 9.85 & .0847 & 20 & .48 \\
\hline .00 & 32.44 & 0.6 & 3 & 287.2 & 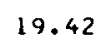 & 349 & 17. & .3658 & .284 & 1952. & 46999. & .1441 & .00390 & 9.95 & .0812 & 2.150 & so \\
\hline 40 & 31.44 & $30: .5$ & 303.6 & 285.4 & 18.2 & 570 & 506. & .0359 & .974 & 2075 & 5349. & .1301 & .00416 & 5 & & 40 & 16 \\
\hline .80 & 30.35 & 303.6 & $2.49: 6$ & 283.3 & 16 & 987. & 495 & .1066 & 771 & 2309 & 43644 & .1147 & .00465 & 16 & 54 & & 13 \\
\hline 3.10 & 29.44 & 39.9 & 245.9 & 281.5 & 1 & 522 & 486 & .1228 & .658 & 2611. & 42281 . & .1015 & .00528 & 0.25 & .0732 & 150 & 43.18 \\
\hline 0 & 28.85 & 5.7 & 291.7 & 280.4 & 11.32 & 743. & 478 & .1365 & 0.583 & 3308 & 41262 & .0730 & .00671 & 10.31 & .0713 & & 50.79 \\
\hline 0 & 27.25 & 9 & 206.9 & 277.1 & 9.86 & 6596. & 465. & .1578 & .486 & 3731 . & 39255 & .0681 & .00773 & 10.49 & .0685 & 4.350 & 63.67 \\
\hline 0 & 5.68 & .6 & 281.6 & 273.7 & -7.87 & $\cdot$ & 452 . & .1790 & .412 & 4712. & 37308 . & .0437 & .009 & 10.67 & .0658 & 5.380 & 81.81 \\
\hline
\end{tabular}


tAB_E : ICONTUI FGRCED COIVECTION BOILING

RUN NO. 52.0 N-BUTINCL TEST SECTION NO. 5 IVSIDE DIAMETER.0I=0.038917 FT.

FLOW IIATE, N=1400. LBS/HR MASS VELOCITY,G $=326.4$ LBS/SEC.SQFT POWER = 9.69 KILIWATTS HEAT FLUX,Q 65978 . $3 T$ TU/AR.SQFT TENPERATURE BEFDRE FLASH= $292 . i \mathrm{~F}$ VELOCITY BEFURE FLASH $=2.4 \mathrm{FIJSEC}$

\begin{tabular}{|c|c|c|c|c|c|c|c|c|c|c|c|c|c|c|c|c|c|}
\hline$L, F T$ & FSIA & To & rI & $T B$ & DELT & reOA: & HLIO & $x$ & $X T r$ & NUB & RENOL & $B O=E 4^{\circ}$ & STANTN & RNOL & DP/QL & DP/OLIP & TP/LIO \\
\hline .25 & 40.15 & 323.9 & 319.9 & $30 c . .1$ & 1.9 .83 & 2327 & 6.57. & - & 0. & 1960. & 68680 & 0512 & .00311 & 9.26 & 1313 & 0.550. & .19 \\
\hline .50 & 39.95 & 323.0 & $31 \div . c$ & 299.8 & 19.19 & $\equiv 438$. & $06 t$. & - & 0. & 045. & 68518 & .6591 & .00322 & 9.28 & 214 & 000 & .51 \\
\hline .00 & 39.30 & 323.2 & 319.2 & 298.8 & 20.47 & 5223 & 64. & .0014 & 49.711 & 1914. & 67830 & .6518 & .00302 & 9.33 & $.1 \equiv 12$ & 580 & .04 \\
\hline .50 & 38.42 & 321.2 & 317.2 & 297.4 & 19.81 & 3331 & 652. & .0209 & 4.123 & 1974. & $t 5866$ & .6422 & .00312 & 9.41 & $.1 \div 59$ & 2.082 & 16.39 \\
\hline .00 & 37.28 & 313.7 & $3: 1.7$ & 295.5 & 29.13 & 3449. & $\leqslant 38$. & .0420 & 2.118 & 2038 & 63565 & .0297 & $.0,0323$ & 9.50 & .1224 & 500 & 20.43 \\
\hline .40 & 35.16 & 315.2 & $312 . ?$ & 293.7 & $18.4 \%$ & 3568 . & $\epsilon 20$. & .0004 & 1.476 & 2101 & 01476. & . & .00334 & 9.60 & $.1: 85$ & 380 & 24.30 \\
\hline .80 & 34.85 & 313.2 & 307.2 & 291.5 & 17.74 & $371 \varepsilon$. & 613. & $.030 \mathrm{C}$ & 1.103 & $21 \mathrm{cl}$ & 59212. & .5036 & .00349 & 9.72 & $.1=45$ & 350 & 29.26 \\
\hline 3.10 & 33.75 & 310.5 & 30.5 & 289.5 & 16.92 & 3900. & 602. & .0955 & 0.910 & 2281 & 57371 & $.570 y$ & .00366 & 9.83 & .1114 & 30 & 34.13 \\
\hline 3.40 & 32.46 & 305.7 & 302.7 & 287.2 & $15.4 !$ & 4280. & 589. & .1123 & 0.757 & 21994 & 55343 & $.575 z$ & . 0402 & 9.95 & .1380 & 4.420 & 40.92 \\
\hline .70 & 31.02 & 301.2 & 247. & 204.6 & 12.62 & $522^{\top}$. & $57 \dot{0}$ & $.1 \geq 02$ & 0.636 & 3934. & 53150 & .5586 & .30492 & 10.09 & .1345 & 240 & 50.13 \\
\hline .00 & 29.25 & 205.3 & 291.2 & 231.2 & 10.08 & 6543. & 551. & .1505 & 0.530 & 3775. & 0585. & .5378 & .00617 & 0.27 & 1007 & .323 & 72.70 \\
\hline
\end{tabular}




\section{tABle V ICONTU) FGRCEO CONVECTION BOILINE}

RUN NO. 53.0 N-BUTANOL TEST SECTION NO.; INSIDE DIAMETER,DI=0.038917 FT.

FLOW RATE,W=1745. LBSIHR MASS VELOCITY,G=407.5 LES/SEC.SOFT PTJER= 9.70. K.ILJWATTS HEAT FLUX,Q GSOSO. BTJ/TR.SQFT TEMPERATURE BEFORE FLASH= $292.4 \mathrm{~F}$. VELDCITY DEFORE: FLASH= $2.9 \mathrm{FT} / \mathrm{SEC}$

\begin{tabular}{|c|c|c|c|c|c|c|c|c|c|c|c|c|c|c|c|c|c|}
\hline LEFT & PS:IA & To & TI & T.B & DELT & HEUIL & HLIQ & $x$ & XIr & : Yuo & RENOL & $B J \cdot E 4$ & STANTN & PRNDL & $D P / D L L$ & DP/OLTP & TP/LIO \\
\hline 0.25 & 43.40 & 325.3 & $322: 3$ & 304.9 & 17.41 & 3796. & 803. & • & 0 . & 2277 & 88750. & .1549. & .00285 & 9.01 & .1922 & 0.360 & $1: 37$ \\
\hline 0.50 & 43.34 & 328.1 & $324 . \mathrm{i}$ & 304.8 & 19.25 & 3433 & 803. & - & 0. & 2059 & $88704:$ & .1544 & .00257 & 5.02 & .1922 & 0.520 & 2.71 \\
\hline $1: 0.0$ & .42 .94 & 328.4 & 324.4 & 304.3 & 20.17 & 3276. & 802 . & - & 0 . & $1: 63$. & 88330. & .1512 & .00246 & 9.05 & $\therefore 1923$ & 0.930 & 4.84 \\
\hline 1.50 & 42.28 & 326.6 & 322.6 & 303.3 & 19.34 & 3417 & 801. & $\therefore$ & 0. & 2043. & 87681. & .1558 & .00256 & 9.10 & .1925 & .450 & .58 \\
\hline 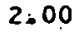 & 41.32 & 324.5 & 320.5 & 301.9 & 1 & 548 . & 79 & .0031 & 24. & $\bar{c} 1$ & 86465. & .1479 & .3 & 9.17 & .1917 & 10 & 11 \\
\hline 0 & 40.30 & 322.3 & 318.3 & ac. 3 & 1 & 682 . & 784. & .0155 & 4.735 & 2192. & 84164 & .1395 & .00 & 9.25 & .1858 & 670 & 14.40 \\
\hline $2: 80$ & 39.00 & 3.19 .3 & 315.3 & 298.3 & 17.03 & 3880 & 769. & .03598 & 2.521 & 2303 . & $\$ 1407$ & .1282 & .00291 & 9.36 & .1815 & 3.350 & 18.46 \\
\hline 36.10 & 37.90 & 3.16 .6 & $312: 6$ & 296.6 & 16.01 & 4126. & 757 & .04 .95 & 1.829 & 2442. & 79202 & $.1185^{\circ}$ & .00310 & 9.45 & .1773 & 3.980 & 22.45 \\
\hline 3.40 & 36.6 & .313 .3 & 307.3 & 294.5 & 1 & 4461. & 745. & .0644 & 1.398 & $2 \pm 31$. & 76767 & $.1075^{\circ}$ & .00335 & 9.56 & .1728 & 4.800 & 27.77 \\
\hline 70 & 3 & 308.0 & 307.0 & 292.2 & 1 & 5607. & 732. & .0802 & 1.106 & $3 \geq 92$. & 7.4172 & .0953 & .00422 & 9.68 & $.168 \mathrm{~L}$ & 5.730 & 35.07 \\
\hline & & & & & $70^{\circ}$ & 97. & 1.4 . & .09 & 0.867 & $4+38$. & 70818. & .0775 & .00572 & 9.86 & .1626 & 7.330 & 45.09 \\
\hline
\end{tabular}




\section{BIB LIOGRAPHY}

1. Robert G. Deissler, Analysis of Turbulent Heat Transfer and. Flow in Entrance Regions of Smooth Passages, National. Advisory Committee for Aeronautics Report NACA-1210, 1955.

2. R. Siegel and E. M. Sparrow, Turbulent Flow in a Circular Tube with Arbitrary Internal Heat Sources and Wall Heat Transfer, Trans. ASME Series C, J. Heat Transfer 81, 280 (1959).

3. Roger M. Wright, Downflow Forced-Convection Boiling of Water in Uniformly Heated Tubes ( $\mathrm{Ph}$. D. Thesis), Lawrence Radiation Laboratory Report UCRL-9744, Aug. 1961.

4. L. S. Sterman, On the Theory of Heat Exchange on Boiling in Pipce, Zh. Terh. Fiz. 24, No. 2, 250 (1954) (A. E. K. E. Lib. /Trans. 579).

5. R. C. Martinelli and D. B. Nelson, Prediction of Pressure Drop During Forced-Circulation Boiling of Water, Trans. ASME 70, 695 (1948).

6. R. W. Lockhart and R. C. Martinelli, Proposed Correlation of Data for Isothermal Two-Phase, Two-Component Flow in Pipes, Chem. Eng. Progr. 45, 39 (1949).

7. V. E. Schrock and L. M. Grossman, Forced-Convection Boiling in Tubes, Nucl. Sci. Eng. 12, 474 (1962).

8. C. F. Staley and M. Baker, Heat-Transfer Rate Between Heated Tubes and Boiling Refrigerant, J. Am. Soc. Heating, Refrig. and Air Conditioning Engrs, 1, 83 (1959).

9. Carl E. Dengler, Heat Transfer and Pressure Drop for Evaporation of Water in a Vertical Tube (Sc.D. Thesis), Massachusetts Institute of Technology, 1952.

10. C. E. Dengler and J.N. Addoms, Heat Transfer Mechanism for Vaporization of Water in Vertical Tubes, Chem. Eng.; Progr. Symp.Ser. 52, No. 18, 95 (1956).

11. J. F. Mumm, Heat:Transfer to Boiling Water Forced Through a Uniformly Heated Tube, Argonne National Laboratory. Report ANL-5276, Nov。1954. 
12. W. F. Davidson, P. H. Hardie, C. G. R. Humphreys, A. A. Markson, and T. Ravese, Studies of Heat Transmission Through Boiler Tubing at Pressures from 500 to 3000 Pounds, Trans. ASME 65, 553 (1943).

13. V. E. Schróck and L. M. Grossman, Forced-Convection Boiling Studies, University of California Institute of Engineering Research (Berkeley), Series No. 73308-UCX 2182, Issue No. 2, Nov. 1, 1959.

14. J. A. R. Bennett, J. G. Collier, H. R. C. Pratt, and J. D. Thornton, Heat Transfer to Two-Phase Gas-Liquid Systems, Atomic Energy Research Establishment. Report AERE-R3159, 1959.

15. Robert L. Sani, Downflow Boiling and Nonboiling Heat Transfer in a Uniformly Heated Tube, Lawrence Radiation Laboratory Report UCRL-9023, Jan. 1960.

16. E. J. Davis and M. M. David, Heat Transfer to High-Quality Steam-Water Mixtures Flowing in a Horizontal Rectangular Duct, Can. J. . Chem. Eng. 39; 99 (1961).

17. A. Kvamme, M. Sc. Thesis, University of Minnesota, 1959.

18. L. S. Sterman, V. G. Morozov, and.S. A. Kavalev, Study of Heat Exchange During Boiling of Water and Ethyl Alcohol.in Pipes, J. Eng. Phys.:(Russia) 2, 40 (1959) (UCLRL Translation 694).

19. S. A. Guerrieri and R. D. Talty, A Study of Heat Transfer to Organic Liquids in a Single-Tube, Natural Circulation VerticalTube Boilers, Chem. Eng. Progr. Symp. Series 52, No. 18, 69.(1956).

20. M. Altman,.R. H. Norris, and F. W. Staub, Local and Average Heat Transfer and Pressure Drop for:Refrigerants Evaporating in Horizontal Tubes, Trans. ASME: Series C, J. Heat. Transfer 82, 189 (1960). 
21. P. A: Lottes, M. Petrick, and J. F. Marchaterre, Lecture Notes on Heat Extraction from Boiling Water Power Reactors, Argonne National Laboratory Report. ANL-6063, 1959.

22. R. Jenkins,. M. Sc. Thesis, University of Delaware, Newark, Delaware, 1947.

23. G. A. Hughmark and B.S. Pressburg, Holdup and Pressure Drop with Gas-I.iquid Flow in a Vertical Pipe, A.I. Ch.E. J. $\underline{7}$, 4, 677 (1961).

24. H. S. Ibsen, R. H. Moen, R。O.Wickey, D. R. Mosher, and H. C. Larson, Two-Phase Steam-Water Pressure Drop, Chem. Eng. Progr. Symp. Ser. No. 23, 55, 75 (1959).

25. J. F。 Marchaterre, M, Petrick, P,A. Lottes, R. J。Weatherhead, and.W.S. Flynn, Natural and Forced-Circulation Boiling Studies, Argonne National Laboratory Report ANL-5735, 1960.

26. M. R. Hatch and R.B. Jacobs, Prediction of Pressure Drop in Two-Phase Single-Component Fluid Flow, A.I. Ch.E。 J. 8, 1,18 (1962).

27. V. E. Schrock and L. M. Grossman, Local Pressure Gradients in Forced-Convection Vaporization, Nucl. Sci. Eng. 6, 245 (1959).

28. Manufacturing Chemists Association Research Project, Selected Values of Properties of Chemical Compounds, 1961.

29. L.W. Shemilt, R。W. Esplen, and R。S. Mann, Thermodynamic Properties of Some Organic Conmpounds, Can. J。 Chem. Eng. 37, 142 (1959).

30. Robert C. Reid and Thomas K. Sherwood, The Properties of Gases and Liquids (McGraw-Hill Book Company. Inc., New York, 1958).

31. O.K. Bates and G. Hazzard, Thermal Conductivity of Alcohols, Ind. Eng. Chem. 37, 193 (1945).

32. P. Sachs and R. A. K. Long, A Correlation for Heat Transfer in Stratified Two-Phase Flow with Vaporization, Intern. J. Heat Mass 'Iransfer 2, 222 (1961). 
33. C. F. Bonilla and C. W. Perry, Heat Transmission to Boiling Binary Mixtures, Trans. A. I. Ch. E. 37, 685 (1941).

34. M. E. Ellion, A Study of the Mechanism of Boiling Heat Transfer, Memorandum 20-88, Jet Propulsion Laboratory, March 1954.

35. Frank Kreith, Principles of Heat Transfer (International Textboole Co., Scranton, 1958).

36. R. P. Stein, J. W. Hoopes, Jr., M. Markles, Jr., W. A. Selke, A. J. Bendler, and.C. F. Bonilla, Pressure Drop and Heat Transfer to Nonboiling and Boiling Water in Turbulent Flow in an Internally Heated Annulus, Chem. Eng. Progr. Symp. Ser. No. 11, 50, 115 (1954). 
This report was prepared as an account of Government sponsored work. Neither the United States, nor the Commission, nor any person acting on behalf of the Commission:

A. Makes any warranty or representation, expressed or implied, with respect to the accuracy, completeness, or usefulness of the information contained in this report, or that the use of any information, apparalus, melhod, or process disclosed in this report may not infringe privately owned rights; or

B. Assumes any liabilities with respect to the use of, or for damages resulting from the use of any information, apparatus, method, or process disclosed in this report.

As used in the above, "person acting on behalf of the Commission" includes any employee or contractor of the Commission, or employee of such contractor, to the extent that such employee or contractor of the Commission, or employee of such contractor prepares, disseminates, or provides access to, any information pursuant to his employment or contract with the Commission, or his employment with such contractor. 